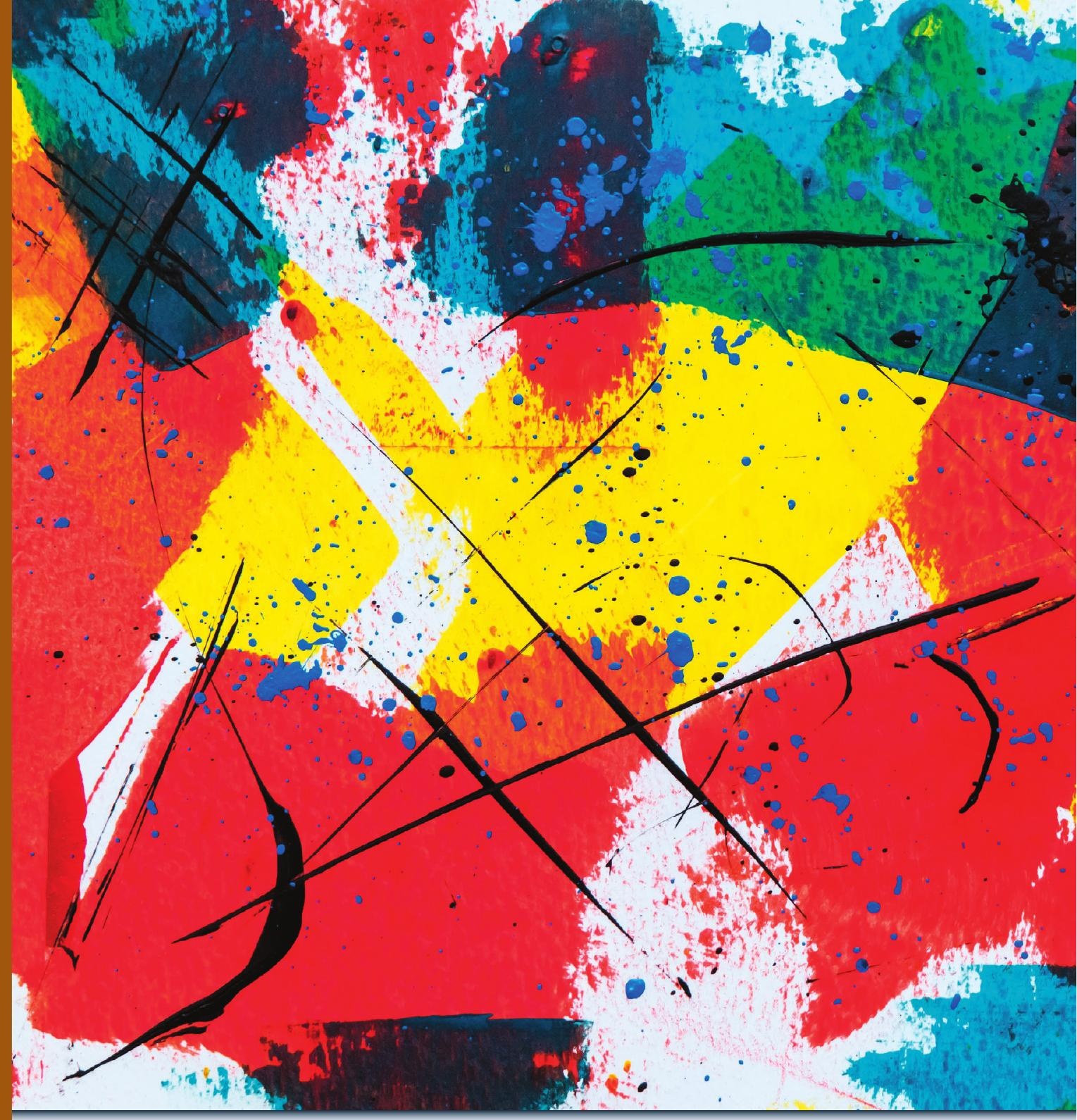

\title{
USOS Y TEORÍAS: ESTUDIOS DE LA MAESTRÍA EN LINGÜÍSTICA
}

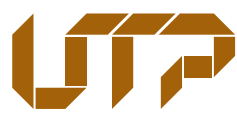

Universidad Tecnológica de Pereira

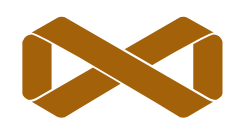

Editorial UTP
Coordinadora Mireya Cisneros Estupiñán 



\title{
Usos y Teorías: Estudios de la Maestría en Lingüística
}

\author{
Coordinadora \\ Mireya Cisneros Estupiñán
}

Autores

Miguel Ángel Mahecha Bermúdez

Mireya Cisneros Estupiñán

Clarena Muñoz Dagua

Giohanny Olave Arias

Juan Camilo Cortes Patiño

Andrés Felipe Molina Montes

Claudia Liliana Agudelo Montoya

Gladys Yolanda Pasuy Guerrero

Santiago Cifuentes Osorio

Paula Andrea Hoyos Giraldo

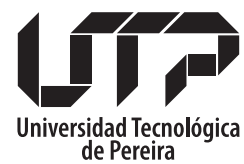

Facultad de Ciencias de la Educación

Colección Ensayos

2020 
Usos y teorías : Estudios de la Maestría en Lingüística / Miguel

Ángel Mahecha Bermúdez y otros. - Pereira : Editorial

Universidad Tecnológica de Pereira, 2020.

160 páginas. -- (Colección Ensayos).

\section{ISBN: 978-958-722-516-7}

1. Lingüística - Investigación 2. Filosofía del lenguajes 3

Sociolingüística 4. Gramática comparada y general 5. Léxico -

Enseñanza 6. Lenguaje y educación 7. Maestria - Enseñanza

8. Análisis del discurso.

CDD. 460.71

Usos y teorías: estudios de la Maestría en Lingüística.

(C) Mireya Cisneros Estupiñán

(C) Miguel Ángel Mahecha Bermúdez

(C) Mireya Cisneros Estupiñán

(c) Clarena Muñoz Dagua

(c) Giohanny Olave Arias

(C) Juan Camilo Cortes Patiño

(C) Andrés Felipe Molina Montes

(C) Claudia Liliana Agudelo Montoya

(C) Gladys Yolanda Pasuy Guerrero

(C) Santiago Cifuentes Osorio

(C) Paula Andrea Hoyos Giraldo

(C) Universidad Tecnológica de Pereira

ISBN: 978-958-722-516-7

Imágen de Cubierta: Steve Johnson. Tomado de https://stocksnap.io/photo/abstract-art-

QAQDUHXFCF

Universidad Tecnológica de Pereira

Vicerrectoría de Investigaciones, Innovación y Extensión

Editorial Universidad Tecnológica de Pereira

Pereira, Colombia

Coordinador editorial:

Luis Miguel Vargas Valencia

luismvargas@utp.edu.co

Teléfono 3137381

Edificio 9, Biblioteca Central "Jorge Roa Martínez"

Cra. 27 No. 10-02 Los Álamos, Pereira, Colombia

www.utp.edu.co

Montaje y producción:

María Alejandra Henao Jiménez

Universidad Tecnológica de Pereira

Pereira 


\section{CONTENIDO}

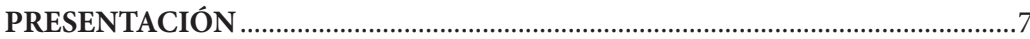

Capítulo uno. El discurso disciplinar de la lingüística en programas de licenciatura en lengua castellana ................................................................................. 13

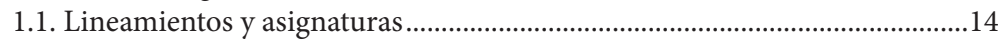

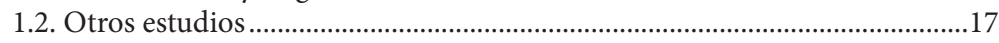

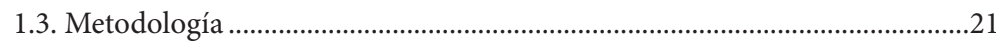

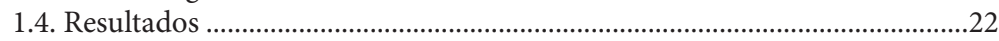

1.4.1. Información de los planes de estudio y los syllabus .....................22

1.4.1.1. Tópicos abordados en los cursos...................................................23

1.4.1.2. Textos manejados en los cursos de lingüística ............................25

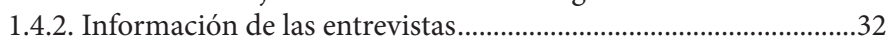

1.4.2.1. Discusión derivada de los datos presentados ...............................34

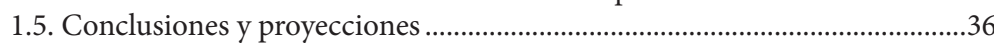

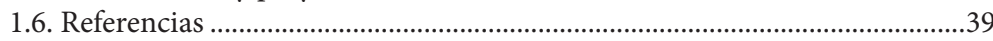

Capítulo dos. Una mirada a los escritos universitarios desde la Teoría de la Valoración de la Lingüística Sistémica Funcional...................................................53

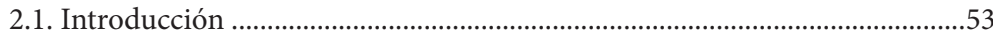

2.2. De análisis textual en el contexto de la Lingüística Sistémico

Funcional (LSF) ..............................................................................................56

2.3. De textos académicos en el contexto universitario ........................................59

2.4. De actitudes y compromisos en textos académicos.........................................63

2.5. A modo de cierre ..........................................................................................

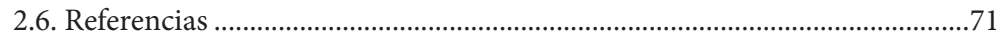

Capítulo tres. Usos del metadiscurso en el combate público verbal .........................77

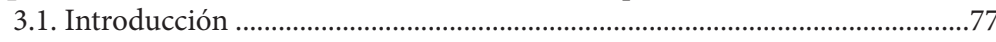

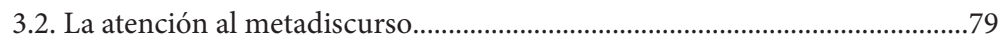

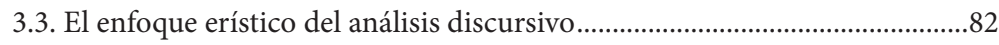

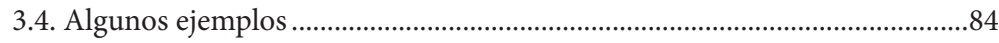

3.4.1. La vigilancia metadiscursiva de la discusión racional..................84

3.4.2. La función reactiva del metadiscurso.................................................8

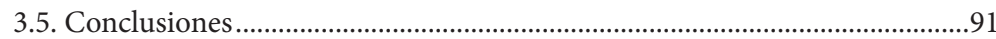

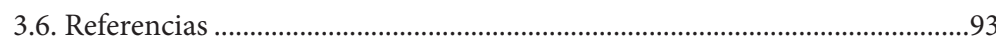

Capítulo cuatro. Aproximación a las estrategias discursivas de Claudia López como candidata a la Alcaldía de Bogotá: la nominación, la negación y los

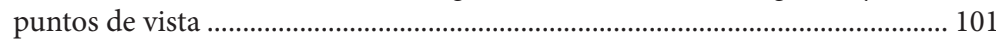

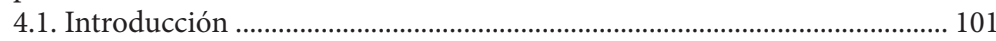

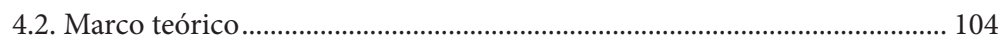

4.2.1. La nominación.............................................................................. 104

4.3. Polifonía del discurso de Ducrot (1987): los puntos de vista

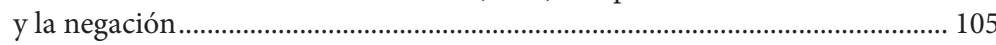

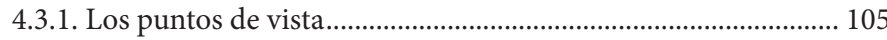




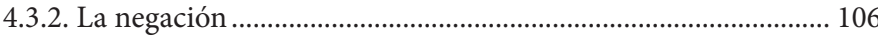

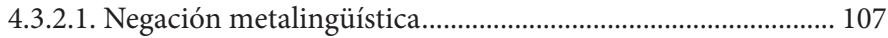

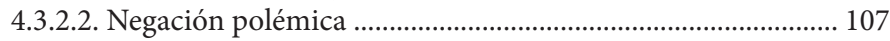

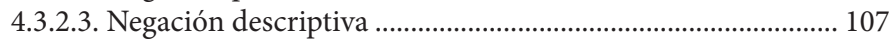

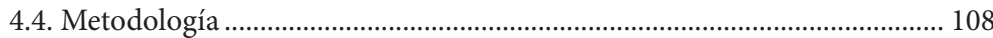

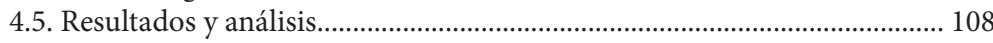

4.5.1. Nominación ............................................................................. 108

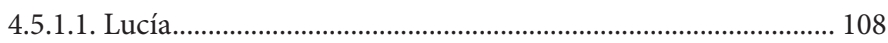

4.5.1.2. Enrique Peñalosa..................................................................... 110

4.5.1.3. María Jimena .............................................................................. 110

4.5.1.4. Unidades nominales que hacen referencia al

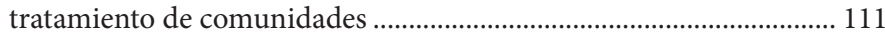

4.5.1.4.1. Grupo uno: los victimarios..................................................... 112

4.5.1.4.2. Grupo dos: las víctimas.......................................................... 113

4.5.1.4.3. Grupo tres: los no victimarios-no víctimas.......................... 115

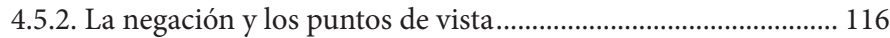

4.5.2.1. La negación metalingüística .................................................. 116

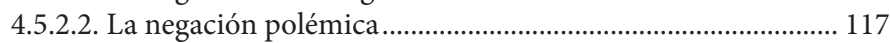

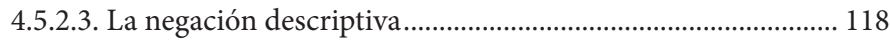

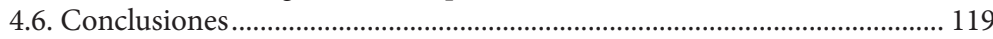

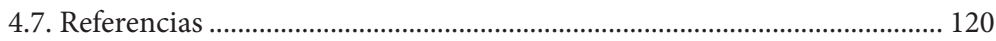

Capítulo cinco. Lecciones semánticas: la resemantización y la metáfora............. 127

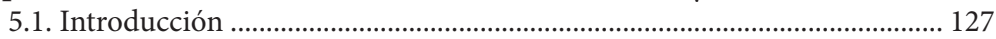

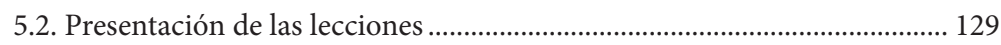

5.2.1. Primera lección: la metáfora es un juego .................................... 130

5.2.2. Segunda lección: las metáforas pueden ser verbales ................. 130

5.2.3. Tercera lección: la metáfora cumple diversas funciones........... 131

5.2.4. Cuarta lección: la metáfora posee contenido cognitivo ............ 132

5.2.5. Quinta lección: la metáfora expresa el significado

en sentido ............................................................................................. 133

5.2.6. Sexta lección: el sentido creado por la metáfora no

es indeterminado ....................................................................................... 134

5.2.7. Séptima lección: la metáfora se fija en una red de

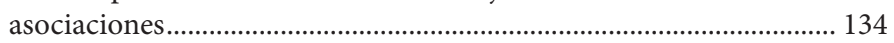

5.2.8. Octava lección: la interpretación de la metáfora radica en descubrir la intención comunicativa del hablante ............................... 135

5.2.9. Novena lección: la metáfora se fundamenta en modelos de conocimiento previos............................................................................ 136

5.2.10. Décima lección: las metáforas son producto de modelos

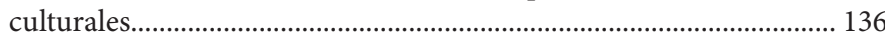

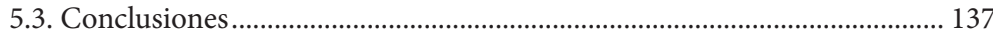

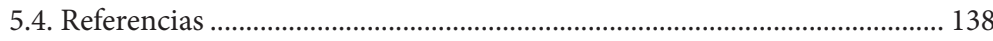

Capítulo seis. Ir a + infinitivo: una mirada desde la prensa escrita

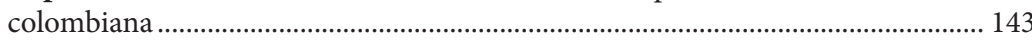

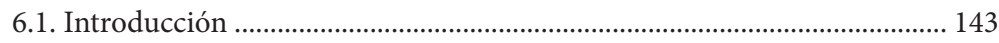

6.2. Caracterización del corpus......................................................................... 145 


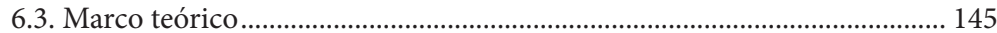

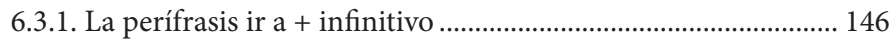

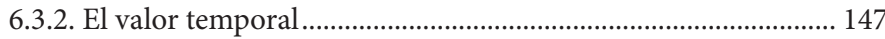

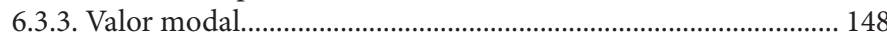

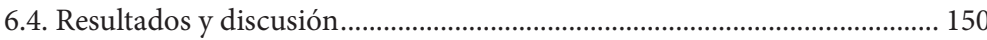

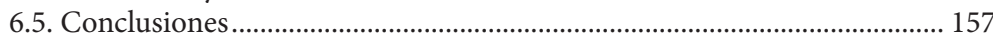

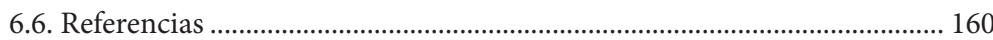




\section{Índice de tablas}

Tabla nro. 1. Asignaturas básicas del área de la Lingüística...................................17

Tabla nro. 2. Porcentaje de tipos de cursos respecto el total de cursos de

lenguaje.

Tabla nro. 3. Contenidos disciplinares del área lingüística: número de programas en los que se abordan y porcentaje...................................................23

Tabla nro. 4. Contenidos disciplinares del área lingüística...................................32

Tabla nro. 5. Contenidos disciplinares del área de lingüística y especialidad de

los profesores.

Tabla nro. 6. Mecanismo metadiscursivo en la interacción pública de un académico y un abogado.

Tabla nro. 7. Discusión pública con disputas autorreguladas a través de la agresividad pasiva compartida................................................................................. 86

Tabla nro. 8. Metadiscursividad para el rechazo de desacreditación....................88

Tabla nro. 9. Tipos de nominación...................................................................... 104

Tabla nro. 10. Ejemplos de Unidades lexicales o nominales que hacen referencia al tratamiento de comunidades. .......................................................................... 112

Tabla nro. 11. Funciones y valores de ir a + infinitivo: editorial. ...................... 152

Tabla nro. 12. Funciones y valores de ir a + infinitivo: cultural. ....................... 153

\section{Índice de figuras}

Figura nro. 1. Distribución de las perífrasis verbales en El Tiempo................. 151

Figura nro. 2. Distribución de ir a + infinitivo en El Tiempo. 


\section{PRESENTACIÓN}

Por cuarta vez, la Maestría en Lingüística pone en consideración de la comunidad académica, interesada en los estudios del lenguaje, una obra construida con los aportes de profesores estudiantes, conferencistas y egresados de este programa de postgrado. Así, las sucesivas publicaciones en las que, mediante convocatoria pública, hay participación de los distintos estamentos, los cuales conforman dicha maestría, se convierten en un espacio académico en donde se comparten, fortifican y adquieren conocimientos teóricos y prácticos, así como metodologías, para la investigación lingüística en diferentes entornos socioculturales. Esto a través del estudio de la lengua, tanto en su fase de sistema formal como en su uso contextual.

Los capítulos de esta obra, como en las anteriores, ofrecen elementos de discusión, los cuales se espera sirvan de motivación para investigar el lenguaje desde disciplinas y teorías que abordan el sistema formal de la lengua y las interdisciplinariedades que explican su uso. De ese modo, el presente escrito se organiza en seis capítulos así: 
En el primer capítulo, el profesor Miguel Ángel Mahecha Bermúdez sintetiza una experiencia de indagación adelantada con profesores del área de Lingüística en diferentes universidades del país. Allí recoge testimonios y reflexiones en torno a los saberes disciplinares y pedagógicos al momento de formar futuros profesores de españoly de lenguas extranjeras, y procura responder preguntas como las siguientes: ¿Qué dicen los lingüistas de la lingüística y de su enseñanza? ¿De qué manera los contenidos del área de lingüística tienen una incidencia positiva en el quehacer pedagógico de un futuro profesor de lengua materna y lenguas extranjeras? ¿Qué se forma cuando se forma en lenguaje? ¿Cuáles podrían ser las causas del divorcio entre teoría lingüística y enseñanza del español? ¿Qué tipo de lingüística debe enseñarse en las carreras de lenguas? ¿Para qué sirve la lingüística?

En el segundo capítulo, las profesoras Mireya Cisneros Estupiñán de la Universidad Tecnológica de Pereira y Clarena Muñoz Dagua de la Universidad Colegio Mayor de Cundinamarca, con base en la teoría de la Valoración de la Lingüística Sistémica Funcional, concretamente con los sistemas de Actitud, Compromiso y Gradación, analizan los recursos léxicos gramaticales elegidos por los aspirantes a la Maestría en Lingüística para redactar un texto adecuado a las condiciones exigidas por los posibles evaluadores y conseguir la aprobación de ingreso al mencionado programa.

En el tercer capítulo, el doctor Giohanny Olave Arias realiza una aproximación analítica a la metadiscursividad en situaciones de disputa verbal pública. Con ella contribuye al desarrollo de una propuesta analítica de dichos casos, especialmente para los momentos más tensos de la confrontación. En este capítulo, orientado por los principios epistemológicos de la perspectiva interpretativa interdisciplinar del análisis del discurso desarrollada por Arnoux (2019) y adaptada para el análisis de disputas públicas—, se abre una ruta de indagación para el estudio de futuros corpus discursivos. 
En el cuarto capítulo, los maestrandos Juan Camilo Cortés Patiño y Andrés Felipe Molina Montes realizan una aproximación a las estrategias discursivas de Claudia López como candidata a la Alcaldía de Bogotá. En ella, desde una perspectiva analíticadiscursiva y de manera exploratoria, resaltan la nominación, la negación y los puntos de vista en uno de los discursos; para legitimar las propuestas políticas en materia de movilidad para dicha alcaldía. Concluyen que Claudia López, a través de la negación y la desligitimación de su antecesor, logra construir una imagen de una ciudadana, mujer y política sensata.

En el quinto capítulo, las doctoras Claudia Agudelo Montoya y Gladys Yolanda Pasuy Guerrero exponen de manera particular y amena diez lecciones sobre la resemantización como mecanismo por el cual el sistema de una lengua multiplica su capacidad generativa al conferirle a un signo lingüístico, ya establecido, una nueva correlación entre su significante y su significado (polisemia); de tal manera, dicho parentesco entra a operar como una nueva acepción del término. Revisan los mecanismos generadores de sentido en el habla colombiana, para lo cual, toman como objeto de estudio un conjunto de ciento ochenta verbos resemantizados del parlache. Se trata de un estudio documental y descriptivo, el cual utiliza fuentes bibliográficas propias de la teoría gramatical y de la filosofía del lenguaje, y detalla las propiedades formales y funcionales las cuales posee la lengua española.

En el sexto capítulo, los egresados de la Maestría en Lingüística, Santiago Cifuentes Osorio y Paula Andrea Hoyos Giraldo analizan las construcciones perifrásticas en la prensa escrita, y resaltan concretamente, las funciones y valores de las perífrasis verbales de ir a + infinitivo en El Tiempo, periódico colombiano de circulación nacional. Clasifican y contrastan en dos secciones de este diario (cultural y editorial), su frecuencia de aparición. Esto, mediante un estudio cuantitativo el cual les permite establecer cuáles son las construcciones perifrásticas prevalecientes en ese contexto. 
Finalmente, los distintos temas son abordados desde los estudios gramaticales y desde los estudios interdisciplinares que dan cuenta, en distintas situaciones comunicativas, de la lengua en uso. Se espera, como en anteriores ocasiones, tener la acogida y la mirada crítica de los lectores frente a estos trabajos, unos con la madurez de sus autores y otros con el mérito de aventurarse a hacer sus primeros pininos en el exigente mundo de la escritura académica. 


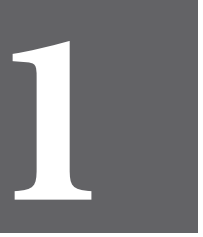

CAPÍTULO

UNO 



\section{El discurso disciplinar de la lingüística en programas de Licenciatura en lengua castellana}

Miguel Ángel Mahecha Bermúdez ${ }^{1}$

Este capítulo es un informe técnico de una experiencia de indagación adelantada con colegas y profesores del área de lingüística en diferentes universidades del país. Contiene reflexiones que se han ido forjando a lo largo del ejercicio de una docencia universitaria cuestionada y cavilada en donde preguntas, en apariencia sencillas de responder, han logrado sobrevivir a las respuestas ofrecidas por aquellos osados en proponerlas, buscando integrar, como es lo esperado, los saberes disciplinar y pedagógico al momento de formar a futuros profesores de español y de lenguas extranjeras. Interesa aquí saber lo que los lingüistas creen acerca de la lingüística y de su enseñanza, de qué

1 Profesor de lingüística, Universidad Surcolombiana, Neiva. Conferencista en la Maestría en Lingüística de la Universidad Tecnológica de Pereira. Integrante grupo de investigación Estudios del lenguaje y la educación, categoría A1. Correo electrónico: miguelangel.mahecha@usco.edu. co 
manera los contenidos que se anuncian y se desarrollan en los programas del área de lingüística inciden de manera positiva en el quehacer pedagógico de los futuros profesores de lengua materna y lenguas extranjeras: qué tipo de formación se da en las áreas de lenguaje, el porqué de esa especie de divorcio que se percibe entre teoría lingüística y enseñanza del español cuando se forma en lenguaje, qué tipo de lingüística debe enseñarse en las carreras de lenguas y, por supuesto, para qué sirve la lingüística. Con base en estas inquietudes o interrogantes, se abordarán los temas que se desarrollan a continuación.

\subsection{Lineamientos y asignaturas}

Los programas de Licenciatura en Lengua Castellana de las universidades consideradas en este ejercicio académico, se esforzaron en elaborar una reforma curricular siguiendo la lógica de competitividad planteada por el Ministerio de Educación Nacional (MEN). Si bien el objetivo es encomiable, las razones que lo motivaron están lejos de ser eficaces como los casos de Finlandia y Japón. Las propuestas de renovación curricular con la consabida redacción de los Proyectos Educativos de Programa (PEP), se apegaron a lo reglamentado en la Ley 115 de 1994, la Ley 1188 del 25 de abril de 2008, el Decreto 1295 del 20 de abril de 2010, el Decreto 2450 del 17 de diciembre de 2015, la Resolución 2041 del 3 de febrero de 2016 y su versión remozada en la forma, y la Resolución 18583 del 15 de septiembre de 2017; mediante las cuales se establecen las características específicas de calidad de los programas de licenciatura para la obtención, renovación o modificación del registro calificado.

En el proceso de reforma, dichos programas se apoyaron en dos documentos complementarios que trazaban lineamientos tanto para el perfil de los futuros licenciados en educación como para la proyección pedagógica universitaria. Estos fueron emanados por el MEN con las siguientes designaciones: 1) Los Lineamientos de calidad para las licenciaturas en educación. 
Programas de Formación Inicial de Maestros (versión agosto de 2014), y 2) Sistema colombiano de formación de educadores $y$ lineamientos de política (2013). En las licenciaturas en lengua castellana, con sus nuevas denominaciones, es decir, Licenciatura en Humanidades y Lengua Castellana/Licenciatura en Literatura y Lengua Castellana y Licenciatura en Literatura (Resolución 18583, 2017), el componente lingüístico sigue ocupando un lugar destacado en las mallas curriculares. Pastor (2000), al analizar las hipotéticas $-\mathrm{y}$ problemáticas - relaciones entre la teoría lingüística y la enseñanza-aprendizaje de lenguas, destaca cuatro aspectos que confirman la importancia de esta área disciplinar y la necesaria integración con el área de didáctica y la enseñanza (práctica pedagógica): 1) Establecer cómo y en qué ha influido la teoría lingüística en la enseñanza de lenguas. 2) Cómo aprovechar para la enseñanza del español y de otras lenguas, el amplio bagaje teórico ofrecido por la disciplina lingüística. 3) Identificar, por un lado, el nivel de reflexión metalingüística el cual debería estar presente en el contexto de aula y, por otro lado, si dicho nivel es una estrategia efectiva de aprendizaje del alumno. Y4) Definir la pertinencia y presencia de la teoría lingüística en los planes curriculares de formación del futuro profesorado.

Le compete al profesor de lengua materna y de las asignaturas del área de lingüística contar cómo, en la práctica pedagógica, se integran estos factores (el cómo del qué). No obstante, no es tarea sencilla ya que se presentan dos situaciones discursivas las cuales debe enfrentar el profesor. Tal y como lo presenta Negrin (2003), la primera está ligada a la integración de los saberes disciplinar y pedagógico en el ejercicio docente, dado que

En el curriculum universitario suele ocurrir que la preparación pedagógico-didáctica sea posterior a la formación en las disciplinas de referencia. Se supone que es a partir de la conjunción de estos dos campos de conocimientos que el profesor podrá derivar con facilidad modos de intervención para la práctica. Sin embargo, suelen ser las 'prácticas de la enseñanza' las que ponen al descubierto el fracaso de este modelo, en tanto evidencian el 
desencuentro entre los saberes transmitidos por la institución universitaria y el conjunto de saberes que demanda la profesión docente (p. 308).

La segunda tiene que ver con la transposición didáctica en donde es preciso "poner de manifiesto las transformaciones que experimentan los saberes en su pasaje desde las instituciones - generalmente científicas- donde fueron generados, hasta alcanzar finalmente las instituciones educativas» (p. 309).

En la TABLA NRO. 1 se presenta una lista de las asignaturas del área de lingüística en los currículos de las universidades estudiadas ${ }^{2}$.

\begin{tabular}{|c|c|}
\hline $\begin{array}{l}\text { Instituciones de } \\
\text { Educación Superior }\end{array}$ & Asignaturas \\
\hline $\begin{array}{l}\text { Universidad } \\
\text { Surcolombiana }\end{array}$ & $\begin{array}{l}\text { Introducción a la lingüística; Niveles de lengua; Lenguaje y Cultura; } \\
\text { Análisis gramatical; Lenguaje, cognición y educación; Lenguaje y } \\
\text { Discurso; Historia de la lengua. (Siete asignaturas). }\end{array}$ \\
\hline $\begin{array}{l}\text { Universidad Distrital } \\
\text { FJC }\end{array}$ & $\begin{array}{l}\text { El lenguaje y la lengua como sistema de conocimiento; La lingüística y } \\
\text { sus desarrollos científicos I y II; Lengua española: contextos históricos y } \\
\text { políticos; Gramática del español morfosintaxis y fonética; Adquisición y } \\
\text { desarrollo del lenguaje; Semántica y pragmática; Estudios y análisis del } \\
\text { discurso: componente semiodiscursivo; Gramática de textos: descripción, } \\
\text { narración y argumentación; Lenguaje, sociedad, comunicación y cultura. } \\
\text { (Diez asignaturas). }\end{array}$ \\
\hline $\begin{array}{l}\text { Universidad de } \\
\text { Antioquía }\end{array}$ & $\begin{array}{l}\text { Taller de fonética y fonología; Tensiones y rupturas en los estudios del } \\
\text { lenguaje; Morfología de la lengua castellana; Sintaxis de la lengua } \\
\text { castellana; Semántica de la lengua castellana; Taller de interpretación y } \\
\text { producción textual; Pragmática; Proyecto de psicolingüística; Cognición, } \\
\text { cultura y aprendizaje; Proyecto de sociolingüística; Historia de la lengua } \\
\text { castellana; Seminario de investigación lingüística. (Doce asignaturas). }\end{array}$ \\
\hline $\begin{array}{l}\text { Universidad del } \\
\text { Tolima }\end{array}$ & $\begin{array}{l}\text { Lenguaje y pensamiento; Estructura de la lengua; Lenguaje y otras } \\
\text { disciplinas; Análisis del discurso I y II; Interacción comunicativa; } \\
\text { Procesos lectoescriturales en el niño I y II; Lenguaje y medios; Temas y } \\
\text { problemas de investigación en lenguaje; Análisis sociolingüístico; } \\
\text { Semántica y sintaxis de la lengua; Temas y problemas de investigación } \\
\text { en lenguaje; Semiótica del texto. (Catorce asignaturas). }\end{array}$ \\
\hline $\begin{array}{l}\text { Universidad } \\
\text { Tecnológica de } \\
\text { Pereira }\end{array}$ & $\begin{array}{l}\text { Lenguaje y socialización; Corrientes lingüísticas contemporáneas; } \\
\text { Sociolingǘstica; Sicolingüística; Semiótica; Filosofía del lenguaje; } \\
\text { Fonética y fonología del español; Seminario de pragmática de la lengua; } \\
\text { Morfosintaxis del español I y II; Lingüística textual; Análisis del } \\
\text { discurso; Semántica del español. (Trece asignaturas). }\end{array}$ \\
\hline $\begin{array}{l}\text { Universidad de } \\
\text { Nariño }\end{array}$ & $\begin{array}{l}\text { Lingüística general; Fonética y fonología; Análisis morfosintáctico; } \\
\text { Historia del castellano; Semántica; Psicolingüística; Semiótica; } \\
\text { Sociolingüística; Lingüística aplicada; Análisis del discurso. (Diez } \\
\text { asignaturas). }\end{array}$ \\
\hline
\end{tabular}

2 Datos recogidos en el primer trimestre del año 2017. Algunos de los programas han modificado sus mallas curriculares. 


\begin{tabular}{ll}
\hline $\begin{array}{l}\text { Universidad la Gran } \\
\text { Colombia }\end{array}$ & $\begin{array}{l}\text { Introducción a la lingüística; Fonética española; Desarrollo } \\
\text { morfosintáctico; Semántica; Psicolingüística; Sociolingüística; } \\
\text { Lingüística del discurso; Seminario de profundización en lingüística. } \\
\text { (Ocho asignaturas). }\end{array}$ \\
\hline $\begin{array}{l}\text { Fundación } \\
\text { Universitaria }\end{array}$ & $\begin{array}{l}\text { Introducción al estudio del lenguaje; Teoría lingüística; Análisis del } \\
\text { discurso; Cognición y procesos lectoescriturales; Concepción y función } \\
\text { del lenguaje; Filosofia del lenguaje; Historia de la lengua española; } \\
\text { Sintaxis y semántica del español; Sociolingüística. (Nueve asignaturas). }\end{array}$ \\
\hline
\end{tabular}

TABLA NRo. 1. Asignaturas básicas del área de la Lingüística. Elaboración propia.

\subsection{Otros estudios}

Por la semejanza de intereses compartidos con la investigación, se reseña como complemento un grupo de trabajos cuyas conclusiones se quieren discutir e integrar a este escrito. En primer lugar, se mencionan dos trabajos de Cisneros et al. (2015; $2018)^{3}$ cuyo foco de interés es la integración de la didáctica con el discurso disciplinar de la lingüística. Destacan los autores la escasez de trabajos dedicados al diseño de «una didáctica más global que incluya a la lingüística como objeto de saber, base para el desarrollo de la competencia comunicativa» (p. 160), lo cual, sin lugar a dudas, afecta los procesos de preparación y diseño curricular de los programas de licenciaturas relacionadas con la formación de maestros de lenguaje.

Otro de los trabajos que conviene relacionar, entre otros afines, es una investigación que fue adelantada por la Licenciatura en Humanidades y Facultad de Educación de la Corporación Universitaria Minuto de Dios, cuyo propósito era identificar las características y tendencias más sobresalientes en la formación de docentes de humanidades y lengua castellana en Colombia. Los detalles de este estudio se sintetizan en el artículo de Perdomo et al. (2016), donde se formulan una serie de categorías de análisis para evaluar los proyectos curriculares y educativos de las licenciaturas: 1) fundamentación conceptual respecto al lenguaje y

3. Didáctica y Lingüistica: un desafio desde la universidad para la educación básica (2015) y La formación didáctica de profesores de español en Colombia (2018). 
la lengua, 2) la concepción de literatura, 3) el acercamiento a otros sistemas simbólicos abordados por la semiótica, 4) la incursión de los medios de comunicación, 5) la proposición de didácticas en torno a la lengua, 6) la coherencia de las prácticas pedagógicas con la implementación de procesos investigativos y 7) los estudios hermenéuticos. Interesan en particular las categorías 1) y 5). Los autores hacen una síntesis apretada y no muy lejana de la realidad, aunque requiere de precisiones por parte de cada programa curricular y cada universidad.

En relación con el lenguaje y la lengua, gran parte de los currículos optan por una formación teórica de la lingüística y la literatura, con su respectivo sustento filosófico, psicológico y biológico. En este sentido, los proyectos curriculares proponen relaciones entre la lengua y su uso en el contexto social desde el ámbito verbal y no verbal; igualmente, se hace énfasis en las ciencias del lenguaje y sus vertientes como la psicolingüística, la sociolingüística y el análisis del discurso.

De otra parte, se observa una aproximación hacia los aspectos formales de la lengua, como la gramática, la sintaxis, la fonología y la ortografía; sin embargo, se privilegia una perspectiva discursiva. En esa medida, se evidencia una enseñanza de la lengua que pretende trascender del desarrollo de las habilidades lingüísticas para acercarse a las funciones de la lengua en un contexto social. Se propone abordar el lenguaje desde el proceso de significación, entendido como el nivel que permite otorgar cierta categoría de signo a los fenómenos sociales y a los discursos presentes en la interacción cultural (Perdomo et al., 2016, p. 148).

¿Cómo se sustentan los argumentos de la síntesis? Los autores hablan de «documentos» de los proyectos curriculares, pero no se sabe a ciencia cierta, si se trata de los PEP y/o de los syllabus de cada asignatura. Tampoco se mencionan detalles de la formación teórica en lingüística con su respectivo sustento filosófico o del trabajo con la lectura de los textos disciplinares. Así, al tratar de manejar la generalidad, no pueden explicar sucesos individuales; por ejemplo, el caso de la Universidad Surcolombiana el cual en 
la TABla Nro. 1, muestra que no le asigna ningún espacio de formación en lingüística, literatura y comunicación. Seguramente, los autores se limitaron a consultar en la web y dan por cierta una información desactualizada y descontextualizada.

Para la categoría cinco, los escritores concluyen que el componente didáctico es importante para las licenciaturas - si en alguna no lo fuera, ¿merecería el nombre de licenciatura?-, pues se percibe la creación de metodologías e implementación de materiales para desarrollar competencias en los educandos. La enseñanza de la lengua y la literatura $-y$ no se entiende si se trata del componente disciplinar de las áreas-, está mediada por la intercesión didáctica $y$, destaca extrañamente, incluso contradictoriamente que los espacios destinados a esta son pocos en relación con los cursos disciplinares, a sabiendas de que los currículos se definen como procesos de formación integral donde se incluye lo humanístico. Estas afirmaciones deberían confrontarse con cada uno de los programas de licenciatura, dado que aciertan en el juicio de que en estos hay desconexión entre los procesos investigativos y la reflexión e impacto en los respectivos desarrollos formativos.

¿Cómo y qué enseñar a un grupo de estudiantes que tienen como lengua materna el español? Como respuesta inicial, la enseñanza, la práctica pedagógica y $\bigotimes$ detrás de ella $\bigotimes$ la formación inicial) apuntan a cumplir tres objetivos: 1) desarrollar las destrezas comunicativas, 2) ayudar a entender la estructura, la función y el funcionamiento de la propia lengua y 3) explicar la consolidación de la experiencia cognitiva, afectiva y cultural. Estos tres propósitos encajan perfectamente tanto en el plano disciplinar como en el plano pedagógico. Así, respecto al primero, se inscriben en una teoría lingüística (cuyo objeto es el lenguaje/ lenguas), la cual describe y explica al tiempo; por una parte, su naturaleza biológica y social; y por otra, sus dimensiones y temas, esto es lo psicológico, lo neuronal, lo cultural y lo simbólico (Fernández, 1999). 
Frente a este planteamiento, Martín Hernández (2013), destaca e insiste que educar al futuro docente en el saber, en lo que a esta área se refiere (la lingüística), significa guiarlo en el conocimiento y reflexión de dos procesos fundamentales, el que tiene que ver con el lenguaje en todas sus manifestaciones y el que tiene que ver con la pedagogía. Estos procesos convergen en la «formación lingüística», proceso que se da en dos vertientes. La primera, apunta «a adquirir el conocimiento necesario para propiciar el desarrollo del lenguaje de niños, y la otra tiene que ver con la formación que recibe el docente para desenvolverse como un comunicador en el uso de la lengua oral y escrita» (Martín Hernández, 2013, p. 46). Este mismo autor analiza «problemas y propuestas relacionadas con la formación lingüística del docente de educación inicial y primaria en algunos países de Iberoamérica» (2013, p. 41). En este se identifican dos categorías de análisis: 1) la problematización de la formación docente en el área de lengua, y 2) la visión prospectiva de la formación lingüística del docente. Para cada una de ellas se precisan elementos discursivos los cuales describen la realidad particular de cada referente (país), así: tres para la primera categoría, estructura de los programas de formación de maestros, formación de base con la que ingresan los estudiantes a las carreras docentes, seguimiento y la evaluación de los docentes en servicio; y dos para la segunda, qué deben hacer las carreras de formación de docentes/para qué, y las políticas públicas. Después de analizar los casos de cinco países (España, México, Costa Rica, Colombia y Chile) con respecto a la formación lingüística de docentes ${ }^{4}$, se destaca que, si bien es cierto que los trabajos proceden de latitudes distantes, los problemas (vistos desde las categorías de análisis y de los elementos discursivos) son bastante similares. Se precisa, además, que, a pesar de la gravedad de la situación, es decir, conforme a la débil formación lingüística,

4 Menciona a los autores de cada país estudiado: de España, Urbano Marchi, Brigitte y González Las, Catalina. (2013); de México, Flores Chávez, Marcelo y López Guerra, Susana. (2011); de Costa Rica, Murillo Rojas, Marielos. (2007); de Colombia, Grupo Lenguaje, Educación y Desarrollo, conformado por Mejía, Lucy; Pineda, Laura; Briceño, Miriam; Ospina, Mario; Calderón, Gladys (2008); de Chile, Sotomayor, Carmen; Parodi, Giovani; Coloma, Carmen; Ibáñez, Romualdo; Cavada, Paula (2011). 
todos denuncian la ausencia de proyectos acuciosos, los cuales reportan lo que sucede; y de la aplicación de propuestas dirigidas a innovar en esta área. ¿Qué se recomienda como conclusión y proyección? Una renovación profunda de la formación docente.

La mayoría de las investigaciones que trata el tema de la formación lingüística de los educadores propone que ésta debe encararse a partir de la identificación, reflexión, confrontación crítica de los saberes y creencias que tienen los educadores en torno al lenguaje; sobre todo de aquellos saberes y creencias que tienen consecuencias negativas sobre la labor pedagógica, la relación con el lenguaje y la relación que los educadores establecen consigo mismos, en tanto usuarios del lenguaje (Martín Hernández, 2013, p. 62).

Tal vez la definición que más se adapta a lo propuesto por Martín Hernández (2013) es la diseñada por Baena (1996) en su formulación conceptual del enfoque semántico-comunicativo, donde expresa:

No existe una lingüística de la lengua por fuera, por encima o al margen de un análisis científico del lenguaje y del habla; la lingüística no agota su objeto en el 'sistema', abandonando el análisis de unas condiciones que lo determinan y unas funciones que lo explican; la lingüística, si cabe reducirla a una definición, es la disciplina científica que explora la posibilidad de dar una explicación al nexo que existe entre lo que decimos con una intención comunicativa, y los objetos, relaciones y eventos de la realidad objetiva, material y social (p. 92).

\subsection{Metodología}

Se adelantó una investigación exploratoria de enfoque cualitativo y descriptivo en donde se examinó el componente disciplinar de lingüística en la formación inicial de profesores de lengua castellana. 
Para este fin se recolectaron los planes de estudio de ocho programas de Licenciatura en Lengua Castellana y los syllabus de ochenta y tres asignaturas del área de lingüística. Igualmente se entrevistó a doce profesores, para lo cual se siguió el método de la autoetnografía, adaptada al discurso oral (Bourdieu, 2006; Bénard, 2019); esto, con el fin de recolectar sus impresiones sobre la importancia de la lingüística en la tradición cultural del país y en la formación de futuros docentes de español/lengua materna en términos de la elaboración de ciclos de vida profesional (Aravena y Quiroga, 2018). La duración de cada entrevista fue de aproximadamente sesenta minutos. El formato de la entrevista se basa en la autoetnografía dirigida al autoanálisis disciplinar, donde se tiene en cuenta su experiencia inicial como estudiantes y graduados de licenciatura, y su posterior y actual papel de profesores con postgrados en el área. Cinco de los docentes entrevistados son mayores de cincuenta años (primera generación) y de género masculino, los siete restantes son menores de treinta y cinco años (segunda generación), cuatro de ellos son de género femenino. Las entrevistas a profundidad llevaron a los autores a reconstruir, en términos de autoanálisis, las categorías propuestas por el entrevistador; esto al tener en cuenta que debían limitarse a precisar los rasgos pertinentes para la disciplina lingüística y para un efecto discursivo, a saber, su enseñanza en las universidades. La cita de Bourdieu (2006,) se constituyó en un disparador, dado que «Comprender significa comprender primero el campo con el cual y contra el cual uno se ha ido haciendo» (p. 17).

\subsection{Resultados}

\subsubsection{Información de los planes de estudio y los syllabus}

Se adoptaron para el estudio dos de las seis categorías de análisis propuestas por Sotomayor et al. (2011), las cuales recogen los objetivos esbozados en el syllabus de cada curso, al pensar en la formación de profesores de español, esto es: 1) 
contenidos disciplinares de lenguaje y 2) contenidos disciplinares y estrategias de enseñanza del lenguaje (ver TABLA NRO. 2).

\begin{tabular}{ll}
\hline & Tipos de curso \\
\hline Contenidos disciplinares de lenguaje & $\begin{array}{l}\text { Contenidos disciplinares y estrategias de } \\
\text { enseñanza del lenguaje }\end{array}$ \\
\hline $75.8 \%$ & $24.2 \%$ \\
\hline
\end{tabular}

TABLA NRO. 2. Porcentaje de tipos de cursos respecto el total de cursos de lenguaje. Elaboración propia.

De igual forma, se identificó el porcentaje de programas los cuales incluían los contenidos básicos disciplinares del área de lingüística (ver TABLA NRO. 3)

\begin{tabular}{lll}
\hline $\begin{array}{l}\text { Contenidos disciplinares del área de lingüística (ien qué } \\
\text { contenidos se forma al futuro licenciado en español?) }\end{array}$ & Programas & $\%$ \\
\hline $\begin{array}{l}\text { 1. Panorama de los estudios lingüísticos } \\
\text { 1.1. Escuelas lingüísticas y autores }\end{array}$ & 110 & 91.6 \\
1.2. Modelos teóricos & & \\
1.3. La lingüística y sus desarrollos & 120 & 100 \\
\hline 2. Teoría y análisis gramaticales & 105 & 87.5 \\
2.1. Morfosintaxis & & \\
2.2. Gramática sincrónica y diacrónica & 110 & 91.6 \\
\hline 3. Fonética y fonología & 110 & 91.6 \\
\hline 4. Filosofía del lenguaje, pragmática y discurso & 100 & 83.3 \\
\hline 5. Semántica y semiótica & 95 & 79.1 \\
\hline 6. Sociedad, comunicación y sociolingüística & 80 & 66.6 \\
\hline 7. Cognición, psicolingüística, neurolingüística & 115 & 95.8 \\
\hline 8. Lingüística aplicada & & \\
\hline 9. Historia de la lengua española & & \\
\hline
\end{tabular}

TABLA NRo. 3. Contenidos disciplinares del área lingüística: número de programas en los que se abordan y porcentaje.

Elaboración propia.

\subsubsection{Tópicos abordados en los cursos}

Los tópicos correspondientes a los ítems de los syllabus son, por ejemplo, la justificación, la metodología, los contenidos, la bibliografía, entre otros. Así pues, se seleccionó el tópico «contenido» el cual puede subdividirse, a su vez, en los contenidos propios del discurso disciplinar de la lingüística y estrategias para 
la enseñanza de la disciplina, esto es, el discurso pedagógico y, finalmente, el tipo de habilidades lingüísticas que se desarrollan a lo largo del proceso de formación. Se decide focalizar el discurso disciplinar de la lingüística, en particular, aquellos cursos en donde hay un fuerte ejercicio de comprensión metalingüística, tanto para la comprensión de su marco conceptual y los análisis lingüísticos como para las acciones que de ellos se hacen en el ejercicio de la práctica pedagógica. Las materias hacen parte del núcleo específico de formación donde se comparte con asignaturas del área de la teoría literaria, la comunicación y la didáctica, y la práctica pedagógica. Los tópicos tratados van de la mano con los autores seleccionados, sus respectivos modelos conceptuales (bibliografía) y la capacidad para formar escuela ${ }^{5}$.

Tanto la programación y desarrollo de las materias del área dependen del contenido que se quiera desarrollar. Al tener en cuenta los contenidos especificados de la TABLA NRO. 4 en los cursos relacionados con el tema uno se elabora la programación, dividiendo generalmente el curso en tres temas sin importar el orden de presentación: 1) la lingüística como ciencia (aquí también se trabajan los conceptos básicos, los modelos epistemológicos y la interdisciplinariedad), 2) la historia de las escuelas lingüísticas con la enunciación de objetos de estudio y problemas más relevantes para sus análisis y 3 ) ejercicios de descripción y análisis lingüísticos. Para este último, dichos análisis son elementales y se llevan a cabo tomando como referencia problemas fonético/ fonológicos, pragmáticos y discursivos. Solo en dos programas se realiza algún tipo de análisis gramatical-oracional (específicamente morfosintáctico). En los cursos correspondientes a los temas dos y tres se presentan generalidades históricas y epistemológicas de los campos, y luego se concentran en los respectivos análisis técnicos. Para los temas cuatro, cinco y seis, el trabajo se centra en el análisis discursivo que recoge las técnicas de los respectivos campos disciplinares. En el tema nueve, el recuento histórico y el

5 Puech (2015) y Grishakova y Salupere (2015) constituyen dos excelentes trabajos dedicados a la noción de «escuela» en lingüística. Aportan ejemplos con sus respectivos análisis. 
desarrollo de análisis morfosintácticos constituyen el centro del curso. El tema siete se centra en la lectura crítica de documentos. No se plantea ningún tipo de análisis.

\subsubsection{Textos manejados en los cursos de lingüística}

En un $95 \%$ se utilizan manuales de lingüística porque contienen las generalidades de esta disciplina. En otras palabras, incluyen los contenidos especificados en la TABLA NRO. 3. En la bibliografía de los syllabus se encuentran lecturas obligatorias y complementarias. La lectura de artículos científicos (papers), solo se incluyó en el tema siete como una manera de ilustrar los estudios realizados a nivel de laboratorio. Se citan a continuación los textos presentados como lecturas obligatorias y los cuales se registran en el $90 \%$ de los syllabus:

Akmajian, A.; Harnish, R. M. y Demers, R. A. (1986). Lingüística: una introducción al lenguaje y a la comunicación. Alianza Editorial. -Título original: Linguistics. An Introduction to Language and Communication (1984), Cambridge: MIT Press. Versión española de Violeta Demonte-

Benveniste, É. (1997). Problemas de lingüística general I (19. a ed.) Siglo Xxi Editores.

Benveniste, É. (1999). Problemas de lingüística general II (15. ${ }^{\mathrm{a}}$ ed.). Siglo Xxi Editores.

Bernal Leongómez, J. (2008). Panorama de lingüistas del siglo XX: glosas del autor. Instituto Caro y Cuervo y Academia Colombiana de la Lengua.

Bernal Leongómez, J. (1984). Tres momentos estelares en lingüística. Instituto Caro y Cuervo. 
Cisneros Estupiñán, M. y Silva Villena, O. (2007). Aproximación a las perspectivas teóricas que explican el lenguaje. Editorial Universidad Tecnológica de Pereira.

Coseriu, E. (1983). Introducción a la lingüística. Universidad Nacional Autónoma de México, Instituto de Investigaciones Filológicas.

Fernández Pérez, M. (1999). Introducción a la lingüística. Editorial Ariel S.A.

FOWLER, R. (1978). Para comprender el lenguaje. Una introducción a la lingüística. [Título original en inglés, Understanding Language (1974), London: Routledge y Kean Paul Ltd. Versión española de Gladys Ánfora] Editorial Nueva Imagen.

Gimate-Welsch, A. (1994). Introducción a la lingüística modelos y reflexiones actuales. Universidad Autónoma de Puebla y Fondo de Cultura Económica.

Hockett, Charles. (1971). Curso de lingüística moderna. [Título original en inglés A course in modern Linguistics. New York, Macmillan Company. Traducción y adaptación hecha por Jorge Suárez y Emma Gregores]. Editorial Universitaria de Buenos Aires.

Lyons, J. (1971). Introducción en la lingüística teórica. [Título original, Introduction to Theoretical Linguistics (1968), Cambridge, University Press, London. Versión española y prólogo del profesor Ramón Cerdá] Teide.

Marín, M. (1999). Lingüística y enseñanza de la lengua. Aique, Grupo Editor S.A. 
Martinet, A. (1965). Elementos de lingüística general. [Título original, Éléments de linguistique générale, Paris, Armand Colin, 1960, versión española de Julio Calonge Ruiz] Gredos.

Tusón VAlls, J. (1984). Lingüística. Una introducción al estudio del lenguaje, con textos comentados y ejercicios. Editorial Barcanova.

De igual manera, se citan los textos que hacen parte de las lecturas complementarias:

Alvar, M. (2000). Introducción a la lingüística española. Editorial Ariel.

Barthes, R. (1993). La aventura semiológica. Ediciones Paidós.

Bernárdez, E. (1995). Teoría y epistemología del texto. Cátedra.

Bourdieu, P. (1999). ¿Qué significa hablar? Ediciones Akal.

BüHLER, K. (1979). Teoría del lenguaje. Alianza Editorial.

Сномsкy, N. (1973). Aspectos de la teoría de la sintaxis. Aguilar

Cisneros, M. y Silva, O. (2010). La conformación de la Ciencia Lingüística: desde la antigüedad hasta las proyecciones del siglo Xx. Universidad Tecnológica de Pereira.

Contreras, H. (Comp.). (1976). Los fundamentos de la gramática transformacional. Siglo XXI Editores.

Coseriu, E. (1981). Lecciones de lingüística general. Gredos.

Croft, W. y Cruse, A. (2008). Lingüística cognitiva. Ediciones Akal. 
Cuenca, M. J. y Hilferty, J. (1999). Introducción a la lingüística cognitiva. Editorial Ariel S.A.

Echeverría, R. (2003). Ontología del lenguaje (6. ${ }^{a}$ ed.). Lom Ediciones S.A.

EsCANDEll-VidAl, M. V. (Coord.). (2011). Invitación a la lingüística. Centro de Estudios Ramón Areces.

Gorski, D. P. (Ed.). (1961). Pensamiento y lenguaje. Editorial Grijalbo.

Gramsci, A. (2013). Escritos sobre el lenguaje. Untref,

Halliday, M. A. K. (1994). El lenguaje como semiótica social. La interpretación social del lenguaje y del significado. Fondo de Cultura Económica.

Hjelmslev, L. (1974). Prolegómenos a una teoría del lenguaje. Gredos.

Hudson, R. (1981). La sociolingüística. Editorial Anagrama.

Jackendoff, R. (2010). Fundamentos del lenguaje. Mente, significado, gramática y evolución. Fondo de Cultura Económica.

Jakobson, R. (1984). Ensayos de lingüistica general. Ariel.

Labov, W. (1983). Modelos sociolingüísticos. Ediciones Cátedra.

LERoY, M. (1974). Las grandes corrientes de la lingüística moderna. Fondo de Cultura Económica.

Lyons, J. (1975). Nuevos horizontes de la lingüistica. Alianza Editorial. 
Malmberg, B. (1968). Los nuevos caminos de la lingüística. Siglo XXI Editores.

Mattoso Câmara, J. (1967). Princípios de linguística general. Livraria Acadêmica. ${ }^{6}$

Montes Giraldo, J. J. (1995). Dialectología general e hispanoamericana. Instituto Caro y Cuervo.

Moreno Cabrera, J. C. (1997). Introducción a la lingüística. Enfoque tipológico y universalista. Editorial Síntesis.

Mounin, G. (1969). Claves para la lingüística. Anagrama.

Mounin, G. (1976). La lingüística del siglo xx. Gredos.

Newmeyer, F. (Coord.). Panorama de la lingüistica moderna de la Universidad de Cambridge. Tomos I, II, III y IV. [Edición supervisada por Luis Eguren. Versión española de Luis A. Santos Domínguez, Javier Gómez, Amparo Tusón, Joaquim Llisterri Boix y María Luisa Martín Rojo]. Visor.

Patiño Rosselli, C. (2000). Sobre etnolingüística y otros temas. Instituto Caro y Cuervo.

Pinker, S. (1995). El instinto del lenguaje. Cómo crea el lenguaje la mente. Alianza Editorial.

Real Academia Española y Asociación de Academias de LA Lengua Española. (2009). Nueva gramática de la lengua española. Volumen I y II. Espasa Libros, S. L. U.

6 Este libro fue citado y utilizado por el profesor de la asignatura, pues desde que realizó sus estudios de postgrado en Brasil, encontró que era uno de los libros capitales en el trabajo de enseñanza de la lingüística en Brasil. 
Ricoeur, P. (2006). Teoría de la interpretación Discurso y excedente de sentido. Siglo xxi Editores.

Robins, R. H. (2000). Breve historia de la lingüística. Ediciones Cátedra.

SAPIR, E. (1994). El lenguaje. Introducción al estudio del habla. Fondo de Cultura Económica.

SAussure, F. (1968). Curso de lingüística general. [Versión española de Amado Alonso]. Editorial Losada.

SAussure, F. (1980). Curso de lingüística general. [Edición y traducción de Mauro Armiño]Akal.

SAussure, F. (2004). Escritos de lingüistica general. Gedisa

Schaff, A. (1966). Introducción a la semántica. Fondo de Cultura Económica.

Searle, J. (2009). Actos de habla. Cátedra.

Simone, R. (2001). Fundamentos de lingüística. Ariel.

Tobón de Castro, L. (2007). La lingüística del lenguaje. Estudios en torno a los procesos de significar y comunicar (2. ${ }^{\mathrm{a}}$ ed.). Universidad Pedagógica Nacional.

Vidal, J.; Correa, J. I. y Santiago, A. W. (1999). Lingüística general y lingüística aplicada: de la teoría a la praxis. Corporación Editora Colombiana.

Wodak, R. y Meyer, M. (2003). Métodos de análisis crítico del discurso. Gedisa.

Yule, G. (2007). El lenguaje. Akal. 
Los artículos y capítulos de libro citados en español y en inglés fueron los siguientes:

BennetT, P. (2014). Langacker's cognitive grammar. In Littlemore, J. \& TAYlor, J. R. (EDs.). The Bloomsbury Companion to Cognitive Linguistics (pp. 29-48). Bloomsbury.

Bustos Guadaño, E. (2014). Literatura y cognición en el contexto de las nuevas humanidades: la función de la teoría cognitiva de la metáfora. Forma y Función, 27(1), 89-107. doi:https:// doi.org/10.15446/fyf.v27n1.46946

Fajardo, L. A. (2007). La lingüística cognitiva: principios fundamentales. Cuadernos de Lingüística Hispánica, (9), 6382. https://www.redalyc.org/articulo.oa?id=322230194007.

LANGACKeR, R. W. (2008). The relevance of Cognitive Grammar for language pedagogy. In S. De KnOP \& T. De Rycker (EDS.). Cognitive Approaches to Pedagogical Grammar. A Volume in Honour of René Dirven (pp. 7-35). Montoun de Gruyter.

Moreno MojicA, J. A. (2016). La lingüística cognitiva: una aproximación al abordaje del lenguaje como fenómeno cognitivo integrado. Análisis, 48(88), 41-51. https://doi. org/10.15332/s0120-8454.2016.0088.02.

Ramus, F. (2006). Genes, Brain, and Cognition: A Roadmap For the Cognitive Scientist. Cognition, 101(2), 247-269. doi: 10.1016/j.cognition.2006.04.003.

Tyler, A. y Evans, V. (2004). Applying Cognitive Linguistics to Pedagogical Grammar: The Case of Over. In M. ACHARD Y S. Niemeier. (Eds). Cognitive linguistics, Second Language Acquisition, and Foreign Language Teaching (pp. 257-280). Walter de Gruyter. 


\begin{tabular}{lll}
\hline $\begin{array}{l}\text { Contenidos disciplinares en los cuales se forma al } \\
\text { futuro licenciado en español }\end{array}$ & $\begin{array}{l}\text { Número de } \\
\text { programas }\end{array}$ & $\begin{array}{l}\text { Cursos en los } \\
\text { cuales se aborda el } \\
\text { tema }\end{array}$ \\
\hline 1. Panorama de los estudios lingüísticos & 8 & 13 \\
1.1. Escuelas lingüísticas y autores & & \\
1.2. Modelos teóricos & & 12 \\
1.3. La lingüística y sus desarrollos & 8 & \\
\hline $\begin{array}{l}\text { 2. Teoría y análisis gramaticales } \\
\text { 2.1. Morfosintaxis }\end{array}$ & & 6 \\
2.2. Gramática sincrónica y diacrónica & 6 & 17 \\
\hline 3. Fonética y fonología & 8 & 13 \\
\hline 4. Filosofia del lenguaje, pragmática y discurso & 8 & 11 \\
\hline 5. Semántica y semiótica & 8 & 13 \\
\hline 6. Sociedad, comunicación y sociolingüística & 8 & 1 \\
\hline 7. Cognición, psicolingüística, neurolingüística & 1 & 5 \\
\hline 8. Lingüística aplicada & 5 & \\
\hline 9. Historia de la lengua española & & \\
\hline
\end{tabular}

TABla NRo. 4. Contenidos disciplinares del área lingüística. Elaboración propia.

\subsubsection{Información de las entrevistas}

Frente a la temática de qué tipo de contenidos del área de lingüística se deben incluir en los planes de estudio de los futuros licenciados en Lengua Castellana, el resultado de las entrevistas realizadas a los doce profesores coinciden en que no hay conexión explícita entre los temas propuestos; aun a sabiendas de que en el diseño de los programas se especifica que, en las sesiones correspondientes a las horas prácticas se afinan los análisis teniendo en cuenta los modelos científicos estudiados en las sesiones teóricas previas. En la práctica, cada temática y por ende cada curso, se trabaja de manera independiente y sin establecer ninguna relación con el perfil de formación de los futuros maestros. Esto se explica en la medida en que los docentes manifiestan su preferencia por algunos autores, escuelas y específicos campos del saber.

Cuando se llevó a cabo la entrevista a profundidad, se pudo comprender las razones por las cuales los profesores optaban por una u otra opción. El argumento era más de índole personal que administrativo. Así, en los temas 1) y 2) de los tópicos abordados en los cursos, se limitan a seguir lo especificado en los manuales 
de lingüística, pero es precisamente en la presentación del tercer tema es decir, el 3) del mismo apartado, que hacen su aporte personal y conducen la práctica pedagógica $-\mathrm{y}$ por ende a los estudiantes-, hacia los elementos en los cuales ellos se sienten fuertes, seguros y en los cuales han publicado algún trabajo (ver TABLA NRO. 5). La especialidad a la cual se hace referencia tiene que ver con el nivel de interés, experticia y estudios específicos en una o varias temáticas pertenecientes al campo de la lingüística. Para el caso de los maestros de la primera generación, aquellos mayores de cincuenta años, la especialidad declarada desde el punto de vista autoreflexivo está conformada por las bases de la lingüística general, los estudios gramaticales, la fonéticafonología, la dialectología y la historia de la lengua. Para el caso de la segunda generación, a saber, los profesores menores de treinta y cinco años, dicha característica se remite a la pragmática, al análisis del discurso y a la lingüística aplicada. En esta última, tanto los intereses como los temas están relacionados con las estrategias de enseñanza del lenguaje y el cultivo de habilidades de comunicación: la lectura y la escritura en los diferentes niveles de escolaridad, los programas lectores, la didáctica de la lengua y la literatura, el desarrollo de la argumentación y, en menor medida, la lingüística de corpus.

Sin embargo, si bien sus percepciones no son suficientes para hablar de una generalidad a nivel nacional, estas coinciden con los trabajos mencionados en el estado del arte y con otros estudios a nivel nacional e internacional.

\begin{tabular}{|c|c|}
\hline $\begin{array}{l}\text { Contenidos disciplinares del área de lingüística (¿en } \\
\text { qué contenidos se forma al futuro licenciado en } \\
\text { español?) }\end{array}$ & $\begin{array}{l}\text { Profesores de lingüística los cuales } \\
\text { se declaran especialistas en un } \\
\text { tema }\end{array}$ \\
\hline 1. Panorama de los estudios lingüísticos & 6 \\
\hline 2. Teoría y análisis gramaticales & 5 \\
\hline 3. Fonética y fonología & 5 \\
\hline 4. Filosofía del lenguaje, pragmática y discurso & 6 \\
\hline 5. Semántica y semiótica & 2 \\
\hline 6. Sociedad, comunicación y sociolingüística & 6 \\
\hline 7. Cognición, psicolingüística, neurolingüística & 3 \\
\hline 8. Lingüística aplicada & 7 \\
\hline 9. Historia de la lengua española & 5 \\
\hline
\end{tabular}

TABLA NRO. 5. Contenidos disciplinares del área de lingüística y especialidad de los profesores. Elaboración propia. 


\subsubsection{Discusión derivada de los datos presentados}

El porcentaje de los cursos del área de lingüística oscila aproximadamente entre el 25 y el $35 \%$ del total de créditos del programa académico respectivo. En el objetivo esbozado en los syllabus se ha tenido en cuenta la directriz del MEN (Resolución 18583 del 15 de septiembre de 2017, artículo 2, numeral 2.2) la cual reza:

Componente de saberes específicos y disciplinares. El educador debe consolidar un dominio de los saberes y conocimientos actualizados, de los fundamentos conceptuales y disciplinares del campo o el área en que se desempeñará como licenciado. Adicionalmente, debe estar en capacidad de investigar, innovar y profundizar de forma autónoma en el conocimiento de dichos fundamentos, lo cual involucra: a) Apropiar la trayectoria histórica y los fundamentos epistemológicos del campo disciplinar y/o de los saberes específicos que estructuran el programa de formación, b) Dominar los referentes y formas de investigar del campo disciplinar o profesional, c) Desarrollar actitudes y disposiciones frente al trabajo académico y la formación permanente (p. 5)

Los contenidos de los syllabus apuntan al cumplimiento de los ítems a), b) y c). En esa dirección, se observa que el propósito de la mayoría de cursos del área de lingüística es la comprensión y manejo de los contenidos disciplinares.

Esta tendencia parecería estar acorde con lo planteado en relación con la importancia de reforzar la instrucción disciplinaria durante la formación inicial. Sin embargo, considerando que estos contenidos disciplinares se imparten simultáneamente con estrategias de enseñanza y/o habilidades lingüísticas y que el número de cursos dispuestos en la malla para este fin es menor, cabe interrogarse acerca de la profundidad con que son abordados (Sotomayor et al., 2011, p. 38). 
Valdría la pena verificar si el porcentaje de cursos, su respectiva ubicación en la malla curricular y la distribución temporal, coadyuvaría a formar licenciados en lengua castellana capaces de enfrentar los problemas de habilidades lingüísticas tanto propias como las de sus futuros alumnos, al tener como fundamento el discurso disciplinar del área. Aunque se ha propuesto establecer un diálogo interdisciplinario con las materias de pedagogía/ didáctica y teoría literaria, es posible que el diseño de los syllabus deba modificarse para lograr dicho fin.

Independientemente de la integración de los discursos disciplinar y pedagógico, de buscar puentes como la «formación lingüística» (Martín, 2013) o la pedagogía del lenguaje, los programadores curriculares de cada programa de licenciatura en español; esto es, los profesores del área de lingüística deberían superar el estadio de los diagnósticos y tratar de vencer la polarización cuando se planea el componente disciplinar y el componente pedagógico-didáctico.

Cuenca (como se citó en Pastor, 2000) sintetiza los diagnósticos. Cuando se trata de los defensores del discurso disciplinar, se ofrecen razones como: 1) los objetivos de la lingüística y de la didáctica son bien distintos y no tendrían por qué coincidir, 2) no se puede perseguir siempre una aplicación directa de una determinada teoría lingüística a la enseñanza y 3) la gran variedad de modelos lingüísticos (a veces contradictorios entre sí y con terminología en cada caso distinta), puede hacer dudar al docente sobre cuál es el más apropiado.

Cuando se trata de los defensores del discurso pedagógico hay otras razones: 1) el objetivo del profesor no es la investigación lingüística sino hacer que los alumnos aprendan a usar la lengua. Evidentemente, el docente nunca habrá de enseñar teorías lingüísticas, pero sí debería conocerlas para averiguar qué aspectos de ellas pueden aprovecharse en la práctica diaria; 2) no se tiene por qué adscribirse a una u otra teoría (situación que sí 
le sucede al investigador), sino que se suele optar, en la docencia, por un cierto eclecticismo en la metodología; y 3) la tarea del docente no solo tiene que ver con lo lingüístico: este es uno de los factores implicados, pero tan importante como él, son los factores psicológico y pedagógico.

\subsection{Conclusiones y proyecciones}

Haciendo eco a lo planteado por Fernández et al. (2010), son pocas las investigaciones que se han hecho en torno a los pormenores de la práctica de los profesores universitarios o formadores de futuros docentes en cuanto al manejo del discurso disciplinar. Es precisamente esa escasez de estudios la cual ha sacado de foco la propia práctica pedagógica universitaria, fundamentada en aquel discurso, el cual debe entrar en diálogo y complementarse con la alocución pedagógica a través de un tejido discursivo curricular eficaz, cuyo objetivo no sea darle un nombre a las asignaturas o definir el campo de lengua literatura en relación con el perfil de un profesor en formación-, sino responder a las preguntas planteadas más atrás, a saber: ¿cuál es la proporción de los cursos de Lingüística en las mallas curriculares? ¿Qué tipo de cursos de Lingüística se imparten? ¿Cómo se adapta el contenido disciplinar al perfil del egresado? ¿Cuál es la ubicación temporal de dichos cursos en las carreras de Licenciatura en Lengua Castellana? ¿De qué manera los contenidos del área de lingüística tienen una incidencia positiva en el quehacer pedagógico del futuro licenciado? ¿Qué se forma cuando se forma en lenguaje? ${ }^{7}$

En ese sentido, los profesores universitarios que forman a los futuros profesores en diversas áreas; para este caso, en lengua materna y en español,

7 El término lingüística, el cual se encuentra en cursiva, también quiere decir literatura, didáctica, pedagogía e incluso comunicación. 
...debieran tener un conocimiento de aquellas competencias que los futuros docentes han de poseer para el buen desarrollo de su actividad de enseñanza; competencias, habilidades y destrezas de las que ellos mismos han de disponer para poder darlas a quienes forman (Fernández et al. 2010, p. 347-348).

La idea impuesta por los autores citados consiste en el diseño curricular, la escogencia de las áreas (el núcleo disciplinar específico, el núcleo pedagógico, el núcleo comunicativo), los contenidos técnicos y de tradición, especializados con sus respectivos sustentos epistemológicos y discursivos. En esa misma dirección, los perfiles profesionales y ocupacionales deberían tener como eje transversal el proceso que indica cómo se transforma la materia de enseñanza en algo fácil de asimilar para los estudiantes o futuros licenciados, ya que estos utilizan estrategias en el ejercicio de su profesión las cuales se adaptan más a la mera transmisión del conocimiento que a una verdadera transformación de la materia, esto es, del discurso disciplinar.

El futuro profesor de español/lengua materna no debe confundir la capacidad de mostrar fluidez cuando habla una lengua con la capacidad de ofrecer explicaciones sobre la forma en la cual se construyen las secuencias verbales o se interpretan las oraciones. El estudiante debe ser consciente de que para entender y enseñar una lengua no se puede eludir el marco gramatical, este es preciso entenderlo, aunque no sea todo lo que hay que saber sobre la lengua. El conocimiento «instrumental», es decir, utilizar la lengua para alcanzar diversos fines, lo tiene cualquier hablante nativo. Pero el conocimiento gramatical consciente y la reflexión teórica sobre el sistema gramatical solo lo alcanzan los que lo estudian. De igual forma, en un plan de estudios universitario, dirigido y planeado para un público más maduro, adulto y con un fines más específicos y especializados, se debe tener en cuenta que tanto el componente disciplinar como el mecanismo de la práctica pedagógica implica otras dinámicas cognitivas, a saber, otras lógicas inscritas en la dinámica de la educación superior. En 
la universidad se impone, se trabaja, se adapta y se reproduce el discurso científico; aquel que corresponde al discurso disciplinar y que, en este caso, lleva a definir cómo manejar el discurso de la disciplina lingüística, siendo la reflexión gramatical, un tema central.

Además, para el caso de la formación de licenciados en lengua castellana, el objeto de estudio, la lengua, no puede concebirse como un saber escolar o una asignatura más que se enseña en la escuela, sino como el medio de socialización por excelencia y la manera de significar el mundo. La lengua española es también el vehículo y la llave de entrada al discurso de los demás saberes: a la configuración discursiva de la comunidad. Estas formulaciones deben estar en la base de la construcción curricular de un programa de licenciatura en español para escoger, dentro de las variantes del discurso disciplinar, los enfoques más adecuados de la teoría lingüística con el fin de consolidar la interacción en el aula de clase y, de esta forma, entender qué es la lengua. Es más, si se trata de formar en las facultades de educación futuros docentes de español para que desarrollen la competencia comunicativa de los estudiantes de primaria y bachillerato - no la de Hymes y sus fanáticos seguidores-, el énfasis es sobre todo instrumental, con un leve apoyo en lo conceptual.

Es aquí y ahora - muchos años después-, en donde se puede vislumbrar el verdadero valor del enfoque semántico comunicativo, el cual causó revuelo en los años ochenta por lo novedoso de sus planteamientos: generar un modelo conceptual que pudiera representar la manera como la experiencia humana del mundo se estructuraba en calidad de conocimiento en la utilización del lenguaje dentro de la significación. No se trataba de eliminar, como lo hizo el MEN, la dimensión estructural de la lengua sino complementarla. En una charla ofrecida a los profesores de español de Cali ${ }^{8}$, el profesor Baena (1980) dio en el 
punto al tratar de mostrar cómo la lingüística estaba al servicio de la enseñanza de lenguas en los diferentes niveles educativos. Allí expresó:

Saber una lengua no es simple cuestión de 'conjugar' y 'declinar'; no es poder repetir como un loro lo que ya hemos oído, aunque reconozcamos que ya está estructurado en fonemas, morfemas, construcciones y oraciones. Saber una lengua no es meramente, tener la capacidad de producir mecánicamente, lejos de las condiciones de la vida (que es ante todo interacción) 'todas y solamente las oraciones de la lengua'. Saber una lengua es ser capaz de significar en esa lengua; y significar en una lengua es un proceso que, aunque remite al manejo adecuado de los aspectos formales del sistema de la lengua e implica la capacidad de 'generar y entender todas y solamente las oraciones de una lengua', va más allá, en el sentido de que incorpora fundamentalmente, la capacidad de utilizar esas oraciones en el cumplimiento de actos de comunicación efectivos (pp. 32-33).

El camino a seguir, entonces, después de ver el anterior panorama, no es una senda recta, es tomar desvíos, atajos, sendas alternas y sendas nuevas. Y eso solo se logrará si se hace memoria, si se rescatan las diversas posturas y propuestas, si se enriquecen las experiencias con un toque de narrativa disciplinar autobiográfica y si se reconocen los avances que desde la Lingüística y sus interdisciplinariedades aportan para la reflexión en torno a la complejidad del lenguaje y de la comunicación humana.

\subsection{Referencias}

Akmajian, A.; Harnish, R. M. y Demers, R. A. (1986). Lingüística: una introducción al lenguaje y a la comunicación. Alianza Editorial.

Alvar, M. (2000). Introducción a la lingüística española. Editorial Ariel S. A. 
Aravena, F. y Quiroga, M. (2018). Autoetnografía y directivos docentes: una aproximación experiencial a las reformas educativas en Chile. Revista Electrónica de Investigación Educativa, 20(2), 113-125. https://redie.uabc.mx/redie/ article/view/1600.

Baena, L. A. (1980). Lingüística, orientaciones lingüísticas y metodologías. Lenguaje, 11, 26-34.

- (1996). Lo semántico en la enseñanza de lenguas extranjeras. Lenguaje, 24, 91-97.

BARthes, R. (1993). La aventura semiológica. Ediciones Paidós. https://circulosemiotico.files.wordpress.com/2012/10/ barthes-roland-la-aventura-semiologica-353pag1.pdf.

Bénard Calva, S. M (2019). Autoetnografía. Una metodología cualitativa. Universidad Autónoma de Aguascalientes.

BenNetT, P. (2014). Langacker's cognitive grammar. In Littlemore, J. \& TAYlor, J. R. (EDs.). The Bloomsbury Companion to Cognitive Linguistics (pp. 29-48). Bloomsbury.

Benveniste, É. (1997). Problemas de lingüística general I (19. ${ }^{a}$ ed.) Siglo XXI Editores. https://lamanchagrisdf.files.wordpress. com/2013/09/125422325-emile-benveniste-problemas-delinguistica-general-1.pdf.

. (1999). Problemas de lingüística general II (15. a ed.). Siglo xxI Editores. http://www.textosenlinea.com.ar/academicos/ Problemas\%20de\%20ling\%C3\%BC\%C3\%ADstica\%20 general\%20II.PDF.

Bernal Leongómez, J. (1984). Tres momentos estelares en lingüística. Instituto Caro y Cuervo. 
Bourdieu, P. (1999). ¿Qué significa hablar? Ediciones Akal. . (2006). Autoanálisis de un sociólogo. Anagrama.

BüHler, K. (1979). Teoría del lenguaje. Alianza Editorial.

Bustos Guadaño, E. (2014). Literatura y cognición en el contexto de las nuevas humanidades: la función de la teoría cognitiva de la metáfora. Forma y Función, 27(1), 89-107. doi:https:// doi.org/10.15446/fyf.v27n1.46946.

Сномsкy, N. (1973). Aspectos de la teoría de la sintaxis. Aguilar

Cisneros Estupiñán, M. y Silva Villena, O. (2007). Aproximación a las perspectivas teóricas que explican el lenguaje. Editorial Universidad Tecnológica de Pereira. https://media.utp.edu.co/referencias-bibliograficas/uploads/ referencias/libro/libro-perspectivas-teoricas-completopdfsljg7-libro.pdf.

Cisneros Estupiñán, M.; Olave Arias, G. y Rojas García, I. (2015).Didáctica y Lingüística: un desafío desdela universidad para la educación básica. Cuadernos de Lingüística Hispánica, (26), 159-174. https://doi.org/10.19053/0121053X.3684.

. (2016). Didáctica de la lengua materna en Colombia: Currículos y visiones docentes. Editorial Universidad Tecnológica de Pereira. https://media.utp.edu.co/referenciasbibliograficas/uploads/referencias/libro/didactica-de-lalengua-materna-en-colombpdf-rLgSp-libro.pdf.

. (2018). La formación didáctica de profesores de Español en Colombia. En L. Ramírez-Peña; R. Vallejo-Molina y M. Cisneros-Estupiñán (Comp..). Didáctica del lenguaje y de la literatura. Retrospectivas y perspectivas (pp. 139-159). Ediciones de la U. 
Cisneros, M. y Silva, O. (2010). La conformación de la Ciencia Lingüística: desde la antigüedad hasta las proyecciones del siglo Xx. Universidad Tecnológica de Pereira.

Contreras, H. (Comp.). (1976). Los fundamentos de la gramática transformacional. Siglo Xxi Editores.

Coseriu, E. (1981). Lecciones de lingüística general. Gredos.

. (1983). Introducción a la lingüística. Universidad Nacional Autónoma de México, Instituto de Investigaciones Filológicas.

Croft, W. y Cruse, A. (2008). Lingüística cognitiva. Ediciones Akal.

Cuenca, M. J. y Hilferty, J. (1999). Introducción a la lingüística cognitiva. Editorial Ariel S.A. https://www.escrituradigital. net/wiki/images/Introduccion-Linguistica-Cognitiva-pdf. pdf.

Decreto 1295 De 2010. (2010, 20 de abril). Ministerio de Educación Nacional. Diario oficial No. 47.687. https:// www.redjurista.com/Documents/decreto_1295_de_2010_ ministerio_de_educacion_nacional.aspx\#/.

Decreto 2450 DE 2015. (2015, 17 de diciembre). Ministerio de Educación Nacional. Diario oficial No. 49.729. https:// normograma.info/men/docs/pdf/decreto_2450_2015.pdf.

Echeverría, R. (2003). Ontología del lenguaje (6. a ed.). Lom Ediciones S.A.

Escandell-Vidal, M. V. (Coord.). (2011). Invitación a la lingüística. Centro de Estudios Ramón Areces. 
FAjardo, L. A. (2007). La lingüística cognitiva: principios fundamentales. Cuadernos de Lingüística Hispánica, (9), 6382. https://www.redalyc.org/pdf/3222/322230194007.pdf.

Fernández Pérez, M. (1999). Introducción a la lingüística. Editorial Ariel S.A.

Fernández-de Haro, E.; Núñez-Delgado, M. P. y RomeroLópez, A. (2010). Conocimiento del profesor universitario de lengua, literatura y su didáctica. Magis, Revista Internacional de Investigación en Educación, 2(4), 345356. http://www.scielo.org.mx/scielo.php?script=sci_ arttext\&pid=S1405-66662010000300011

Fowler, R. (1978). Para comprender el lenguaje. Una introducción a la lingüística. Editorial Nueva Imagen.

Gimate-Welsch, A. (1994). Introducción a la lingüística modelos $y$ reflexiones actuales. Universidad Autónoma de Puebla, Fondo de Cultura Económica.

Gorski, D. P. (Ed.). (1961). Pensamiento y lenguaje. Editorial Grijalbo.

Gramsci, A. (2013). Escritos sobre el lenguaje. Untref.

Grishakova, M. y Salupere, S. (Eds.). (2015). Theoretical Schools and Circles: Literary Theories, History, Philosophy. Routledge.

Grupo Lenguaje, Educación y Desarrollo [LED]. (2008). Impacto de la formación de maestros en competencias en el área de lenguaje. Lingüística y literatura, (53), 115-138.

Halliday, M. A. K. (1994). El lenguaje como semiótica social. La interpretación social del lenguaje y del significado. Fondo de Cultura Económica. 
Hjelmslev, L. (1974). Prolegómenos a una teoría del lenguaje. Gredos.

Hockett, C. (1971). Curso de lingüística moderna. Editorial Universitaria de Buenos Aires. http://pdfhumanidades. $\mathrm{com} / \mathrm{sites} / \mathrm{default} / \mathrm{files} / \mathrm{apuntes} / 23_{-}{ }_{-}$Hockett_-_Curso_ de_linguistica_moderna_\%28prefacio\%2C_cap2_ al_13\%29_62_copias.pdf.

Hudson, R. (1981). La sociolingüística. Editorial Anagrama. http://pdfhumanidades.com/sites/default/files/apuntes/ Hudson\%20la\%20socioling\%C3\%BC\%C3\%ADstica.pdf.

Jackendoff, R. (2010). Fundamentos del lenguaje. Mente, significado, gramática y evolución. Fondo de Cultura Económica.

Jakobson, R. (1984). Ensayos de lingüística general. Editorial Ariel.

Labov, W. (1983). Modelos sociolingüísticos. Ediciones Cátedra. http://pdfhumanidades.com/sites/default/files/apuntes/ Labov\%20modelos\%20sociolinguisticos.pdf.

LANGacker, R. W. (2008). The relevance of Cognitive Grammar for Language Pedagogy. Applications of Cognitive Linguistics, 9, 7-35.

Leroy, M. (1974). Las grandes corrientes de la lingüística moderna. Fondo de Cultura Económica.

LEY 115 DE 1994. (1994, 8 de febrero). Congreso de Colombia. Diario oficial Nro. 41.214. http://www.secretariasenado.gov. co/senado/basedoc/ley_0115_1994.html. 
LEY 1188 DE 2008. (2008, 25 de abril). Congreso de la República. Diario oficial Nro. 46.971. https://colaboracion.dnp.gov.co/ CDT/Normatividad/ley\%201188\%20de\%202008.pdf.

Lyons, J. (1971). Introducción en la lingüistica teórica. Teide.

. (1975). Nuevoshorizontes de la lingüística. Alianza Editorial. https://investigacion2018.files.wordpress.com/2017/08/ lyons_horizontes_introduccion_invest0001.pdf.

Mahecha, M. A. (2009). ¿Para qué enseñamos lingüística? Paideia Surcolombiana 14, 21-33. https://journalusco.edu.co/ index.php/paideia/article/view/1075/2092.

. (2012). Diseño de contenidos disciplinares de un curso de «Lingüística general» y mecanismos pedagógicos para su respectiva presentación y evaluación [Ponencia]. XXVII Congreso Nacional de Lingüistica, Literatura y Semiótica, Tunja, Colombia. http://www.uptc.edu.co/export/ sites/default/eventos/2012/cnills/documentos/diseno_ contenidos_disciplinares.pdf.

. (2020). La Lingüística en Colombia y su enseñanza en las universidades. Fundación El Libro Total. http://www. ellibrototal.com/ltotal/ficha.jsp?idLibro $=16160$.

Malmberg, B. (1968). Los nuevos caminos de la lingüística. Siglo XXI Editores.

Marín, M. (1999). Lingüística y enseñanza de la lengua. Aique, Grupo Editor S.A.

Martín Hernández, M. (2013). Tendencias en la formación lingüística del docente de educación inicial y primaria: problemas y perspectivas de solución. Sapiens. Revista Universitaria de Investigación, 14, 41-64. http://ve.scielo.org/ $\mathrm{pdf} / \mathrm{sp} / \mathrm{v} 14 \mathrm{n} 1 /$ art04.pdf. 
Martinet, A. (1965). Elementos de lingüística general. Gredos.

Mattoso CÂmara, J. (1967). Princípios de linguística geral. Livraria Acadêmica.

Ministerio de Educación Nacional [MEN]. (2013). Sistema colombiano de formación de educadores y lineamientos de política. MEN. http://cms.mineducacion.gov.co/static/cache/ binaries/articles-345485_anexo1.pdf?binary_rand=4264.

. (2014). Lineamientos de calidad para las licenciaturas en educación (Versión preliminar). MEN. https://www. mineducacion.gov.co/1759/articles-357233_recurso_1.pdf.

- (s.f.). La práctica pedagógica como escenario de aprendizaje. MEN. https://www.mineducacion.gov.co/1759/ articles-357388_recurso_1.pdf.

Montes Giraldo, J. J. (1995). Dialectología general e hispanoamericana. Instituto Caro y Cuervo.

Moreno Cabrera, J. C. (1997). Introducción a la lingüística. Enfoque tipológico y universalista. Editorial Síntesis.

Moreno Mojica, J. A. (2016). La lingüística cognitiva: una aproximación al abordaje del lenguaje como fenómeno cognitivo integrado. Análisis, 48(88), 41-51. https:// revistas.usantotomas.edu.co/index.php/analisis/article/ view/2719/2625.

Mounin, G. (1969). Claves para la lingüística. Anagrama. . (1976). La lingüística del siglo xx. Gredos.

Murillo Rojas, M. (2007). Formación docente en el área de lengua. Actualidades Investigativas en Educación, 7(2), 1-33. 
Negrin, M. (2003). Saberes teóricos y práctica docente: Razones de un desencuentro. Educación, Lenguaje y Sociedad, 1(1), 307-312. http://www.biblioteca.unlpam.edu.ar/pubpdf/ieles/ n01a19negrin.pdf.

Newmeyer, F. (Coord.). (1992). Panorama de la lingüística moderna de la Universidad de Cambridge. Visor.

Pastor, S. (2000). Teoría lingüística actual y aprendizaje de segundas lenguas. Cuadernos Cervantes, (26), 38-44. https:// rua.ua.es/dspace/bitstream/10045/48779/1/2000_Pastor_ CuadCervantes.pdf.

Patiño Rosselli, C. (2000). Sobre etnolingüística y otros temas. Instituto Caro y Cuervo.

Perdomo Vanegas, W. L.; López Pineda, L. Y. y Mahecha Oviedo, M. F. (2016). Panorama del lenguaje y la literatura en las licenciaturas en humanidades en Colombia. Revista interamericana de educación, pedagogía y estudios culturales, 9(2), 139-158. https://revistas.usantotomas.edu.co/index. php/riiep/article/download/3618/3527/

Pinker, S. (1995). El instinto del lenguaje. Cómo crea el lenguaje la mente. Alianza Editorial.

Puech, C. (2015). Présentation. La notion d' «école linguistique»: unité, singularité, pluralité. Histoire Épistémologie Langage, tome 37, fascicule 2. "Faire école» en linguistique au xxe siècle: l'école de Genève. 5-15.

Ramus, F. (2006). Genes, Brain, and Cognition: A Roadmap For the Cognitive Scientist. Cognition, 101(2), 247-269.

Real Academia Española y Asociación de Academias de la Lengua Española. (2009). Nueva gramática de la lengua española. Volumen I y II. Espasa Libros, S. L. U. 
Resolución 2041 DE 2016. (2016, 3 de febrero). Ministerio de Educación Nacional. Diario oficial No. 49.776. https://normograma.info/men/docs/resolucion_ mineducacion_2041_2016.htm.

ReSOluCión 18583 DE 2017. (2017, 15 de septiembre). Ministerio de Educación Nacional. Diario oficial No 50.357. https:// www.icbf.gov.co/cargues/avance/docs/resolucion_ mineducacion_18583_2017.htm.

Ricoeur, P. (2006). Teoría de la interpretación Discurso y excedente de sentido. Siglo xxI Editores.

Robins, R. H. (2000). Breve historia de la lingüística. Ediciones Cátedra. https://filologiaunlp.files.wordpress.com/2011/08/ r-_h-_robins_-_breve_historia_de_la_ling.pdf.

SAPIR, E. (1994). El lenguaje. Introducción al estudio del habla. Fondo de Cultura Económica.

SAussure, F. (1968). Curso de lingüística general. Editorial Losada. http://fba.unlp.edu.ar/lenguajemm/?wpfb_dl=59. . (1980). Curso de lingüística general. Ediciones Akal. . (2004). Escritos de lingüística general. Gedisa.

Schaff, A. (1966). Introducción a la semántica. Fondo de Cultura Económica.

Searle, J. (2009). Actos de habla. Ediciones Cátedra.

Simone, R. (2001). Fundamentos de lingüística. Editorial Ariel. 
Sotomayor, C.; Parodi, G.; Coloma, C.; Ibáñez, R. y Cavada, P. (2011). La formación inicial de docentes de Educación General Básica en Chile. ¿Qué se espera que aprendan los futuros profesores en el área de Lenguaje y Comunicación? Pensamiento Educativo Revista de Investigación Educacional Latinoamericana, 48(1), 28-41. http://pensamientoeducativo. uc.cl/files/journals/2/articles/446/public/446-2213-1-PB.pdf.

Tobón de CAstro, L. (2007). La lingüistica del lenguaje. Estudios en torno a los procesos de significar y comunicar (2. ${ }^{a}$ ed.).Universidad Pedagógica Nacional.

Tusón Valls, J. (1984). Lingüística. Una introducción al estudio del lenguaje, con textos comentados y ejercicios. Editorial Barcanova.

Tyler, A. y Evans, V. (2004). Applying Cognitive Linguistics to Pedagogical Grammar: The Case of Over. Cognitive linguistics, Second Language Acquisition, and Foreign Language Teaching, 18, 257-280. https://doi.org/10.1515/9783110199857.257.

Vidal, J.; Correa, J. I. y Santiago, A. W. (1999). Lingüística general y lingüística aplicada: de la teoría a la praxis. Corporación Editora Colombiana.

Wodak, R. y Meyer, M. (2003). Métodos de análisis crítico del discurso. Gedisa. https://www.researchgate.net/ profile/Editson_Agudelo_Liz/publication/275634501_ Metodos_de_Analisis_Critico_del_Discurso/ links/554097970cf2320416ed0d01/Metodos-de-AnalisisCritico-del-Discurso.pdf.

Yule, G. (2007). El lenguaje. Ediciones Akal. 



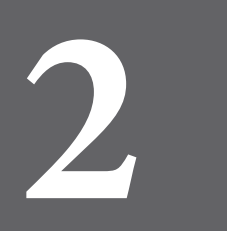

CAPÍTULO

DOS 



\title{
Una mirada a los escritos universitarios desde la Teoría de la Valoración de la Lingüística Sistémica Funcional ${ }^{1}$
}

\author{
Mireya Cisneros-Estupiñán ${ }^{2}$ \\ Clarena Muñoz-Dagua ${ }^{3}$
}

\subsection{Introducción}

Cuando los estudiantes finalizan sus carreras universitarias, se espera que hayan desarrollado habilidades para la elaboración de textos como ensayos y artículos los cuales responden a pautas mínimas definidas en el transcurso de la formación disciplinaria. Esta apreciación se generaliza aún más, cuando se trata de

1 Este trabajo se deriva del proyecto titulado: Estudio de la disponibilidad léxica en profesionales relacionados con el área de la lingüística, inscrito en la Vicerrectoría de Investigaciones, Innovación y Extensión de la Universidad Tecnológica de Pereira, con el código CIE 4-16-5

2 Profesora titular de la Universidad Tecnológica de Pereira. Integrante del grupo de investigación Estudios del Lenguaje y la Educación, Categoría A1. Directora de la Maestría en Lingüística. Correo: mireyace@gmail.com, página: https:/utp-co.academia.edu/MireyaCisnerosEstupinan 3 Profesora de la Universidad Colegio Mayor de Cundinamarca. Integrante del grupo de investigación Estudios del Lenguaje y la Educación, Categoría A1. Asesora de trabajos de grado de la Maestría en Lingüística. Correo electrónico: clargui@yahoo.es 
egresados de carreras relacionadas con el estudio y enseñanza de la lengua quienes aspiran a ingresar a estudios postgraduales. El proyecto Estudio de la disponibilidad léxica en profesionales relacionados con el área de la lingüística, del cual se deriva este capítulo, tiene como objetivo caracterizar el repertorio léxico para elaborar un texto académico, y reconocer las fortalezas y debilidades presentes en la producción escrita de estudiantes que aspiran a ingresar a una maestría en lingüística, con el fin de advertir, en el nivel posgradual, cuáles son los retos por asumir en esta línea de trabajo.

El fundamento teórico y analítico para este capítulo se tomó de la Lingüística Sistémico Funcional de Halliday (1994/2004), en particular, de la Teoría de la Valoración (Martin y Rose, 2003; White, 2003; Martin y White, 2005 ), la cual se ha desarrollado en las últimas décadas como herramienta teórica y analítica que posibilita el estudio de aspectos evaluativos del lenguaje, la emoción, la actitud y los recursos que hacen variar el «compromiso» del emisor con sus enunciados. Con base en los sistemas de Actitud, Compromiso y Gradación se analizan los recursos léxico gramaticales elegidos por los aspirantes para redactar un texto adecuado y en vía a las condiciones exigidas por los evaluadores, para así conseguir la aprobación.

De acuerdo con Halliday y Hassan (1985), en la investigación y el trabajo relacionado con la enseñanza y el aprendizaje de la lengua es necesario centrar el interés en el texto como producto $y$, a la vez, en el texto como proceso. Sobre esta concepción, el proyecto Estudio de la disponibilidad léxica en profesionales relacionados con el área de la lingüística se ocupa del texto como producto en la medida que el corpus del escrito se sustenta en los textos argumentativos, presentados por egresados de carreras relacionadas con la enseñanza de la lengua que aspiran a ingresar a la Maestría en Lingüística. Pero, a la vez, en el transcurso del análisis se caracteriza el repertorio léxico para la elaboración de dicho texto, es decir, se atiende el proceso de selección semántica, 
el cual se puede observar en esta producción escrita, con el fin de advertir pautas de intervención para el mejoramiento de los procesos que conllevan a la escritura de textos académicos en el nivel posgradual.

El corpus está constituido por los textos argumentativos que los aspirantes a la maestría en Lingüística de la UTP presentaron como requisito de admisión, para las cohortes IV y V, correspondientes a los años 2014 y 2015. La recolección de los textos se realizó a través de una convocatoria abierta institucional, ligada al inicio de los estudios de maestría, en la cual se le solicita a cada aspirante la presentación escrita de dos textos argumentativos:

1. Texto en el que argumenta el impacto de la Lingüística en los ámbitos social, lingüístico y educativo.

2. Texto en el que refiere cuál es el tema que pretende desarrollar para su trabajo de grado y por qué.

Para las cohortes IV (16 estudiantes) y v (26 estudiantes) se recolectaron 81 textos: 39 propuestas y 42 escritos a manera de ensayo, con una extensión en promedio de 1175 y 262 palabras, respectivamente. En su mayoría, los aspirantes ejercen como docentes de español en instituciones de educación básica y media, lo que corresponde a su formación profesional en los pregrados; provienen de distintas universidades del ámbito regional del Eje cafetero, de lugares aledaños y también de otras regiones como la Costa Atlántica, el centro y el sur del país (Cisneros-Estupiñán et al., 2018, p. 15).

En el presente capítulo, primero se reseñan los fundamentos teóricos del estudio en el contexto de la Lingüística Sistémico Funcional (LSF) de Halliday (1994/2004), en particular, los estudios de la Teoría de la Valoración (Martin, 2000) y el Sistema de Compromiso (White, 2003). En segundo lugar, se precisan las características de los textos académicos escritos por los aspirantes como requisito para la postulación al ingreso a la educación postgradual. Posteriormente, se analiza el léxico reiterativo, 
utilizado por los graduados de carreras afines a la lingüística, en sus escritos formulados para ingresar al nivel de maestría entre los años 2014 y 2016. Al final, se presentan las conclusiones primarias.

\subsection{De análisis textual en el contexto de la Lingüística Sistémico Funcional (LSF)}

La producción de textos académicos requiere, como toda actividad humana, la adecuación a circunstancias específicas del contexto en situación. En el caso de aquellos que se realizan como requisito para el ingreso a la Maestría en Lingüística, por ejemplo, se precisa el uso de recursos léxico-gramaticales que apoyen la argumentación sobre las razones. En esa dirección, se les solicita elaborar un escrito que responda a unas características formales y técnicas específicas. A nivel general, es de reconocer que, «dada la complejidad y variabilidad del uso de la lengua, los textos se construyen mediante selecciones hechas a partir de una situación comunicativa que implica propósitos de los hablantes, actitudes, carga ideológica, modelos mentales, procesos para la construcción e interpretación del texto y el contexto de la interacción social» (Cisneros-Estupiñán et al., 2014, p. 10).

Desde esta perspectiva, al establecer la ruta de partida para la investigación, se reivindica el modelo Sistémico Funcional de Halliday (1994/2004) el cual postula el lenguaje como una manera - entre otras - , de producir significados motivados social y culturalmente. En particular, en el análisis se utiliza la Teoría de la Valoración la cual se enfoca en la función interpersonal del lenguaje. Así, a partir de esta útil herramienta de trabajo es posible describir y explicar los recursos lingüísticos mediante los cuales los hablantes expresan, negocian y naturalizan sus posiciones intersubjetivas. En el caso de los textos académicos presentados por los aspirantes a la Maestría en Lingüística, el examen de los recursos léxicos de la valoración permite advertir las dificultades exhibidas por los egresados de carreras afines a los estudios 
del lenguaje para lograr el posicionamiento de su propia voz y conseguir el objetivo propuesto en el texto. En este sentido, este consiste en exponer las razones por las cuales eligieron un tema para su trabajo de grado de Maestría en Lingüística.

Ahora bien, la Teoría de la Valoración (Hood y Martin, 2005) divide los recursos léxicogramaticales, utilizados por los hablantes y escritores, para expresar sus evaluaciones. Esto, a partir de tres sistemas semánticos: Actitud, Compromiso y Gradación, los cuales se reseñan a continuación para introducir los elementos básicos del análisis.

«El sistema de Actitud alude, el cual alude a los valores que los hablantes comunican en sus Juicios y las respuestas emocionales y afectivas que asocian a los participantes y los procesos» (Cisneros-Estupiñán y Muñoz-Dagua, 2012, p. 485). Así, concentra los recursos en tres subsistemas: Afecto, Juicio y Apreciación.

El Afecto caracteriza los fenómenos en relación con las emociones; es la evaluación mediante la cual el hablante indica su disposición emocional o reporta las respuestas subjetivas de terceros hacia personas, cosas, situaciones o eventos. Dichas emociones se concentran en tres grandes grupos que tienen que ver con la felicidad o la infelicidad; la seguridad o la inseguridad, y la satisfacción o la insatisfacción (Muñoz-Dagua y AndradeCalderón, 2018, p. 27).

El Juicio describe el comportamiento humano en correspondencia con el conjunto de normas sociales y hace referencia a la evaluación moral de la conducta: normas sobre cómo deben y no deben comportarse las personas. Las pautas sociales que se ponen en juego en estas evaluaciones de Juicio adoptan la forma de regulaciones o de expectativas sociales. En el Juicio, la conducta se puede evaluar como moral o inmoral, legal o ilegal, socialmente aceptable o inaceptable, plausible o deplorable, normal o anormal (p. 54). 
White (2003) clasifica los juicios en: De estima social, subdivididos, a su vez, en juicios relativos a la normalidad (cuán normal es una persona), y la capacidad o la tenacidad demostrada en la conducta (cuán competente o cuán resuelta y decidida es); y De sanción social, relacionados con la veracidad y la integridad moral.

La Apreciación se encarga de la evaluación de objetos y productos (...) en relación con principios estéticos y otros sistemas de valor social. (...). [La Apreciación es considerada como el sistema mediante el cual] se evalúan artefactos, textos, constructos abstractos como planes y políticas, así como objetos naturales o manufacturados. También las personas pueden ser consideradas mediante la Apreciación, pero sólo cuando se perciben como entidades, y no como participantes con conducta. Con estos valores se evalúan la forma, la apariencia, la composición, el impacto y la importancia (Cisneros-Estupiñán y Muñoz-Dagua, 2012, p. 485/497).

Por su parte,

...el sistema de Compromiso incluye los recursos por medio de los cuales la voz textual se posiciona intersubjetivamente. En términos de White (2003), el Compromiso hace referencia a los recursos para posicionar la voz del hablante en relación con las proposiciones y propuestas comunicadas por un texto; en otras palabras, los significados utilizados para negociar un espacio interpersonal y ubicar la voz propia dentro de la diversidad de voces que intervienen en un escrito.

Sobre la base de la noción de polifonía de Bajtin (2005), quien señala que todo texto está conectado dialógicamente con otros textos, White (2003) propone estudiar el sistema de Compromiso en la perspectiva heteroglósica, compatible con la descripción de la función del Modo (Mood) del modelo de Halliday. El lenguaje posiciona a los hablantes y sus textos dentro de la heterogeneidad de posturas sociales y de concepciones del mundo que operan en cualquier cultura. En consecuencia, los textos reflejan una 
determinada realidad social o una posición ideológica. Cada significado dentro de un texto ocurre en un contexto social, donde podrían haberse elegido otros significados alternativos o contrarios. Las principales opciones en el sistema de Compromiso se ubican en la Monoglosia y la Heteroglosia.

Desde la perspectiva dialógica de la Teoría de la Valoración, los enunciados monoglósicos equivalen a las aseveraciones declarativas absolutas. Mediante el uso de estas, los hablantes adoptan posturas socio-semióticas de gran fuerza retórica e interpersonal, que entran en relaciones de tensión con posibles enunciados alternativos o contradictorios. En el caso de la heteroglosia, se incluyen los enunciados que reconocen la existencia de otras voces y posturas alternativas.

(...) el Sistema de Gradación representa los valores por medio de los cuales los hablantes gradúan (aumentan o disminuyen) el impacto interpersonal, la fuerza o el volumen de sus emisiones y regulan (desdibujan o agudizan) el foco de sus categorizaciones semánticas. Las dos categorías principales de la Gradación son la Fuerza y el Foco (Muñoz-Dagua y Andrade Calderón, 2018, p. $18)$.

\subsection{De textos académicos en el contexto universitario}

En este apartado, vamos a considerar algunas caracterizaciones relacionadas con los textos que se producen en el contexto universitario con fines académicos. "Para algunos estudiosos del tema del género, los textos que se especializan en una temática pueden inscribirse en el ámbito de los discursos especializados» (Cisneros-Estupiñán y Muñoz-Dagua, 2014, p. 10). De acuerdo con Parodi (2005), tanto el discurso académico como el profesional poseen ciertas características que permiten incluirlos en esta clasificación. En efecto, ellos

...se agrupan por una co-ocurrencia sistemática de rasgos lingüísticos particulares en torno a temáticas específicas no cotidianas en los cuales se exige experiencia previa disciplinar de 
sus participantes\{formación especializada dentro de un dominio conceptual particular de la ciencia y de la tecnología\}; por otra, son textos que revelan predominantemente una función comunicativa referencial y circulan en contextos situacionales particulares: todo ello implica que sus múltiples rasgos se articulan en singulares sistemas semóticos completos y no de manera aislada y simple [la cursiva es nuestra] (Parodi, 2005, p. 26).

En términos generales, el discurso profesional hace referencia a los textos en los que las comunidades profesionales construyen su identidad. Para Cabré y otros (2001) este comprende los textos que se producen en el ejercicio de un oficio y que desempeñan un papel fundamental entre los miembros de una comunidad profesional y entre estos profesionales y la sociedad (CisnerosEstupiñán y Muñoz-Dagua, 2014, p. 11).

Por su parte, el discurso académico hace

... énfasis en los propósitos didácticos y persuasivos, en un producto que manifiesta prestigio y credibilidad por ser un discurso autorizado para tratar un tema y por el propósito que persigue cual es apoyar a la formación de la comunidad de especialistas mediante la difusión de conocimientos de orden disciplinar. Esta función didáctica y divulgativa hace que estos textos sean más explicativos, fundamentados en justificaciones y demostraciones, con un léxico más asequible; pero, con un alto grado de abstracción semántica y de generalización. La citación de fuentes, para aludir, por ejemplo, a los antecedentes teóricos, es un rasgo significativo y el canal más utilizado para su circulación es el escrito (2014b, p. 11).

Lo anterior requiere un fuerte trabajo en la lectura y la escritura, es decir, en las prácticas que permiten visualizar y comprender el conocimiento disciplinar y los procesos esenciales en la formación de competencias fundamentales para la comprensión y argumentación de dicho conocimiento.

De cierta manera, como destaca Parodi (2005) los géneros 
académicos actúan como un eje articulador entre los géneros profesionales y otros géneros especializados, como los científicos, porque se constituyen en formas obligadas para el acceso al conocimiento y a las prácticas especializadas escritas y, en este sentido, son fundamentales en la construcción de un sello disciplinar especializado. Así mismo, como señalan Martin y Rose (2007) y Bhatia (2004) los géneros discursivos profesionales $\mathrm{y}$ académicos cruzan transversalmente a las disciplinas, pero es posible que haya ciertas diferencias al interior de un mismo género pues al estar presentes en varios contextos pueden adquirir formas y funciones distintas (Cisneros-Estupiñán et al., 2014, p. 18).

\section{Los textos académicos}

abarca[n] dos entornos: uno dado en textos tales como manuales, libros de texto, guías y cuadernillos dedicados a la formación de estudiantes como preparación para la comunidad científica (social y profesional) mientras que el segundo, el autor corresponde a los estudiantes en formación y el destinatario a los docentes y profesionales encargados de evaluar y valorar la producción de la futura comunidad científica (Cisneros-Estupiñán et al., 2014, p. 18).

Los textos de los cuales se ocupa este capítulo corresponden, precisamente, a esta clasificación: 1) son escritos argumentativos que los estudiantes presentan como requisito de admisión, 2) el destinatario de dichos textos son docentes encargados de evaluar, 3) los escritos deben cumplir unas normas formales de presentación (mil palabras máximo), y 4) los trabajos producidos por egresados de diversas universidades colombianas de carreras relacionadas con el estudio y enseñanza de la lengua.

En este orden de ideas, en los textos académicos la selección de los elementos conceptuales relevantes depende, en alto grado, de las mismas estructuras textuales exigidas para el cumplimiento de tareas determinadas en los ciclos educativos pertinentes: definir, resumir, exponer un punto de vista, argumentar, relacionar, 
comparar, debatir, entre otros. En consecuencia, en estos textos se debe conjugar el rigor de la investigación el cual los hace parte de la comunidad discursiva, con los elementos experienciales e intelectuales que se consideran más cercanos al potencial lector. Así, en la selección de qué decir, cobra importancia la finalidad del texto y la figura del interlocutor, sus intereses y sus expectativas, para lo cual se hace necesario el seguimiento a estructuras textuales particulares.

A nivel del contexto situacional, los recursos para garantizar la comprensión en los textos académicos son muchos y variados: secuencias textuales explicativas, definiciones, reformulaciones, paráfrasis, procedimientos narrativos $\mathrm{o}$ de base analógica como ejemplos, comparaciones y metáforas las cuales facilitan comprender lo lejano y abstracto a través de lo más cercano y conocido. De igual manera, en la organización de los textos se encuentran el uso de formas de equivalencia, procesos (verbos) y el empleo de conjunciones (conectores) o formas de comparación.

En el caso de los participantes en el acto comunicativo, existe una relación asimétrica y jerárquica. El emisor es un estudiante en formación y el receptor es un profesor, profesional, especialista o tutor encargado de valorar la producción escrita y los grados de manejo del conocimiento y de los tipos textuales propios del nivel de formación y de las disciplinas en cuestión. Según Wichter (1994), las categorías experto-no experto indican solo los extremos de una escala entre los cuales se podrían definir niveles intermedios. Para el caso que ocupa este proyecto, no es igual un estudiante de pregrado que uno de maestría; ejemplo de ello es que, frente a los dos extremos de la escala, existen diferencias en el dominio de conocimiento especializado y específico.

Así las cosas, «en el contexto de la Lingüística Sistémico Funcional el Campo del discurso se encontrarán indicadores significativos de los recursos para construir el contenido en los textos académicos como la ejemplificación, la reformulación 
y formas metafóricas para explicar los conceptos técnicos o especializados» (Cisneros-Estupiñán et al., 2014, p. 18). Habrá, por tanto, referencia a las dinámicas relacionadas con los diferentes asuntos científicos, al mencionar detalles importantes como fechas, datos biográficos y circunstancias específicas las cuales puedan facilitar la explicación en aquel contexto. Por su parte, en el Tenor, relacionado con los roles sociales de los participantes, se hará referencia a la expresión de actitudes, juicios y valoraciones por parte del estudiante para la emisión de sus proposiciones y propuestas. En cuanto a la organización del mensaje, es decir, el Modo (Mode), los escritos académicos requieren una distribución específica para formar mensajes relevantes que tengan continuidad y énfasis, y puedan ser intercambiados; de allí que utilizan un modo retórico persuasivo y didáctico.

\subsection{De actitudes y compromisos en textos académicos}

Los textos elaborados por los aspirantes a la Maestría en Lingüística deben cumplir con unos parámetros específicos. Por un lado, son escritos argumentativos que los estudiantes presentan como requisito de admisión, cuyo destinatario son docentes especializados, quienes tienen la tarea de evaluar las mínimas condiciones con las cuales llegan los licenciados y, en general, profesores de lengua española. Por otro lado, en tanto el contenido debe referirse a la temática que se desarrollará en el trabajo de grado de Maestría y su justificación, se solicitan unos requisitos formales mínimos: mil palabras como máximo, citación de fuentes, estructura textual, léxico técnico acorde con la comunidad discursiva, entre otros.

Al examinar el corpus a la luz de la Teoría de la Valoración, se advierte que la mayoría de los escritos presentan gran riqueza en el uso de recursos léxico-gramaticales, relacionados con el lenguaje del Afecto, el Juicio y la Apreciación y, aunque se alude a autores reconocidos, no se citan las fuentes, de tal manera que se privilegia un lenguaje informal típico de otras tipologías textuales. 
A continuación, se presentan algunos ejemplos con base en las fichas elaboradas para el análisis. Estas hacen parte de los textos enviados por los aspirantes vía correo electrónico entre 2014 y 2016.

Así, como se puede observar en las fichas 3 y 5 , en la redacción de los textos argumentativos de los aspirantes a la Maestría en Lingüística se hacen presentes los verbos de emoción, los cuales remiten a procesos mentales: amar, odiar, sufrir, gozar, agradecer, gustar, entre otros. Pero, junto a estos, se dan variables en la expresión del Afecto las cuales describen de manera pormenorizada los sentimientos y los efectos de la selección de un tema específico sobre el aspirante, de forma que las emociones se despliegan a lo largo del párrafo en una escala manifestada en usos léxicos que hacen relación a estados presentes y futuros:

[Ficha 3] Durante mi pregrado tuve la oportunidad de acercarme tres ramas en las cuales es posible desempeñarme como docente y aunque la pedagogía y la literatura son dos líneas de pensamiento educativo muy interesante y es de mi total agrado, debo reconocer que la lingüística ha despertado gran interés que me gustaría enfatizar en este campo y para ello tengo como propuesta continuar con el proyecto de mi pregrado ya que su enfoque aunque es más de carácter semiótico, lingüístico y literario debido a que está influenciado por autores como Armando Silva, Marshall Berman, Richard Sennett, Rodrigo Arguello y Orlando Mejía Rivera; la tesis tiene como nombre [...] y la cual me gustaría seguir con este tema pero cambiando el análisis a otra clase de obra literaria para un análisis más extendido dado que los autores citados pueden ofrecer una amplia variedad de situaciones lingüísticas que se pueden rastrear en una obra literaria e incluso en todas las clases de textos a los cuales, como docentes podemos acercarnos de manera detallada ...

En la ficha 5, además de los verbos que remiten a los sentimientos, se utilizan los adverbios que le gradúan el nivel del sentimiento (siempre me ha interesado), o señalan circunstancias de modo, como sucede con especialmente: 
[Ficha 5] Además quiero realizar esta investigación porque siempre me ha interesado y apasionado el estudio de los idiomas o las lenguas conociendo a profundidad su origen, sus componentes, funciones y evolución con el paso del tiempo y el cambio de generaciones con sus respectivos giros y procesos de transformación, pero haciendo especialmente énfasis en conocer sobretodo nuestra lengua materna o idioma castellano pues es preciso identificarnos con la nuestra para entrar a estudiar las demás [El subrayado es nuestro].

De igual manera, en las exposiciones realizadas por los aspirantes se utilizan adjetivos los cuales expresan emoción como ocurre en la ficha 9, con la manifestación de cómo se siente la voz textual, triste, frente a la situación de la mayoría de instituciones educativas. En este ejemplo, se observa el recurso de nominalización de los adjetivos culpable y apático que, en el contexto, le dan fuerza a la descripción:

[Ficha 9] El tema que pretendo desarrollar en mi trabajo es mejorar la calidad de las habilidades comunicativas de los estudiantes de secundaria del colegio xxxx, institución educativa en la que laboro desde hace varios años orientando la materia de español y literatura por medio de la cual he percibido el deficiente desempeño de muchos de nuestros alumnos, es triste ver la mayoría de las instituciones educativas públicas con nuestros jóvenes en lo relacionado a la poca y pobre producción textual donde se nota la apatía por escribir, la apatía por redactar sus propias producciones personales, posiblemente la culpa de ello la tiene el no contar con sólidas y suficientes de gramática, de reglas ortográficas, de signos de puntuación, entre otros, imprescindibles todas ellas para llevar a cabo el ejercicio de redacción; siendo también muy pobre el análisis y la interpretación que realizan en su diaria labor interesándoles muchas veces alcanzar solo la exigencia mínima de los logros planteados en los planes de estudio; por lo tanto veo la necesidad de realizar trabajos académicos en busca de mejorar estas competencias en los estudiantes. 
También en este apartado es posible analizar el subsistema de Juicio, es decir, «la institucionalización de las emociones en el contexto de las propuestas, esto es, normas sobre cómo deben y no deben comportarse las personas» (González Rodríguez, 2011, p. 122). Este subsistema, de acuerdo con Cisneros-Estupiñán y Muñoz-Dagua (2012)

se clasifica en dos grandes tipos: (i) juicios de estima social, subdivididos, a su vez, en juicios relativos a la normalidad (cuán normal es una persona), la capacidad o la tenacidad demostrada en la conducta (cuán competente o cuán resuelta y decidida es); (ii) juicios de sanción social (relacionados con la veracidad y la integridad moral)» (p. 491-492).

Tal como se aprecia en el ejemplo, se realizan juicios de estima social relacionados con la competencia textual de los jóvenes la cual es evaluada como deficiente, poca y pobre en los distintos momentos.

Aunque se encuentran juicios explícitos en los textos, «en muchas ocasiones, la evaluación del Juicio puede permanecer implícita, o ser evocada de manera más indirecta mediante los llamados indicadores (tokens) de juicio. Con estos últimos, la descripción aparentemente fáctica, no evaluada, de un hecho o situación, puede desencadenar una evaluación actitudinal» (Kaplan, 2004, p. 65), como sucede en la ficha 20. El aspirante no califica explícitamente de competente o incompetente a los docentes. Sin embargo, su comentario tiene el potencial de evocar evaluaciones en los lectores las cuales comparten una visión particular acerca del problema que trata de exponer. Esos significados, en apariencia solo informativos, tienen la capacidad de rememorar juicios de valor sobre los sujetos en cuestión:

[Ficha 20] El proyecto de grado estará encaminado a recuperar, adquirir, evolucionar y contextualizar todo ese bagaje lingüístico con que contamos los seres humanos pero que no usamos, dejándonos sumergir en la pobreza conceptual que día a día es $m$ [á] 
s profunda. El nombre de dicho proyecto será... SUEMÉRGETE EN EL OCÉANO LINGÜÍSTICO este permitirá que no solo los estudiantes adquieran y mejoren su lenguaje, sino que también involucrará a los docentes...

La apreciación que incluye los recursos con los cuales se evalúan artefactos, textos, constructos abstractos, objetos naturales y manufacturados, se hace evidente en la ficha 10, en donde se califica a la lectura como placentera y se la compara con un tesoro. Luego, se hace un juicio de integridad moral negativo: no existe desgracia mayor para un pueblo o ser humano que no apreciar el valor fundamental de la lectura.

[Ficha 10] La lectura es una majestuosa herramienta y uno de los grandes placeres de la vida. Brinda compañía, enseñanza, asombro, entusiasmo; con ella se viaja a través del tiempo, hace volar la imaginación y plasmar los pensamientos. La lectura enriquece las mentes llenándolas cada día de conocimientos y cultura, permitiendo a las personas explorar mundos inalcanzables.

Mediante la lectura el deseo y la alegría de aprender siempre estarán vivos; no existe desgracia mayor para un pueblo o ser humano que la de no apreciar el valor fundamental de la lectura; porque desde los inicios del universo y la evolución del ser humano ha existido la lectura ya sea esta de imágenes, señas o la de escritura hasta llegar a la evolución de las comunicaciones. Se debe ver la lectura como un gran tesoro que tienen las personas y asímismo fortalecerlo y enriquecerlo cada día para estar preparado dentro de una sociedad globalizada que avanza a pasos agigantados dentro de todos los ámbitos.

En la ficha 3 se presenta la Apreciación referida a la composición-complejidad de la información acerca del lenguaje, intensificada con los adverbios mucho y más. En seguida, se realiza una evaluación que hace referencia a su importancia como herramienta de comunicación humana (reacción-impacto). 
[Ficha 3] Finalmente me parece importante además de agradable y dispendioso el hecho de estudiar y conocer sobre nuestro lenguaje desde todos los campos de estudios científicos dado que es el lenguaje la principal herramienta de la comunicación humana y por ende el más complejo dadas sus muchas líneas de pensamiento dedicadas a su análisis morfológico, sintáctico, fonológico, psicológico, semiótico, etc.

En cuanto al sistema de Compromiso por medio del cual la voz textual se posiciona intersubjetivamente, como se puede observar en los textos citados, predominan los recursos de intravocalización los cuales destacan la voz del autor en primera persona sobre la cantidad posible de voces. Son menores los recursos de extravocalización, los cuales introducen en el texto diversas fuentes de voces externas.

[Ficha 2] Como docente de lengua castellana, literatura y lectores competentes, es mi deseo elaborar una tesis que mejore mis prácticas educativas y transforme la enseñanza y el aprendizaje mío y de mis estudiantes, fortaleciendo así nuestros conocimientos y creando competencias aplicadas en cualquier circunstancia que la vida nos depare.

Entre los valores de intravocalización se incluyen opciones como la Apariencia, recurso que hace dialógico el texto al destacar la voz del autor. Aquí se encuentran opciones del tipo me parece que, aparentemente, es claro que, la evidencia sugiere que (Kaplan, 2004). En el ejemplo se utiliza la forma es de claro conocimiento para introducir un comentario sobre la importancia de las estrategias lúdicas para promover la lectura.

[Ficha 10] Es de claro conocimiento la apatía que manifiestan los estudiantes de la institución educativa Xxx por el proceso de lectura manifestada en bajos niveles de comprensión y análisis. No se puede negar que el gusto por la lectura se empieza desde el momento en que se inicia el proceso de enseñanza, razón por la cual los docentes de básica primaria debemos tener estrategias 
lúdicas y pedagógicas atractivas para los educandos, que generen expectativas suficientes que los motiven a continuar con este proceso de construcción del sujeto.

En algunos casos, en los escritos se destaca lo fuertemente involucrada que está la voz textual con el punto de vista de quien la emite. Con «los valores de coincidencia, los hablantes o autores representan a la proposición o propuesta como "dada" e irrefutable, ya que coincide con lo que se conoce o cree generalmente. Estos recursos tienen, asimismo, la función retórica de crear un acercamiento entre el autor y el lector» (Kaplan, 2004, p. 71). Una muestra de la coincidencia se puede captar en la ficha 11 donde se afirma, no tenemos duda:

[Ficha 11] No tenemos duda alguna que el lenguaje y la educación siempre han caminado de la mano en el crecimiento intelectual de los individuos y es por esta unión que ha surgido en mí un interés por descubrir a fondo la importancia que tiene el uso de estas nuevas formas de comunicación lingüística en los estudiantes de la Institución

Así, este análisis de los recursos de la Valoración ha permitido indagar, en primera instancia, acerca de las posturas adoptadas por los aspirantes a la Maestría en Lingüística para elaborar sus textos y conseguir su propósito. En este sentido, la Teoría de la Valoración ha proporcionado un marco para explorar en la investigación de qué modo los autores de los escritos adoptan posturas actitudinales hacia el contenido experiencial de sus enunciados (el tema que presentan), hacia el evaluador (formas con las cuales establecen contacto) y cómo se acercan o se distancian de otras voces que operan en sus enunciados (Muñoz-Dagua, 2014). En ese sentido, la presencia reiterativa del lenguaje evaluativo en el corpus de referencia brinda, de manera importante, elementos para argumentar por qué este tipo de análisis resulta útil para definir estrategias que permitan crear condiciones para determinar la función retórica de estos trabajos en el contexto de los estudios de posgrado. 


\subsection{A modo de cierre}

En este análisis de los trabajos académicos, presentados por egresados de carreras relacionadas con el estudio y la enseñanza de la lengua, se pudo establecer que la mayoría tienden en sus textos a concentrarse en un léxico en el cual prima más el afecto y los juicios superficiales y de sentido común que el discurso académico argumentativo, esperable para un nivel que ha superado varias etapas como la educación básica, la media y la universitaria. Además, se reducen, en gran medida, a la voz autoral sin fundamentación teórica y disciplinar recibida en la universidad.

En efecto, en los ejemplos tomados del corpus, es claro el uso recurrente de descripciones y detalles los cuales resultan poco atractivos para el evaluador cuando, por su preparación inicial, los aspirantes tuvieron la posibilidad de asociar en sus escritos el bagaje de su formación y su experiencia con temas de la vida académica sin presiones de tiempo ni de vigilancia, ya que enviaron su propuesta vía correo electrónico.

Aunque, en la tradición escolar, se espera que la producción de textos escritos por parte de los egresados de carreras afines al estudio de la lengua corresponda a un nivel más avanzado que el de otros profesionales (dado el conocimiento que, se supone, tienen de los géneros discursivos), el examen de los escritos, a la luz de los recursos de la Valoración, permite inferir que los graduados en pocas ocasiones diferencian su voz de otras voces y, en su mayoría, se dedican a describir, una y otra vez, los temas que pretenden desarrollar en sus futuros trabajos, sin argumentar. En general, la voz autoral señala, de forma directa, una posición actitudinal frente al tema por desplegar con el léxico del Afecto, el Juicio y la Apreciación. En muchas ocasiones, el texto aparece como una respuesta emocional en la cual se expresa un punto de vista frente a una pregunta espontánea más que un texto preparado para una valoración posterior. 
Por otra parte, el léxico es repetitivo y, en su mayoría, los textos no presentan una estructura mínima de introducción, desarrollo y conclusión. Con estos resultados, surgen inquietudes sobre las exigencias y las valoraciones que se realizan en estos textos escritos por docentes de lengua, en los cuales se plantean conceptos y definiciones que a veces no corresponden a los construidos y utilizados por la comunidad discursiva. Por ello, con este primer acercamiento al corpus, es posible inferir cómo egresan los estudiantes universitarios $\mathrm{y}$, mediante el análisis a partir de los recursos de la Teoría de la Valoración, precisar los problemas lingüísticos presentes en su producción escrita. En suma, se hace imprescindible la tarea que se ha planteado para una segunda etapa de la investigación; esto es, derivar pautas de intervención para fortalecer los procesos que conllevan a la escritura de textos académicos en la Universidad.

\subsection{Referencias}

Cabré, T.; Doménech, M.; Morel, J. y Rodríguez, C. (2001). Las características del conocimiento especializado y la relación con el conocimiento general. En T. CABré y J. Feliu (Ed.), La terminología técnica y científica (pp. 173-186). IULA-UPF.

Cisneros-Estupiñán, M. y Munoz-Dagua, C. (2012) El afecto, la apreciación y el juicio en el habla de las telenovelas. Lenguaje, 40(2), 481-505. DOI: https://doi.org/10.25100/ lenguaje.v40i2.4959

Cisneros-Estupiñán, M.; Muñoz-Dagua, C. y Herrera, J. (2014) Perspectivas y prospectiva en los estudios sobre Lectura y Escritura. Universidad Tecnológica de Pereira.

Cisneros-Estupinán, M. y Munoz-Dagua, C. (2014) Tras las huellas de las investigaciones sobre lectura y escritura en la Universidad. Universidad Tecnológica de Pereira. 
Cisneros-Estupiñán, M.; Olave-Arias, G. y Serna-Pinto, A. (2018). Escritura académica en el acceso al posgrado: Aproximación al léxico disciplinar en Lingüística. Universidad Tecnológica de Pereira.

Halliday, M. \& Hasan, R. (1985). Language, Context, Text: Aspects of Language in a Social Semiotic Perspective. Oxford University Press.

Halliday, M. A. K. (1994/2004). An introduction to Functional Grammar. Edward Arnold Publisher. http://www.uel. br/projetos/ppcat/pages/arquivos/RESOURCES/2004 HALLIDAY MATTHIESSEN An Introduction to Functional Grammar.pdf.

Hood, S. y Martin, J. R. (2005), Invocación de actitudes: El juego de la gradación de la valoración en el discurso. Revista signos, 38(58), 195-220. http://dx.doi.org/10.4067/S071809342005000200004 .

Martin, J. R. (2000). Beyond Exchange: Appraisal Systems in English. En: S. Hunston \& G. Thompson (Eds.) Evaluation in Text. (pp. 142-175). Oxford University Press

Martin, J. R., Y Rose, D. (2012). Learning to write, Reading to learn. Australia: Equinox.

Martin, J. R. y White, P. (2005). The Language of Evaluation: Appraisal in English. Palgrave Macmillan.

Muñoz-Dagua, C. (2014). La Metáfora Interpersonal Léxicogramatical en el discurso de divulgación científica. Universidad Colegio Mayor de Cundinamarca.

Muñoz-Dagua, C. y Andrade-Calderón, M. (2018). Perdonen si los incomodo: Discurso de los vendedores de transporte público en Bogotá. Universidad Colegio Mayor de Cundinamarca. 
Parodi, G. (2005). Discurso especializado e instituciones formadoras. Ediciones universitarias de Valparaíso.

(2007). El discurso especializado escrito en el ámbito universitario y profesional: Constitución de un corpus de estudio. Revista Signos, 40(63), 147-178. http://dx.doi. org/10.4067/S0718-09342007000100008.

Kaplan, N. (2004) Nuevos desarrollos en el estudio de la evaluación en el lenguaje: La Teoría de la Valoración. Boletín de Lingüística, (22), 52-78.

WichteR, S. (1994) Experten-und Laienwortschätze. Umriss einer Lexikologie der Vertikalität. Niemeyer.

White, P. (2003). Beyond modality and hedging: A dialogic view of the language of intersubjective stance. Text, 23(2), 259284. 



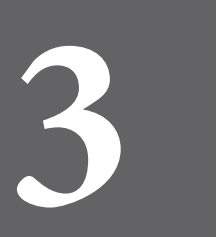

CAPÍTULO TRES 



\title{
Usos del metadiscurso en el combate público verbal $^{1}$
}

\author{
Giohanny Olave Arias ${ }^{2}$
}

\subsection{Introducción}

En este capítulo realizo una aproximación analítica a la metadiscursividad en situaciones de disputa verbal pública. Ese tipo de interacciones aparece intermitentemente en diversos modos del discurso público orientados hacia la confrontación de

1 El capítulo es un producto de dos investigaciones complementaria que se encuentran en curso: «La violencia verbal en redes sociales. Etología de la agresión en el debate público digital» (Universidad Industrial de Santander) y «Contribuciones de los estudios del discurso a la transición hacia la paz en Colombia» (Universidad Tecnológica de Pereira).

2 Doctor en Lingüística, Universidad de Buenos Aires; Magíster en Educación, Universidad Nacional de La Plata y Magíster en Lingüística, Universidad Tecnológica de Pereira. Actualmente es profesor de tiempo completo en la Universidad Industrial de Santander, Colombia. Investigador sénior en las áreas de análisis del discurso, retórica y educación lingüística. Miembro de los grupos de investigación Glotta (Universidad Industrial de Santander, categoría B) y Estudios del lenguaje y la educación (Universidad Tecnológica de Pereira, categoría A1). Libros recientes: Análisis del discurso en disputas públicas. Retorno a la Erística (2019); Retórica de la victoria. Oposición política y paz con las Farc-Ep (2019). Autor de capítulos y artículos en revistas especializadas, disponibles en https://uis.academia.edu/GiohannyOlave. 
opiniones, como los debates en medios de comunicación, pero también en géneros menos asociados con las polémicas verbales, como las entrevistas o las ruedas de prensa. Este acercamiento contribuye al desarrollo de una propuesta analítica de las disputas públicas, interesada especialmente por sus momentos más tensos, que he venido desarrollando con el nombre de erística (Olave, 2018; 2019).

En el marco de ese interés por las luchas verbales, el capítulo avanza hacia el rastreo de las funciones erísticas del metadiscurso, esto es, hacia la introducción del discurso como objeto de discordia en tramos de la confrontación verbal pública. El problema se centra en la atención a esas funciones que, hasta el momento, no han sido atendidas en el tratamiento de la metadiscursividad. Como se trata de una primera aproximación, el capítulo no aborda exhaustivamente el problema, sino que abre una ruta de indagación para el análisis de futuros corpora discursivos.

En cuanto al aspecto metodológico, la reflexión se orienta por los principios epistemológicos de la perspectiva interpretativa interdisciplinar del Análisis del discurso desarrollada por Arnoux (2019) y adaptada para el análisis de disputas públicas. Respecto al tratamiento de los ejemplos, se utilizó una transcripción selectiva (Jenks, 2011), con ayuda del software ELAN 5.0. En cada caso, se ofrece información a pie de página sobre la fuente de origen de los ejemplos. Sin embargo, el capítulo no pretende ofrecer análisis de casos, sino ilustrar las reflexiones desarrolladas a través de extractos de esas interacciones.

En razón del perfil propuesto, el capítulo iniciará con una síntesis del tratamiento del metadiscurso en la bibliografía disponible y los posibles aportes que esas perspectivas ofrecen para el abordaje de disputas públicas verbales. Posteriormente, se retomará el enfoque analítico de la erística y la visión que propone en relación con otros modos de abordar la confrontación de opiniones. En la tercera parte del texto se ilustrará la hipótesis del 
uso erístico del metadiscurso a través de tres ejemplos extraídos de interacciones transmitidas por medios de comunicación digitales.

\subsection{La atención al metadiscurso}

En su concepción más general, «el discurso acerca del discurso o la comunicación acerca de la comunicación» (Vande, 1985, p. 83) manifiesta la capacidad de convertir la forma del decir -y no necesariamente el contenido de lo dicho-, en el foco o problema principal de la interacción comunicativa.

El estudio de este carácter o función doblemente autorreferencial e intersubjetiva del discurso ha sido muy útil en la retórica de la escritura y en la pedagogía de la lengua escrita para orientar el aprendizaje del registro académico. Hyland (2005), por ejemplo, analiza en extenso este asunto a partir de la siguiente definición de metadiscurso: «aquellos aspectos de un texto que organizan explícitamente el discurso, comprometen al público lector y señalan la actitud del escritor» (p. 437). Desde esta perspectiva, dicho elemento es un recurso pragmático que se usa estratégicamente en la situación de escritura para influir en la recepción del texto. Por tanto, como conjunto de recursos retóricos, el metadiscurso se agrupa en categorías diferenciales de acuerdo con sus dos funciones principales: guiar al lector a lo largo del texto (metadiscurso «interactivo» a través de marcadores textuales de transición, endofóricos, evidenciales, entre otros), e involucrarlo en el texto (metadiscurso «interaccional» a través de marcadores de actitud, de compromiso, automenciones, mitigadores, entre otros) (Hyland, 2005).

Sin embargo, ese punto de vista presupone la transparencia de las intenciones comunicativas y su orientación hacia los principios pragmáticos de cooperación fundamentales. Desde una perspectiva crítica, Fairclough (1993) incluye el metadiscurso dentro de otro tipo de recursos de índole ideológica, con los cuales «el hablante se sitúa por encima o por fuera de su propio 
discurso, en una posición que favorece su capacidad de controlar o manipular» (pp. 122-123). Asimismo, el autor destaca las funciones del metadiscurso en la construcción de la subjetividad, ya que le permite al hablante mostrar la capacidad de distanciarse de su propio discurso, lo cual puede resultarle conveniente para sus fines políticos e ideológicos.

En esa idea, Fairclough (1993) está partiendo de la lectura de Pêcheux (2016/1975), desde una perspectiva materialista del discurso. Para el filósofo marxista, el sujeto puede tomar distancia de la formación discursiva que le impone ciertos modos de decir, esto a través de un proceso de «contra-identificación», que

consiste en una separación (distanciamiento, puesta en duda, puesta en cuestión, puesta en entredicho, revuelta...) respecto de lo que el "Sujeto universal" le "da a pensar": lucha contra la evidencia ideológica, en el terreno de esta evidencia, evidencia afectada por la negación, invertida en su propio terreno. El desvío comporta trazos lingüísticos: "lo que usted llama la crisis del petróleo", "sus ciencias sociales", "tu Santa Virgen (...). En suma, el sujeto (...) se contra-identifica con la formación discursiva que le impone el "interdiscurso" como determinación exterior de su interioridad subjetiva, lo que produce las formas filosóficas y políticas del discurso-contra. (p. 187)

Así, las reflexiones de Pêcheux (2016/1975) ubican el problema de la metadiscursividad en el terreno de la construcción del sujeto como efecto de la ideología. De tal manera, la estrecha relación entre esta última y la lengua se explica porque no hay discurso sin sujeto ni sujeto sin ideología, pese a que el individuo haya «olvidado» cuál es la ideología que lo ha construido o interpelado como sujeto.

Los trabajos de Authier-Revuz (1984; 1995) incorporan ese interés en el sujeto discursivo, al identificar y clasificar los recursos enunciativos que puede utilizar el locutor para comentar su propio decir («autonimia»), mostrar en su enunciado voces diferentes a 
la propia («heterogeneidad mostrada») y establecer relaciones de diferenciación con esas voces («las no coincidencias del decir»). Estas últimas son resumidas por la misma autora de la siguiente forma:

- No coincidencia de la interlocución: "como dice usted...», «en sus palabras...», «si seguimos su visión...», «voy a usar sus términos...», entre otras.

- No coincidencia del discurso consigo mismo: «lo que llaman...», «según x...», «desde la perspectiva de...», «según se ha propuesto...», entre otras.

- No coincidencia entre las palabras y las cosas: «digámosle x...», "por ponerle un nombre...», "por así decir...», «si es que puede llamarse así...», entre otras.

- No coincidencia con las palabras mismas: «en el sentido de...», "con un concepto amplio de...», «literalmente hablando...», «de modo figurado», entre otras. (Authier-Revuz, 1995, pp. 192-196)

Este abordaje de la metadiscursividad es reconocido ampliamente en el ámbito de los estudios del discurso y de las teorías de la enunciación, además de ser utilizado comúnmente para el análisis de la modalidad (Etkin, 2016; Maingueneau, 2009), es decir, para identificar la manifestación lingüística de los juicios del sujeto hablante 3 . Sin embargo, Authier-Revuz (1995) prefiere hablar de metaenunciación y de autonimia en vez de metadiscursividad, esto para "partir sistemáticamente de las formas de la lengua y no de categorías comunicacionales, como ocurre, de manera dominante, en los trabajos sobre metadiscurso» (p. 184). En el mismo sentido, la modalización autonímica no está interesada en el nivel de los intercambios verbales ni en su interpretación situada.

3 Sigo aquí la definición clásica de Bally (1932) sobre modalidad: «forma lingüística de un juicio intelectual, de un juicio afectivo o de una voluntad que un sujeto pensante enuncia a propósito de una percepción o de una representación de su espíritu» (p. 3), pero remito al lector a la amplia discusión sobre su concepto, expuesta por Etkin (2016). 
Propongo una aproximación a la metadiscursividad que no parta únicamente de las formas autonímicas, sino de las acciones de fuerza verbal entre los participantes de una interacción pública tensa. El énfasis en la lógica contenciosa o erística orientará la interpretación de las movidas metadiscursivas como parte de las acciones que construyen la disputa en las arenas públicas y mediatizadas.

\subsection{El enfoque erístico del análisis discursivo}

La perspectiva erística se interesa por los fenómenos de inscripción en el discurso de discordias apasionadas y desbordadas, en las cuales las reglas del debate ceden ante los imperativos del combate. La manifestación discursiva de desacuerdos de este tipo configura disputas en las cuales los participantes se atacan y se defienden a través de acciones simbólicas de fuerza y de hostilidad, entre las cuales cobran especial importancia las agresiones verbales y paraverbales. En trabajos anteriores (Olave, 2019), propuse que la erística constituye una dimensión de la expresión del desacuerdo; una condición transversal de las relaciones sociales y, por extensión, de buena parte de las interacciones argumentativas, si bien ella misma no constituye un tipo de argumentación ${ }^{4}$, sino más bien su reverso:

La erística es más una modalidad dentro del debate público, como lo es también el debate racional, pero no a través de sus mismos procedimientos, pues conserva una parte sustancial de la naturaleza material del combate físico que, a priori, no responde a exigencias normativas, pero sí a parámetros o componentes que aparecen regularmente (Olave, 2019, p. 50).

\footnotetext{
4 Por lo tanto, no se inscribe en alguna teoría de la argumentación ni conforma otra, sino que recupera una discusión filosófica clásica dentro de la dimensión dialéctica del logos, la cual opone la tradición platónico-aristotélica a la tradición sofística y erística. La primera de ellas se actualiza en la pragmadialéctica (Van Eemeren, 2010) y la lógica informal (Walton, 1999; 2003); la segunda, en la dialéctica de Schopenhauer (2011/1864).
} 
Como lo sugiere Budzyńska (2013), las aproximaciones conceptuales a la erística tienen una fuerte dependencia de los momentos disciplinares en los cuales se originan. Para el caso de la retórica clásica, la erística es presentada como un juego verbal contencioso, engañoso y deleznable (Platón, 1987) o como un modo de razonamiento defectuoso y falso para la refutación racional (Aristóteles, 1995). En Schopenhauer (2011/1864), en cambio, la erística es el trasfondo de la dialéctica, el arte de las disputas en las cuales los sujetos buscan ganar a cualquier precio y usan todo tipo de estratagemas verbales. Kotarbiński (1963), por su parte, continúa la reflexión de Schopenhauer, pero define la erística como una competencia o habilidad en las disputas para obtener el reconocimiento de un tribunal que juzga y define quién tiene la razón. Este punto de vista, con énfasis en los veredictos judiciales, ha sido recuperado desde finales del siglo pasado en el ámbito ruso por Blazevic y Selivanov (1999). Recientemente, se han evaluado los crecientes trabajos sobre erística de Kampka, Kochan, Lewinskiy Min Liu (como se citaron en Hordecki, 2018) como aproximaciones con un marcado énfasis instrumental en las técnicas o tácticas de la disputa y con poca atención a los contextos socioculturales dentro de las cuales aparecen.

El área de los estudios clásicos también presta atención a la erística como un conjunto de técnicas de refutación derivadas de la dialéctica socrática, pero con objetivos diferentes a la búsqueda de la verdad. En la antigüedad clásica, esas técnicas no aludían a una escuela o movimiento en particular, sino que se les llamaba «erísticas» para etiquetarlas peyorativamente, con lo cual se denostaba a los intelectuales de la época que no compartían las ideas de Platón y, por lo tanto, no merecían llamarse «filósofos» (Mársico, 2014; Ramírez Vidal, 2016). Sin embargo, como lo propone Gardella (2017), la erística logra configurar una dialéctica socrática alternativa, centrada en los modos de la antilogía, con funciones críticas (la imposibilidad de acceder a lo real a través de las palabras), persuasivas (la imposición de un punto de vista sobre otro acerca de la misma cosa) y refutativas (la capacidad de objetar cualquier posición u opinión sobre algo). 
En este trabajo, la erística es abordada interpretativamente en su dimensión discursiva como prácticas insertas en disputas públicas contingentes, históricas y políticas, en las cuales los actores luchan apasionadamente por someter a sus adversarios con el fin de reforzar un orden social determinado y profundizar desacuerdos específicos en la esfera pública. Con los ejemplos que siguen, ilustro algunas funciones de la metadiscursividad cuando los contendientes la involucran en sus disputas públicas.

\subsection{Algunos ejemplos}

\subsubsection{La vigilancia metadiscursiva de la discusión racional}

En algunos tramos de disputas públicas, la metadiscursividad aparece utilizada para vigilar evaluativamente el desarrollo de la discusión en términos normativos de la interacción racional. Las representaciones de esas normas compartidas se hacen explícitas bajo formas de la reclamación realizada por los contendientes entre sí cuando alertan algún tipo de trasgresión u omisión de esas regulaciones de la interacción verbal. En esta medida, las normas compartidas e implícitas son involucradas en la dinámica de los ataques y las defensas en nombre de la preservación de la racionalidad del debate, la cual se presenta como garantía de la calidad de los argumentadores.

El reclamo de mantener la discusión dentro de los límites de las normas del debate desplaza tanto los contenidos de esa discusión como los argumentos y puntos de vista enfrentados. Sin embargo, apelar al llamado de esos términos es una forma de ganar ventaja en los momentos en los cuales la lucha verbal se exacerba y los argumentos son reemplazados por los ataques y las defensas como acciones de fuerza. 
Extraigo la siguiente interacción pública ${ }^{5}$ álgida entre un académico y un abogado en un programa de debates radiales para ilustrar el mecanismo metadiscursivo en su función de vigilancia de las normas del debate (ver TABLA NRO. 6).

\begin{tabular}{lll}
\hline Tiempo & Académico & Abogado \\
\hline 43 min $10 \mathrm{~s}$ & $\begin{array}{l}\text { ¡Míralo! Él solo sirve para gritar, él } \\
\text { solo sirve para gritar, él solo sirve } \\
\text { para gritar. }\end{array}$ & $\begin{array}{l}\text { ¡Vuelves a decir otra cosa de esas y tendrás } \\
\text { que verte conmigo aquí cuando salgamos! }\end{array}$ \\
\hline $43 \operatorname{min~} 15 \mathrm{~s}$ & $\begin{array}{l}\text { mira, mira... } \\
\text { ¿Como hombre! ¡Farsante! ¡No te acepto } \\
\text { eso! }\end{array}$ \\
\hline $43 \min 16 \mathrm{~s}$ & $\begin{array}{l}\text { No he dicho-no he dicho-no he dicho } \\
\text { una sola palabra grosera, señor } \\
\text { abogado. }\end{array}$ & $\begin{array}{l}\text { ¡Miserable! ¡Miserable! ¡Usted es un } \\
\text { miserable! ¡Yo no dije eso! ¡Yo no dije } \\
\text { eso, farsante! }\end{array}$ \\
\hline $43 \min 22 \mathrm{~s}$ & $\begin{array}{l}\text { Él me ha dicho imbécil, minimí. } \\
\text { farsante. Y mire cómo grita. }\end{array}$ & ¡Es que lo eres! ¡Lo eres! \\
\hline $43 \min 24 \mathrm{~s}$ & & $\begin{array}{l}\text { ¡Eunuco mental: eso es lo que eres tú! } \\
\text { ¡Homúnculo! }\end{array}$ \\
\hline
\end{tabular}

TABLA NRo. 6. Mecanismo metadiscursivo en la interacción pública de un académico y un abogado. Elaboración propia.

Este es un tramo de la interacción especialmente tenso, dominado por el solapamiento de voces y las exclamaciones estridentes del abogado. A nivel suprasegmental, sin embargo, el volumen de la voz del académico es mucho más bajo que el de su contradictor, lo cual permite la transcripción precisa de ambas voces simultáneas y muestra las diferencias en ambas tácticas de lucha: el abogado intenta intimidar, mientras que el académico trata de invalidarlo acusándolo frente al moderador del debate y frente a la audiencia mediática.

Contra la vehemencia del abogado, el académico reorienta la discusión hacia la incapacidad que demuestra su contrincante al debatir en vez de gritar. Con ello, este último ha logrado anular el papel argumentativo del opositor, utiliza los insultos que recibe como prueba de esa incapacidad y, por lo tanto, gana la ventaja. A los 43 min 16 s reclama esa breve victoria mostrándose a sí mismo

5 Los actores, un analista político y un reconocido abogado, mediados por la periodista que condujo el programa, discutieron desde orillas opuestas sobre la posesión de líderes exguerrilleros de las Fuerzas Armadas Revolucionarias de Colombia (FARC) como congresistas de la República, en cumplimiento del Acuerdo de Paz, el cual se implementa actualmente en Colombia. 
como aquel capaz de discutir sin insultar, es decir, como quien ha seguido las normas de la discusión en contraste con la voz que vitupera, vociferante, frente a su aparente serenidad. El juego intimidatorio del abogado introduce el logos en una exhibición verbal de la superioridad de la fuerza a través del grito, el insulto y el desafío, contrasta con el juego metadiscursivo del académico para quien la lucha se convierte en reclamo de la normatividad del logos.

En general, se puede pensar que quien asume el papel de vigilante metadiscursivo es el contendiente más sosegado en medio de discusiones acaloradas o de interacciones hostiles; sin embargo, esto no implica que aquel a quien se le reclama respetar las normas de la discusión esté siempre en un momento de pasiones desbordadas. Extraigo ${ }^{6}$ el siguiente tramo de una discusión pública para mostrar que las disputas también aparecen fuertemente autorreguladas a través de una agresividad pasiva compartida. Conservar la calma parece ser un requisito de la discusión racional y, en ese sentido, cualquier táctica que sirva para poner en duda esa racionalidad de los argumentadores puede darle ventaja al combatiente verbal quien la utilice (ver TABLA NRO. 7).

\begin{tabular}{lll}
\hline Tiempo & Parlamentario uno & Parlamentario dos \\
\hline $7 \mathrm{~min} 51 \mathrm{~s}$ & $\begin{array}{l}\text { para ponernos de acuerdo sobre la base de } \\
\text { discus- discutir un tema | porque si uno } \\
\text { discute sobre algo y no sabe sobre qué está } \\
\text { discutiendo } \mid \text { usted hace parte de la gente } \\
\text { que cree que no hay que respetar }\end{array}$ \\
\hline $7 \mathrm{~min} 59 \mathrm{~s}$ & los acuerdos $\mid$ que hay que hacerlos & no:: yo no he dicho eso \\
\hline $8 \mathrm{~min} 00 \mathrm{~s}$ & $\begin{array}{l}\text { trizas/ pues eso es lo que le he escuchado } \\
\text { aquí }\end{array}$ & \\
\hline $8 \mathrm{~min} 04 \mathrm{~s}$ & & entonces no me ha escuchado bie::n \\
\hline $8 \mathrm{~min} 05 \mathrm{~s}$ & $\begin{array}{l}\text { pues entonces explíquese bien/ } / \text { porque } \\
\text { usted/ } \mid \text { realmente da brincos }|\mathrm{y}|\end{array}$ & no no doy ningún brinco_es que \\
& & uste:d no- \\
\hline $8 \mathrm{~min} 09 \mathrm{~s}$ & su discurso es un poco esquizofrénico & bueno (0.2) ese calificativo para mí \\
\hline $8 \mathrm{~min} 11 \mathrm{~s}$ & & es una ofensa \\
\hline $8 \mathrm{~min} 14 \mathrm{~s}$ & es decir $\mid$ esquizofrénico es & esquizofrénico es cuando \\
\hline $8 \mathrm{~min} 15 \mathrm{~s}$ & cuando uno tiene dos discursos & $\begin{array}{l}\text { uno vive en una realidad paralela } \\
\text { como en la que viven ustedes. }\end{array}$ \\
\hline $8 \mathrm{~min} 16 \mathrm{~s}$ & &
\end{tabular}

TABLA NRO. 7. Discusión pública con disputas autorreguladas a través de la agresividad pasiva compartida. Elaboración propia.

6 La grabación completa se extiende durante $48 \min 34$ s y fue analizada en Olave (2019). 
El parlamentario uno utiliza su turno de habla para dejar claras las normas de base de la discusión, principalmente, el acuerdo sobre el objeto de discordia. La formulación incompleta del condicional ( $7 \mathrm{~min} 51 \mathrm{~s}$ ), presupone que se trata de una regla básica sobre la cual no habría diferencias, pero ese condicional encubre una paráfrasis acerca de lo dicho por el parlamentario dos. Esa paráfrasis es juzgada por este último como una mala comprensión (8 min $04 \mathrm{~s}$ ), contrapunteo que impacienta al primer parlamentario y lo lleva al reclamo metadiscursivo directo en 8 min $05 \mathrm{~s}$, acompañado de un ataque frontal a la racionalidad del oponente.

El rechazo de la ofensa, con el incómodo silencio de dos segundos en $8 \mathrm{~min} 11 \mathrm{~s}$, es el espacio de oportunidad del atacado para usar también la metadiscursividad en su favor. La disputa por el tema en cuestión se ha convertido en una lucha por las definiciones de lo dicho y, específicamente, por hacer hincapié sobre el primer parlamentario que ha transgredido las normas del debate al insultar a su contradictor. Los solapamientos de voces en $8 \mathrm{~min} 14 \mathrm{~s}$ y en $8 \mathrm{~min} 15 \mathrm{~s}$ son las principales acciones de fuerza en torno a esa disputa por las definiciones. A pesar de la ruptura de las reglas del diálogo, aquel solapamiento no se muestra exactamente como un «diálogo de sordos», pues los parlamentarios retoman la palabra del contradictor para reorientarla, al mismo tiempo que continúan desarrollando sus propios alegatos. Como se ve en 8 min $16 \mathrm{~s}$, el reclamo no está exento del ataque personal, pero la función de ser el defensor de una discusión con altura ya le ha sido arrebatada al primer parlamentario.

Capitalizar la racionalidad del debate en medio de la lucha no es un modo de desactivar el combate, sino una forma de desplazar el tema en disputa y concentrarse, por medio de su vigilancia metadiscursiva, en la autopresentación de cada uno como el mejor argumentador. 


\subsubsection{La función reactiva del metadiscurso}

A través del metadiscurso, un contendiente puede repeler el ataque de su contradictor al criticar el uso inadecuado dado por este último. Se trata de un mecanismo de defensa que también puede servir para pasar al ataque en un momento tenso de la interacción, particularmente cuando se juega la posición de cada uno de ellos en el espacio político de fondo. En el siguiente extracto $^{7}$ de una entrevista radial, apelar a la metadiscursividad sirvió para que el entrevistado, un candidato a la Presidencia de la República en plena campaña electoral, rechace un intento mitigado de desacreditación de su candidatura (ver TABLA NRO. $8)$.

\begin{tabular}{|c|c|c|}
\hline Tiempo & Periodista & Candidato \\
\hline $29 \min 19 \mathrm{~s}$ & $\begin{array}{l}\text { Por qué no hace esto en vez de invitar } \\
\text { a un levantamiento popular }\end{array}$ & \\
\hline $29 \min 23 \mathrm{~s}$ & $\begin{array}{l}\text { usted está es- usted está invitando a } \\
\text { un levan- }\end{array}$ & es que- $\|$ vea $\mathrm{xxx}$ | yo le pido \\
\hline $29 \min 25 \mathrm{~s}$ & & $\begin{array}{l}\text { le pido a usted que:: eeh:: tenga respeto } \\
\text { conmigo } \| \text { ¿sí? Porque usted me pone } \\
\text { frases }\end{array}$ \\
\hline $29 \min 32 \mathrm{~s}$ & $\begin{array}{l}\text { no no no le esto- le estoy diciendo } \\
\text { que xxx le dijo eso par- para que no } \\
\text { pase por alto eso } \| \text { iusted está } \\
\text { invitando a un levantamiento } \\
\text { popular? }\end{array}$ & suyas | en mi boca $\|$ \\
\hline $29 \min 40 \mathrm{~s}$ & & $\begin{array}{l}\text { vuelvo a decirlo xxx | ahora me lo pone } \\
\text { con signo de interrogación | le admito que } \\
\text { al menos || le puso un signo de } \\
\text { interrogación ahora ||| pero al principio no } \\
\text { le puso signo de interrogación } \| \text { entonces } \\
\text { estaba usted afirmando que yo dije } \\
\text { levantamiento popular } \| \text { yo estoy aspirando } \\
\text { a llegar a la presidencia de la república }\end{array}$ \\
\hline $29 \min 59 \mathrm{~s}$ & usted oye solo lo que quiere escuchar & por medio de- por medio del voto popular \\
\hline
\end{tabular}

TABLA NRO. 8. Metadiscursividad para rechazar una desacreditación. Elaboración propia.

En medio de una entrevista radial, al candidato presidencial se le acusa veladamente de incitar a un levantamiento popular si los resultados de las elecciones le son adversos. Frente a la

7 Entrevista radial con una duración total de 2 h 19 min. El video de la entrevista fue retransmitido en redes sociales y en la página web de la cadena radial. 
reacción metadiscursiva inmediata del candidato (29 min $23 \mathrm{~s}$ ), el periodista reformula su interrogación hacia él (29 min $19 \mathrm{~s})$ en forma de interrogación directa (29 min $32 \mathrm{~s}$ ). Este cambio de modalidad es muy importante porque sobre ella recae el juicio de adecuación o inadecuación de la conducta periodística, la cual finalmente será el objeto de la crítica por parte del candidato. Así, este último reprueba que el periodista sea impreciso al referir las palabras del aspirante, pues esa tergiversación lo convertiría en un promotor de la violencia. En $29 \mathrm{~min} 40 \mathrm{~s}$ el candidato hace explícita su molestia y utiliza el juego del cambio de modalidad para contraatacar al periodista. Es un momento de fuerzas opuestas que conduce al solapamiento de voces en el min 29 con $59 \mathrm{~s}$, donde la disputa se profundiza a través del juicio personal negativo.

La corrección de las atribuciones revierte la responsabilidad sobre lo dicho y desmarca la voz referida de la voz propia. La orientación de las preguntas es rechazada por el candidato, acusándolas de implicar deducciones particulares que no serían fieles a sus declaraciones. El ejemplo muestra una corrección atributiva del siguiente tipo «lo que usted dijo que yo dije, lo dijo usted, no yo».

En ese caso, la movida de defensa no se dirige hacia el periodista como individuo, sino como representante de su gremio. Según el candidato, el periodismo «traduce de otra manera» sus palabras, por lo cual él se desmarca de esa responsabilidad enunciativa. La toma de distancia es un efecto de la modalización autonímica (Authier-Revuz, 1995), en la cual, la no coincidencia con el interlocutor se marca explícitamente en la corrección de la atribución del enunciado. Vemos entonces que el desdoblamiento del sujeto discursivo, en este tipo de interacciones, funciona como distanciamiento con respecto a la posición del interlocutor. En este sentido, la reacción metadiscursiva es también una reacción ideológica, o más específicamente, una reacción contra- 
ideológica a través de la cual los contendientes rechazan el sistema de representaciones compartidas al que se ven asociados en el intercambio verbal.

Enlosejemplos ofrecidos, aparecen huellas dela representación más o menos compartida del ideal del debate razonado en la esfera pública. A nivel político, ese ideal compartido se sostiene sobre la comprensión de la acción social como acción comunicativa racional, la cual admite ser sometida a juicio y que, por medio del lenguaje, posibilita confrontar puntos de vista divergentes y llegar a consensos a partir del intercambio de argumentos válidos sometidos, a su vez, a condiciones normativas de validez, aceptadas por los participantes en desacuerdo (Habermas, 1989). Si bien, para Habermas también se trata de una dinámica de fuerzas, estas no serían erísticas sino orientadas normativamente, según la definición ofrecida de acción comunicativa como una

fuerza que obliga a considerar también a los actores como hablantes $\mathrm{u}$ oyentes que se refieren a algo en el mundo objetivo, en el mundo social y en el mundo subjetivo, y se entablan recíprocamente a este respecto pretensiones de validez que pueden ser aceptadas o ponerse en tela de juicio. Los actores no se refieren sin más intentione recta a algo en el mundo objetivo, en el mundo social o en el mundo subjetivo, sino que relativizan sus emisiones sobre algo en el mundo teniendo presente la posibilidad de que la validez de ellas pueda ser puesta en cuestión por otros actores (Habermas, 1989, p. 493).

En cambio, en el tipo de interacciones mostradas, los actores no están dispuestos a que otros pongan en cuestión la validez de sus opiniones; pero como la discusión racional así se los exige, asumen el papel de vigilantes epistémicos del debate para controlar las contradicciones y neutralizar los ataques del contendor. La metadiscursividad es la principal herramienta para cumplir ese papel y obtener posibles ventajas en la lucha verbal. La racionalización del debate público se sostiene sobre la idealización del intercambio argumentativo y, por tanto, constituye más un 
proyecto o una meta que una vía de comprensión profunda de la realidad de esas interacciones.

\subsection{Conclusiones}

Existen modos de acción y reacción verbales que aparecen en tramos específicos de las interacciones públicas y escalan la tensión en esos momentos. Esto transforma la conversación o el debate en combate, ya no cuerpo a cuerpo, sino «palabra a palabra». Algunos de esos conflictos discursivos presentan desplazamientos de los temas en contienda hacia la materialidad verbal involucrada en la disputa misma ( $a d$ rem a ad logos). En este sentido, los contendientes movilizan la habilidad para utilizar a su favor la dimensión metadiscursiva hacia la lógica de la defensa y el ataque verbal.

En cuanto al primer punto, el análisis de los modos de contraataque y reacción verbal permite establecer demarcaciones diferenciales en el tratamiento de la disputa en contraste con el análisis de conversaciones. Si bien las interrupciones y solapamientos proporcionan evidencias de las reglas de toma de turno y de cómo los interlocutores siguen o transgreden en las interacciones orales (Schegloff, 2000), tanto en la tradición del Análisis de la conversación como en sus desarrollos actuales, el interés en los solapamientos estriba en las formas en las cuales los interlocutores los utilizan para negociar los turnos y vehiculizar -o reparar-, el flujo del diálogo (Clift, 2016; Hayashi, 2013; Liddicoat, 2007), es decir, se les enmarca en una orientación cooperativa de la conversación. En el análisis propuesto, los solapamientos ayudan a entender precisamente lo contrario: las formas no cooperativas del intercambio, que convierten la conversación en disputa, en algunos tramos de la interacción.

Por su parte, los turnos contrapunteados muestran la lucha por tomar el turno de habla, acapararlo e, inclusive, arrebatarlo al interlocutor. Este tipo de acciones de fuerza contrasta con la 
noción de «asignación de turno» (Turn Allocation), un sistema organizado de la interacción dialogal cuyo presupuesto de base es una «motivación intrínseca para escuchar todos los enunciados en la conversación, independientemente de otras motivaciones, como el interés en el tema y la cortesía» (Sacks et al., 1974, p. 727).

El desplazamiento ad rem a ad logos se muestra como una forma de crítica, persuasión y refutación, con una complejidad sobre la cual vale la pena seguir indagando. En efecto, los usos metadiscursivos analizados en clave de la lucha entre el candidato y los periodistas ponen en cuestión la verdad de las palabras (de unos y otros), aspiran a orientar la opinión pública y rechazan opiniones para imponer otras que las contradicen. La reflexión filosófica en esta área sugiere desandar la trayectoria predominante del logos y de la dialéctica como herramienta política del consenso, y revisar otras rutas alternativas, en las cuales la palabra y el diálogo sirven a fines no cooperativos distintos. La erística es una perspectiva en la que esas reflexiones son centrales y estimulan los análisis de los discursos públicos.

Además de lo anterior, traté de ilustrar con ejemplos que el metadiscurso puede funcionar efectivamente como «contradiscurso» en términos de «contra-identificación» (Pêcheux, 2016/1975), de manera que, parece viable extender la reflexión sobre lo metadiscursivo hacia el campo de las disputas y de su dimensión ideológica. Esa reflexión es necesaria y ha sido poco transitada en los estudios sobre metadiscursividad, pues se ha concentrado tradicionalmente en la retórica de la escritura académica (Hyland, 2005), y en los fenómenos enunciativos de heterogeneidad mostrada y autonimia (Authier-Revuz, 1984; 1995).

Desde este punto de vista, la metadiscursividad participa en las disputas por el sentido e incide en el escalamiento de las interacciones hostiles. También permite comprender por qué en las disputas públicas más tensas y menos ejemplares (en términos 
de la acción comunicativa habermasiana), los debatientes reclaman el respeto por las reglas de la discusión y llegan a exigir «debates con mayor altura» en la esfera pública.

En esta perspectiva analítica, no interesa evaluar la razonabilidad de los enunciados ni su contenido lógico en términos de validez de los argumentos. El análisis evaluativo implicaría identificar los «mejores argumentos»y, por extensión, invalidar a los argumentadores que transgreden las reglas de la discusión racional - estos objetivos no forman parte de la perspectiva propuesta-. En cambio, propuse concentrar el análisis en el desarrollo de la lucha verbal para comprender sus mecanismos metadiscursivos concretos, en luchas específicas y sus implicaciones para las discusiones políticas.

Mostré que analizar discursivamente contiendas verbales resulta productivo para calibrar las acciones de fuerza desplegadas en el ámbito público. Omitir a propósito la evaluación de los argumentos sirve para concentrarse en la reconstrucción de los mecanismos erísticos de orden metadiscursivo que atraviesan la interacción hostil y permiten profundizar la comprensión de las disputas verbales. Sin embargo, dejé de lado casi por completo un aspecto fundamental: los elementos suprasegmentales y los mimo-posturo-gestuales, los cuales tienen protagonismo en el desarrollo de las discordias políticas y requerirían un análisis más detenido.

\subsection{Referencias}

Aristóteles (1995). Sobre las refutaciones sofísticas. En Tratados de lógica (pp. 237-292). Gredos.

Arnoux, E. (2019). El Análisis del discurso como campo académico y práctica interpretativa. En Ó. I. Londoño y G. Olave, Métodos de análisis del discurso. Perspectivas 
argentinas (pp. 19-40). Ediciones de la U.

Authier-Revuz, J. (1984). Hétérogénéité(s) énonciative(s). Langages, 19(73), 98-111. . (1995). Palavras incertas. as nao-coincidências do dizer (E. Puccinelli Orlandi, Trad.). Unicamp.

BALly, C. (1932). Linguistique générale et linguistique française. Francke.

Blazevic, N. \& Selivanov, F. (1999). Ėristika: kurs lekcij. Tûmenskij ûridiceskij Institut.

BluRadio (2018, 23 de mayo). Gustavo Petro habló en Mañanas BLU sobre su cierre de campaña y aspiraciones presidenciales. Entrevista [video]. YouTube. https://www.youtube.com/ watch?v=Ch_BpEf-rpg

Budzyńska, A. (2013). Eristic and Dispute. Applications and Interpretations. Forum Artis Rhetoricae, 2, 7-20.

Clift, R. (2016). Conversation Analysis. Cambridge University Press.

Etkin, S. (2016). La modalidad. Enciclopedia semiológica. Eudeba.

Fairclough, N. (1993). Discourse and Social Change. Polity Press.

Gardella, M. (2017). Erística. Génesis y desarrollo de un fenómeno difuso [Tesis de doctorado, Universidad de Buenos Aires].

Habermas, J. (1989). Teoría de la acción comunicativa. Taurus.

Hayashi, M. (2013). Turn Allocation and Turn Sharin. En J. Sidnell \& T. Stivers (Eds.), The Handbook of Conversation Analysis (pp. 167-190). Wiley-Blackwell. 
Hordecki, B. (2018). The Strategic Dimension of the Eristic Dialectic in the Context of the General Theory of Confrontational Acts and Situations. Przeglad Strategiczny, 11, 19-26. DOI: 10.14746/ps.2018.1.2.

Hyland, K. (2005). Metadiscourse. Exploring Interaction in Writing. Continuum.

Jenks, C. (2011). Transcribing Talk and Interaction: Issues in the Representation of Communication Data. John Benjamins Publishing.

KotARbiŃski, T. (1963). Léristic, cas particulier de la théorie de la lutte. Logique et Analyse, 6, 19-29.

Liddicoat, A. (2007). An Introduction to Conversation Analysis. Continuum.

Maingueneau, D. (2009). Análisis de textos de comunicación. Ediciones Nueva Visión.

Mársico, C. (2014). Encrucijadas dialécticas: elenchos, dispositivos antierísticos y filosofía megárica en las refutaciones sofísticas. Archai, 14(14), 137-148. Doi: http:// dx.doi.org/10.14195/1984-249X $14 \quad 10$.

Olave Arias, G. (2018). Una perspectiva erística para el estudio de disputas verbales públicas. En M. Cisneros-Estupiñán (Comp.), Miradas y decires: estudios de la Maestría en Lingüística (pp. 125-148). Editorial Universidad Tecnológica de Pereira.

. (2019). Análisis del discurso en disputas públicas. Retorno a la Erística. Ediciones UIS. 
PÊcheux, M. (2016). Las verdades evidentes. Lingüística, semántica, filosofía (M. Glozman. Trad.). Centro Cultural de la Cooperación. (Trabajo original publicado en 1975).

Platón (1987). Eutidemo. En Diálogos II (pp. 191-272). Gredos.

RAmírez VidAL, G. (2016). La invención de los sofistas. Universidad Nacional Autónoma de México.

Sacks, H.; Schegloff, E. \& Jefferson, G. (1974). A Simplest Systematics for the Organization of Turn-Taking for Conversation. Language, 50(4), 696-735.

Schegloff, E. (2000). Overlapping Talk and the Organization of Turn-Taking for Conversation. Language in Society, 29, 1-63.

Schopenhauer, A. (2011). Dialéctica erística. O el arte de tener razón. Editorial Trotta. (Trabajo original publicado en 1864).

VAnde, W. J. (1985). Some Exploratory Discourse on Metadiscourse. College Composition and Communication, 36(1), 82-93.

Van Eemeren, F. (2010). Strategic Maneuvering in Argumentative Discourse. Extending the Pragma-Dialectical Theory of Argumentation. John Benjamins Publisching.

WRadio (2017, 22 de junio). Cuadrilátero de la W: María Fernanda Cabal e Iván Cepeda. Debate [video]. YouTube. https://www.youtube.com/watch?v=zfN6hnIzyKY.

. (2018, 19 de julio). Ariel Ávila y Abelardo de la Espriella con \#VickyDavilaEnLaW. Debate [video]. YouTube. https:// www.youtube.com/watch?v=F-f2nKFN8yo 
Walton, D. (1999). One-sided Argumentos. A Dialectical Analysis of Bias. State University of New York Press.

_. (2003). Relevance in Argumentation. Lawrence Erlbaum Associates. 



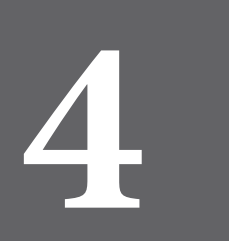

CAPÍTULO

CUATRO 



\title{
Aproximación a las estrategias discursivas de Claudia López como candidata a la Alcaldía de Bogotá: la nominación, la negación y los puntos de vista ${ }^{1}$
}

\author{
Juan Camilo Cortes Patiño ${ }^{2}$ \\ Andrés Felipe Molina Montes ${ }^{3}$
}

\subsection{Introducción}

El presente trabajo representa un análisis discursivo exploratorio, surgido como ejercicio investigativo en el Seminario de Análisis del Discurso I. Este tiene el propósito de hacer un acercamiento al análisis del discurso en la esfera política colombiana. Para lo cual, se planteó como objetivo analizar las

1 Este escrito es resultado del trabajo final del Seminario de Análisis del Discurso I, orientado por el doctor Luis Fernando Carrillo Holguín, y la magíster y doctoranda Sandra Patricia Díaz Arrieta en el tercer semestre de la VI Cohorte de la Maestría en Lingüística de la Universidad Tecnológica de Pereira.

2 Estudiante de la VI Cohorte de la Maestría en Lingüística, Universidad Tecnológica de Pereira. Licenciado en Lenguas Modernas, Universidad del Quindío. Correo: juancamilo.cortes@utp. edu.co.

3 Estudiante de la VI Cohorte de la Maestría en Lingüística, Universidad Tecnológica de Pereira. Licenciado en Lenguas Modernas, Universidad del Quindío. Correo: afmolina@uniquindio.edu. co. 
estrategias discursivas usadas por Claudia López (exsenadora y alcaldesa de Bogotá), en uno de sus discursos para legitimar propuestas políticas en materia de movilidad para optar por dicha alcaldía.

Inicialmente, se determinó, desde la perspectiva de Pardo Abril (2013) y a través del análisis de las nominaciones, cuáles son los roles asignados a los diferentes actores sociales convocados en la alocución. Seguidamente, desde la perspectiva polifónica del discurso de Ducrot (1987), se describió cómo Claudia López se relaciona con los puntos de vista presentes en su discurso. Para ello, se analizó la entrevista realizada el día miércoles 3 de abril del 2019 por la periodista María Jimena Duzán (2019) de la revista Semana a la precandidata por el partido político Alianza Verde, Claudia López.

Desde el análisis del discurso, se han estudiado diferentes fenómenos discursivos, presentes en los enunciados emitidos por sujetos políticos. A nivel internacional, se han estudiado casos particulares como el del actual presidente de Ecuador, Lenin Moreno (Minervini, 2017), al describir y examinar el discurso de investidura desde su posesión. En otros trabajos, se han observado las emociones en el discurso político, tal y como lo identifica Bermúdez (2014), sobre el expresidente argentino Néstor Kirchner. También en Argentina, Caleri (2005) analizó el de Elisa Carrió, candidata a la presidencia de ese país - para el periodo 2002-2003 - , con el fin de validar su liderazgo y estatus. Por otra parte, Maizels (2013), estudió la negación en los discursos de la campaña política de Cristina Fernández de Kirchner para comprender la incidencia de esta en la construcción del ethos. Además, desde Chile, se ha analizado el impacto del movimiento zapatista en México, al usar como técnica metodológica el denominado Análisis Crítico del Discurso (Meneses et al., 2012). Por su parte, Romero (2001) planteó una caracterización general del discurso político de Hugo Chávez. 
En el ámbito nacional colombiano, existen múltiples trabajos los cuales han estudiado el discurso del expresidente Âlvaro Uribe Vélez. Uno de ellos examina la representación mediática hecha por el diario El Tiempo sobre las campañas de este candidato y de Carlos Gaviria Díaz en la elección presidencial del año 2006 en Colombia (García López y Quintero Vélez, 2013). De manera similar, Arrieta Arvilla (2013) investigó la construcción de los sujetos en el discurso de Álvaro Uribe Vélez. En otro estudio, Delgado Marulanda (2013) revisólos rasgos y momentos polémicos de aquel discurso el 25 de julio de 2010, en el Fuerte Militar de La Macarena (Meta-Colombia). Además, se observó la contribución de los argumentos ad hominem, a través del «terrorismo» (signo ideológico) para la configuración del enemigo político. Además de estos, el estudio de Cárdenas Támara (2013) se centra en la construcción de unidades de interpretación hermenéutica y busca identificar la experiencia de orden del expresidente. Para añadir, otros trabajos han comparado los discursos de Álvaro Uribe Vélez y Hugo Chávez con el fin de describir sus tipos de liderazgo (Fraschini, 2014) y definir sus discursos de investidura (posesión) para sus reelecciones (Álvarez y Chumaceiro, 2009).

En cuanto a otros sujetos políticos, también se han analizado las estrategias discursivas de las campañas publicitarias de Samuel Moreno y Enrique Peñalosa (García León y García León, 2014). Finalmente, Villarraga (2012) llevó a cabo un análisis del discurso de investidura del expresidente Juan Manuel Santos, en el cual se abordaron sus estrategias como enunciador con el fin de establecer una ideología llamada «Unidad Nacional», con la cual comenzó su gobierno. Ahora bien, a pesar de la existencia de trabajos que han analizado el discurso de diversos políticos colombianos, ningún estudio similar ha analizado el discurso de la exsenadora colombiana Claudia López del partido político colombiano Alianza Verde. 


\subsection{Marco teórico}

\subsubsection{La nominación}

La nominación es definida por Pardo Abril (2013) como el elemento por medio del cual lingüísticamente se identifica los objetos y los seres del mundo. Además, este mismo autor propone lo siguiente: «la nominación en el discurso sigue un conjunto de estrategias y procesos lingüísticos consecuentes con unos fenómenos socio-discursivos, socioculturales y sociopolíticos, que dan cuenta de las maneras como se representa en el discurso un fenómeno social» (p. 111). A partir de ello, se tomó como base las formas de nominación, es decir, la propia, la común y la retórica:

\begin{tabular}{|c|c|c|}
\hline Nominación común & Nominación propia & Nominación retórica \\
\hline $\begin{array}{l}\text { Cuando la nominación recoge } \\
\text { una categoría de cosas o seres en } \\
\text { el mundo [...] es decir, se hace } \\
\text { referencia a sus rasgos } \\
\text { esenciales, los cuales, en razón } \\
\text { de su asociación con un } \\
\text { conocimiento general, son } \\
\text { aplicados a un número } \\
\text { indefinido de objetos o de seres. }\end{array}$ & $\begin{array}{l}\text { En los casos en que la } \\
\text { nominación denota seres u } \\
\text { objetos en el mundo con la } \\
\text { función cognitiva de afirmar su } \\
\text { individualidad, [...] el cual está } \\
\text { asociado a un conocimiento } \\
\text { específico y, por lo tanto, } \\
\text { construye una imagen } \\
\text { particular de lo que se nombra. }\end{array}$ & $\begin{array}{l}\text { El tipo de nominación que } \\
\text { se elabora a partir de una } \\
\text { figura retórica y en la que } \\
\text { coexisten dominios } \\
\text { conceptuales distintos en la } \\
\text { consolidación de su } \\
\text { significación e } \\
\text { identificación. }\end{array}$ \\
\hline
\end{tabular}

TABla NRo. 9. Tipos de nominación. Adaptada de Pardo Abril (2013, p. 110-111).

Además, Pardo Abril (2013) considera otras subclasificaciones de nominación más específicas, las cuales se desprenden de su uso y función gramatical: nominación funcional, valorativa, esencial (clase, relacional y físico), con titulación (de afiliación y honorífica), formal, semiformal, informal, de ocultamiento (seudónimo-apodo), metonímica, y analógica. Así, este trabajo considera las subclasificaciones funcional, valorativa, esencial, de afiliación, honorífica y semiformal. 


\subsection{Polifonía del discurso de Ducrot (1987): los puntos de vista y la negación}

\subsubsection{Los puntos de vista}

La teoría polifónica de la enunciación de Ducrot (1987) plantea tres tesis o hechos fundamentales. La primera tiene que ver con el cuestionamiento a uno de los postulados de la lingüística moderna: la unicidad del sujeto hablante. Es decir, la hipótesis consiste en que cada enunciado posee un solo autor. A este respecto, este autor, propone una distinción entre el sujeto empírico y el locutor. Inicialmente, el sujeto empírico o sujeto hablante del enunciado es «el autor efectivo, el ser de la realidad social que produce el enunciado, personaje que, de hecho, es difícil, e incluso a veces imposible, determinar» (Puig, 2013, p. 129). En cuanto al locutor, en palabras de Ducrot (1984), este es «un ser que, en el sentido mismo del enunciado, se presenta como su responsable [...] A él remite el pronombre yo y las otras marcas de la primera persona» (p. 193). Ducrot (como se citó en Puig, 2013) describe que el locutor es un concepto netamente lingüístico y consiste en el supuesto responsable del enunciado; aquel es el ente a quien le corresponde la responsabilidad de la enunciación y puede presentarse como un personaje ficticio. En su teoría, este autor francés también distingue al enunciador, quien incluye los distintos puntos de vista, que se manifiestan de manera explícita o implícita en un enunciado (la voz propia, la voz ajena de un interlocutor, los refranes, las voces anónimas) sin ser responsable del mismo.

La segunda tesis de dicho escritor es que el sentido de un enunciado consiste en una descripción de su enunciación. Es importante distinguir, entonces, entre esta última y su descripción. Para el primer caso, Ducrot (1987) concibe la enunciación como «... un acontecimiento histórico [en el cual] se da existencia a algo que no existía antes de que se hablase y que ya no existirá después» (p. 179). En tal definición, se puede inferir que ninguna 
enunciación será semejante a alguna otra; esto se debe a que las condiciones de producción de los enunciados siempre cambian. Para el segundo caso, la descripción de la enunciación implica la identificación de uno o varios sujetos.

La tercera tesis consiste en afirmar que ciertas proposiciones presentan una pluralidad de puntos de vista. Como lo menciona Puig (2013), un aspecto original de la teoría ducroniana es la de introducir «intermediarios» entre el locutor y los puntos de vista que exponen el sentido del enunciado; a saber, los enunciadores. Sin embargo, «en este caso no se trata de personajes propiamente dichos, sino de "voces" que exhiben el enunciado» (Puig, 2013, p. 130). A cada punto de vista le corresponde un emisor el cual se identifica como el origen de dicho punto de vista. Así lo expresa Ducrot (2001): «por definición, el enunciador se adhiere [...] al punto de vista que se le atribuye y no puede distanciarse de él» (p. 20). De tal manera, según Ducrot (1987), en la teoría de la polifonía del enunciado pueden existir una multitud de perspectivas y el locutor puede tomar diferentes actitudes con relación a todas estas.

En cuanto al sentido del enunciado, un elemento de este es la indicación de la posición del locutor. Por lo tanto, el locutor es presentado como el responsable del enunciado $\mathrm{y}$, consecuentemente, es quien designa a los enunciadores $\mathrm{y}$ posiciona los puntos de vista. De este modo, la posición del locutor con su perspectiva se ve mediada por las actitudes que se mantienen con los enunciadores; por ende, dicha posición puede ser de identificación, de aprobación, de admiración, de oposición, entre otras (Puig, 2013).

\subsubsection{La negación}

Por otra parte, la negación en la teoría polifónica de Ducrot constituye uno de los fenómenos que, según Puig (2013), ilustran la pertinencia de una concepción polifónica de la lengua. En la 
mayoría de los enunciados negativos, la negación incluye otra voz que afirma. Para Ducrot (1987): «la mayoría de los enunciados negativos [...] hacen aparecer su enunciado como el choque de dos visiones antagónicas, una positiva imputada a un enunciado $\mathrm{E}$ 1, y la otra, que es una negativa de la primera, imputada a $\mathrm{E} 2 »(\mathrm{p}$. 219). Al respecto Ducrot (1984), distingue tres tipos de negación:

\subsubsection{Negación metalingüística}

En palabras de García (2012), Ducrot caracteriza la negación metalingüística como un elemento que contradice los términos mismos de una palabra efectiva la cual se pretende refutar, por ello siempre opone dos locutores diferentes. Para el autor francés, es justamente en el marco de la refutación de un locutor adverso que la negación a) puede anular las presuposiciones del enunciado positivo previo; b) puede tener, en lugar del efecto habitualmente descendente, un valor ascendente.

\subsubsection{Negación polémica}

Como lo explica García (2012), la negación polémica «siempre supone la presencia de dos puntos de vista antagónicos e internos al propio discurso» (p. 59). Por tanto, esta negación solo tiene un efecto descendente, es decir, del tipo «menos que».

\subsubsection{Negación descriptiva}

Es analizada como un derivado delocutivo de la polémica. Según Ducrot (1984) este tipo de negación permite «representar un estado de cosas sin que su autor presente su palabra como oponiéndose a un discurso adverso» (pp. 216-217). Es decir, en este tipo de negación no hay ninguna inscripción, ni ningún punto de vista; solo se da cuenta de algo que puede ser verificable. 


\subsection{Metodología}

El corpus para este análisis discursivo estuvo conformado por la transcripción de una entrevista realizada por la periodista María Jimena Duzán (2019) —de la revista Semana-, a la precandidata a la Alcaldía de Bogotá para el periodo 2020-2023, por el partido político Alianza Verde, a saber: Claudia Nayibe López Hernández. Esta entrevista tuvo lugar el día miércoles 03 de abril del año 2019 en el marco de la consulta interpartidista de dicho partido político, de cara a las elecciones en el mes de octubre del año 2019. La entrevista completa tiene una duración de 26 min y $12 \mathrm{~s}$ y se encuentra disponible en el canal de divulgación YouTube y de la revista Semana. Ahora bien, para el propósito de este trabajo se transcribió (Molina y Cortés, s.f.) y se analizó solamente la sesión de la entrevista comprendida entre los 4 min con 50 s y 16 min con 18 s. La razón para esta elección se debió a que en esta sección de la entrevista se trata un tema álgido: la movilidad en Bogotá. Este tema ha sido polémico y es siempre base de discusión y análisis para cualquier candidato a dicho cargo público. La sesión escogida parte de la pregunta hecha por la concejal Lucia Bastidas a la precandidata Claudia López con relación a su posición en cuanto a la construcción de un tramo de Transmilenio por la carrera Séptima y a la construcción de la segunda línea del Metro de Bogotá. El análisis se centró en la respuesta ofrecida por Claudia López. Posteriormente, se delimitaron las marcas discursivas y se definieron las categorías de análisis la nominación (Pardo, 2013), la negación y los puntos de vista (Ducrot, 1984; 1987; 2001).

\subsection{Resultados y análisis \\ 4.5.1. Nominación \\ 4.5.1.1. Lucía}

Los enunciados que contienen esta nominación se clasificaron en nominación propia y a nivel de subtipo funcional, esencial, de afiliación y semiformal. No se encontraron nominaciones para esta unidad léxica en los subtipos valorativa y honorífica. 
Cuando Claudia López introduce la unidad léxica en «Lucía, que es una concejal y una mujer con la que tengo diferencias, pero a la que respeto profundamente» (Molina y Cortés, s.f., p. 3) logra sentar -desde un principio-, su distancia político-ideológica con esta concejal. Más adelante, se dan otros tratamientos de la unidad léxica Lucía, los cuales se introducen en enunciados como «voy a completar Lucía» (p. 3), «vamos menos de 20.000 pasajeros hora sentido Lucia», «y resulta que en Suba y Engativá hay $45 \mathrm{mil}$ Lucía» (p. 3) y «pero como la plata no es infinita querida Lucía» (p. 7), a través de los cuales la locutora introduce la unidad léxica Lucía cada vez que presenta un argumento que apoya sus propias ideas y contradice las de la concejal, Lucia Bastidas. Por lo tanto, estos enunciados legitiman el estatus de Claudia López como una mujer sensata y crítica; a la vez, presentan una oposición y juicio al planteamiento de Bastidas sobre por qué sí debe conservarse la propuesta de Enrique Peñalosa de construir solo una primera línea del Metro de Bogotá y de realizar el Transmilenio por la Séptima.

También, el uso de la unidad léxica Lucía se da con propósitos realizativos o persuasivos en enunciados como «tú que representas los intereses de los bogotanos» (p. 4), «no hables de la segunda Lucía» (p. 4), «yo digo no señora» (p. 5), con los cuales la locutora (Claudia López) pretende que la concejal reflexione sobre su quehacer político y actúe por el bien de lo público, entendido este último como aquello conveniente a las mayorías. Estos enunciados, entonces, constituyen un tipo de exhortación político-social ejercida por la locutora hacia su interlocutora.

De manera similar, también se observan relaciones de distanciamiento con enunciados tales como «como lo está diciendo tu candidato» (p. 4), en el cual la locutora reconoce que la afiliación política de Lucia Bastidas quien, a pesar de pertenecer a la misma colectividad política a la cual pertenece Claudia López, simpatiza de manera amplia con el entonces Alcalde de Bogotá, Enrique Peñalosa, con quien, de manera contraria, esta última tiene distanciamiento. 


\subsubsection{Enrique Peñalosa}

Los enunciados que contienen esta nominación se han clasificado en nominación propia y a nivel de subtipo valorativo, esencial y de afiliación. No se encontraron nominaciones para esta unidad léxica en los otros subtipos, es decir, el funcional, honorífico y semiformal. En general, todos los tratamientos de la unidad nominal «Enrique Peñalosa» en enunciados como «por qué no al transmilenio por la séptima que propone tu alcalde Peñalosa» (p. 3) logran un efecto de distanciamiento con el actuar político de Peñalosa. Efectos similares de contraste y descalificación se materializan en enunciados tales como «Peñalosa decidió que la inversión importante es la del estrato 4, 5 y 6 de Usaquén y Chapinero» (p. 4), «2 billones de pesos que se quiere malgastar Peñalosa en la séptima» (p. 4), «Peñalosa propone medio metro para hacer muchos transmilenios» (p. 6), «ah qué bonito señor Peñalosa, para hacerle el negocio a los constructores que financiaron su campaña» (p. 6). Es decir, cada vez que se hace una entrada léxica para este, la locutora desacredita sus acciones como alcalde, al tiempo que reafirma que sus futuras acciones como la próxima alcaldesa de Bogotá serán diferentes.

Desde un punto de vista cuantitativo, los diez enunciados utilizados de manera regular para disentir con las acciones de Enrique Peñalosa contrastan con los dos enunciados en los cuales la locutora deja entrever un reconocimiento hacia el mismo sujeto. Estos son: «Peñalosa, que tiene el mérito de que consiguió la plata» (p. 3) y «Peñalosa está proponiendo otros transmilenios que sí se necesitan» (p. 6). Estos enunciados reafirman la estrategia de descalificación y de no afiliación política de López en relación con Peñalosa.

\subsubsection{María Jimena}

Los enunciados que contienen esta nominación se clasificaron en nominación propia y a nivel de subtipo esencial. 
No se encontraron nominaciones para esta unidad léxica en los otros subtipos, es decir, en el funcional, valorativo, de afiliación, honorífico y semiformal. En general, todos los tratamientos de la unidad nominal "María Jimena», en los ocho enunciados identificados, corresponden a una estrategia discursiva a través de la cual la locutora logra introducir información factual, verificable y real, la cual sirve al mismo tiempo para que esta dé sustento a las propuestas para la Alcaldía de Bogotá. La estrategia discursiva, además de usar esta nominación propia, también hace uso de

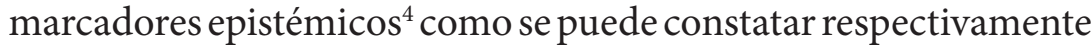
en «De manera que mi propuesta es muy concreta María Jimena, y esto no es antipeñalosismo» (p. 6) y «aquí María Jimena la gente no sabe en la localidad de San Cristóbal que hay una reserva muy bonita» (p. 7). De esta manera, la locutora usa a la periodista María Jimena Duzán como un medio para canalizar información, la cual pretende hacer llegar a quienes le escuchan.

\subsubsection{Unidades nominales que hacen referencia al tratamiento de comunidades}

La TABLA NRO. 10 muestra los resultados obtenidos para las unidades nominales por medio de las cuales la locutora hace referencia a diversos entes sociales (instituciones, elementos y personas). Estos son clave en su discurso. Los enunciados que contienen estas nominaciones se han clasificado a nivel general de nominación común, propia y retórica; y a nivel de subtipos en funcional, valorativa, esencial, y de afiliación. No se encontraron nominaciones para esta unidad léxica en los subtipos honorifica y semiformal.

4 Desde la perspectiva planteada por Fernández Sanmartín (2009), la modalidad epistémica es «la expresión lingüística del grado de compromiso que el hablante asume respecto a la factualidad de su enunciado» (p. 577). 


\begin{tabular}{|c|c|c|c|}
\hline & Nominación propia & Nominación común & $\begin{array}{l}\text { Nominación } \\
\text { Retórica }\end{array}$ \\
\hline Funcional & $\begin{array}{l}\text {-Claudia López alcaldesa } \\
\text { no hace transmilenio } \\
\text {-para hacerle el negocio a } \\
\text { los constructores que } \\
\text { financiaron su campaña }\end{array}$ & $\begin{array}{l}\text {-le estamos diciendo a los jueces } \\
\text { por favor tranquen esto } \\
\text { - ¿porque ellos si tienen lobistas, } \\
\text { tiene gremios que hablan por } \\
\text { ellos? } \\
\text {-los servidores públicos estamos } \\
\text { es para representar el interés } \\
\text { público }\end{array}$ & \\
\hline Valorativa & $\begin{array}{l}\text {-Peñalosa decidió que la } \\
\text { inversión importante es la } \\
\text { del estrato 4, } 5 \text { y } 6 \text { de } \\
\text { Usaquén y Chapinero } \\
\text {-como lo está diciendo tu } \\
\text { candidato } \\
\text {-yo digo no señora }\end{array}$ & $\begin{array}{l}\text {-es un crimen social }[\ldots] \text { con } \\
\text { familias de estratos } 1,2 \text { y } 3 \text {, } \\
\text { clase media, sectores populares } \\
\text {-y no el de los poderosos }\end{array}$ & \\
\hline Esencial & $\begin{array}{l}\text {-así como se hizo en } \\
\text { Ciudad Bolivar } \\
\text {-hagamos más bien el } \\
\text { metrocable de El Codito } \\
\text {-la primera línea del metro } \\
\text { hasta Suba y Engativá } \\
\text {-como mataron a Oscar } \\
\text { Giovanny }\end{array}$ & $\begin{array}{l}\text {-en la séptima vamos menos de } \\
20.000 \text { pasajeros } \\
\text {-45 mil pasajeros hora sentido } \\
\text {-donde trabaja y estudia la gente } \\
\text {-dejar a [...] } 2 \text { millones y medio } \\
\text { de personas por fuera }\end{array}$ & \\
\hline $\begin{array}{l}\text { De } \\
\text { Afiliación }\end{array}$ & $\begin{array}{l}\text {-cupo de endeudamiento } \\
\text { que todavía tenemos con } \\
\text { el gobierno nacional } \\
\text {-los vecinos de la séptima } \\
\text { llevan más de dos años en } \\
\text { sus propias } \\
\text { organizaciones }\end{array}$ & $\begin{array}{l}\text {-no podemos abusar del bolsillo } \\
\text { de los bogotanos y de los } \\
\text { colombianos } \\
\text {-yo vivo [...] en el parque de los } \\
\text { Hippies }\end{array}$ & \\
\hline Símil & & & $\begin{array}{l}\text {-en un transmilenio } \\
\text { como sardinas }\end{array}$ \\
\hline
\end{tabular}

TABLA NRO. 10. Ejemplos de Unidades lexicales o nominales que hacen referencia al tratamiento de comunidades. Elaboración propia.

El uso de estas nominaciones atiende a tres estrategias discursivas generales $y$, por ende, a tres propósitos sociales esenciales: 1) atribuir a ciertas personas y entidades sociales el papel de victimario y de tener la responsabilidad de ayudar a los demás; 2) reconocer a una parte de la población como víctima o como aquella población que debe ser ayudada; y 3) simpatizar con ciertos entes sociales y no atribuirles ni una función de victimario ni de víctima.

4.5.1.4.1. Grupo uno: los victimarios. Este grupo contiene trece enunciados y su estrategia discursiva consiste en usar nominaciones de diferente naturaleza (tanto propia como común) 
y de diferente subcategoría (funcional, valorativa y esencial) para hacer referencia a un grupo social de personas y entidades las cuales conciben la locutora desde el papel de victimarios y de tener la responsabilidad de ayudar a los demás. Claros ejemplos de ello son nominaciones como «los poderosos», «lobistas», «los estratos más acomodados de Usaquén y Chapinero».

Sin embargo, es necesario resaltar cómo el tratamiento de algunas nominaciones varía en el discurso de la locutora. Este es el caso tanto de la nominación transmilenio como de la nominación pasajeros. Esto se da porque en la estrategia discursiva utilizada por ella, en ocasiones, se refiere al transmilenio por la séptima como algo negativo, en el sentido que es inequitativo, ilógico, y no beneficia a las mayorías bogotanas o a los sectores populares. En cambio, cuando usa la misma nominación, pero la específica en otros sectores de la ciudad, tales como «el tramo de transmilenio sur de la avenida Ciudad de Cali» (p. 6) o «la troncal [de transmilenio] de la Caracas que se termina en Molinos» (p. 7), la connotación dada al objeto a través de la denominación ya no es la del papel del victimario sino la de justo, lógico y socialmente justificado. Esto mismo se da con la nominación pasajeros en «en la séptima vamos menos de 20.000 pasajeros» (p. 3). Por una parte, cuando la anunciadora considera a estos 20000 pasajeros de la séptima, les atribuye una función de responsabilidad. Así, de hacerse el transmilenio por la séptima, ellos serían el motivo por el cual más de dos billones de pesos se habrían invertido mal en un medio de transporte que no era necesario. Ahora bien, la estrategia cambia cuando la locutora considera la nominación pasajeros en el contexto de Suba y Engativá donde se les atribuye un papel de beneficiarios, es decir, de aquella parte de la población por quienes sí se justifica invertir una alta cantidad de dinero en materia de movilidad.

4.5.1.4.2. Grupo dos: las víctimas. Este grupo contiene veintiún enunciados a través de los cuales se observa una estrategia discursiva contraria a la del grupo uno, esto es, en vez de usar 
nominaciones para identificar victimarios o responsables, en este grupo se victimiza o se identifica a esa parte de la población bogotana la cual debe ser ayudada. Considérense los ejemplos: «los sectores populares de Lijacá, Verbenal, el Codito» (p. 5), «los 2 millones y medio de colombianos humildes, trabajadores, de clase media, de Suba y Engativá» (p. 6), «Oscar Giovanny» (pp. $5,7)$ y «la reserva van der Hammen» (pp. 5, 6). Estas veintiún nominaciones son también de distinta naturaleza (tanto propia como común), al igual que en el grupo uno. Una diferencia es que en el grupo dos hay una nominación retórica del subtipo símil, esta es «sardinas», estrategia discursiva emergente, la cual no se contempla en Pardo Abril (2013) como una subclasificación de las nominaciones. Con esta nominación la locutora victimiza a una gran parte de la población de los sectores populares de Bogotá, quienes son los que usan transporte público y, por ende, se ven expuestos al hacinamiento en un mismo articulado del mismo. En este grupo dos también se encuentran enunciados de los subtipos valorativo, esencial y de afiliación.

No obstante, es interesante anotar que ninguna de las nominaciones fue clasificada dentro del subtipo funcional. Esto pone de manifiesto que, la estrategia discursiva de la locutora no consiste en atribuir el rol social de agente, el cual tiene responsabilidad sobre las acciones político-sociales emanadas sobre la ciudad, a ninguna de las personas o entidades sociales las cuales se pueden identificar como víctimas en estas veintiún nominaciones.

Dentro de ellas prima la victimización y llama la atención el enunciado «la verdad no es una idea mía, es idea de la comunidad que vive allá» (p. 7). Ya que, por una parte, esta nominación como estrategia discursiva pretende visibilizar a una colectividad vulnerable (la que se beneficiará del metrocable San Cristóbal). Por otra parte, la misma estrategia permite construir el estatus de líder con sentido social de Claudia López, en cuanto a que, no solo escucha a las comunidades mayoritariamente vulnerables o 
de sectores populares, sino que también les da voz y voto en las decisiones político-sociales las cuales afectan a la ciudad.

4.5.1.4.3. Grupo tres: los no victimarios-no víctimas. En este tercer grupo de doce enunciados, se observa una estrategia discursiva la cual, a diferencia de los grupos uno y dos no se inscribe en ninguno de los extremos del discurso de victimario o víctima. Claros ejemplos de estas nominaciones son los jueces, los servidores públicos, la gente de Bogotá. Para ello, dicha estrategia reside en usar nominaciones de diferente naturaleza (tanto propia como común) y de diferente subcategoría (funcional, esencial y de afiliación), para hacer referencia a un grupo social de personas y entidades con los cuales la locutora simpatiza ya que resultan ser convenientes para su plan de gobierno.

También es relevante mencionar la no identificación de ninguna nominación del grupo tres dentro de los subtipos nominación valorativa. Es decir, la enunciadora nunca emitió ningún adjetivo axiológico sobre las doce nominaciones las cuales pudiese entenderse como un trato personal hacia las personas e instituciones nombradas tales como los jueces y los servidores públicos. Esta estrategia discursiva puede obedecer a dos propósitos: 1) brindar una imagen de neutralidad ante el electorado y ante la opinión pública; y 2) evitar la adulación y reiterar su carácter político, tradicionalmente caracterizado por el uso de un lenguaje directo.

La nominación «Claudia López alcaldesa no hace transmilenio» (p. 5) llama la atención ya que es la misma locutora quien la enuncia. Es decir, la locutora hace una nominación propia del tipo funcional para enfatizar en su rol como alcaldesa, en el caso de ser elegida. En cuanto a la nominación «la gente en Bogotá» (p. 6), la enunciadora hace un uso estratégico de ella para referirse no de manera genérica a un grupo poblacional, sino que al enunciar la gente identifica grupos estratégicos para su campaña: los estratos populares uno, dos y tres de la ciudad de 
Bogotá, simpatizantes y personas interesadas en la construcción del metro de Bogotá y en dar soluciones a los problemas de movilidad en esta ciudad.

\subsubsection{La negación y los puntos de vista 4.5.2.1. La negación metalingüística}

A través deeste tipo denegación, ClaudiaLópezlogravisibilizar aquellos posicionamientos de Lucia Bastidas y Enrique Peñalosa los cuales representan un punto de quiebre con sus propuestas a la Alcaldía de Bogotá. A la vez que fortalece la imagen de que sus propuestas son las más convenientes en materia de movilidad. Por ejemplo, en enunciados como «Además, todo esto energía limpia, energía renovable, porque el metro no contamina, a diferencia de transmilenio que son buses con diésel que nos están matando los pulmones» (p. 5), la autora pretende anular la presuposición de que los buses de transmilenio no contaminan y no afectan la salud de los seres humanos. También, con este enunciado logra el efecto de valor ascendente en la negación metalingüística propuesto por Ducrot (1984) con el cual la locutora establece que transmilenio no es la única opción para la movilidad en Bogotá, sino que existen otras opciones como el metro de Bogotá, el metrocable y la línea del ferrocarril. Considérese el siguiente enunciado:

María Jimena: pero hablando de transmilenio por la séptima, y eso lo dice también su contrincante, Antonio Navarro dice "a mí no me gusta eso, no me gusta ese proyecto, estoy en contra", pero ya se va a abrir licitación en abril creo que... Claudia: no se ha contratado, María Jimena, no se ha contratado, y los vecinos de la séptima llevan más de dos años en sus propias organizaciones, han interpuesto varios recursos jurídicos que están en curso... (p. $5)$.

En este, al igual que en el anterior, Claudia López anula, tal como lo propone Ducrot (1984), la presuposición del enunciado previo en el cual se afirma que el proyecto de transmilenio por 
la Séptima ya va a abrir licitación. De esta manera, este tipo de negación le permite a Claudia López legitimar sus propuestas a la Alcaldía de Bogotá a través del funcionamiento de otras voces cuyas presuposiciones son anuladas por la locutora.

\subsubsection{La negación polémica}

Este tipo de negación le permite a Claudia López establecer su rechazo explícito a diversos puntos de vista correspondientes a las políticas de movilidad establecidas por Enrique Peñalosa. Considérese los siguientes enunciados:

María Jimena: ¿cuál es tu candidato? Claudia: otro, claramente no soy yo, yo digo no señora, no vamos a dejar a la gente de estrato 1, 2 y 3 de Suba, de Lisboa, del Cortijo, de Quirigua en Engativá, de Suba a Tibabuyes, de la Gaitana, sectores populares que están absolutamente embotellados, en Suba y en Engativá, esperando 40 años. Claudia López alcaldesa no hace transmilenio por la séptima, libera 2 billones de pesos y completa la primera línea del metro (pp. 4-5).

En este epígrafe la locutora, por una parte, visibiliza las propuestas de movilidad de Enrique Peñalosa y, por otra, expresa abiertamente su rechazo a este posicionamiento. Esta estrategia discursiva también se evidencia en el siguiente enunciado:

Claudia: [...] [hablando del metro que] va a llegar hasta SubaTibabuyes, es decir, no va a tocar un centímetro, porque vamos a proteger, la reserva van der Hammen, eso es lo lógico, eso es lo que se necesita en movilidad, eso es lo socialmente responsable, no gastarse una billonada en los estratos más acomodados de Usaquén y Chapinero, mientras que a los sectores populares de Lijacá, Verbenal, el Codito, los podemos bajar con dos metrocables, conectarlos a la línea del ferrocarril y llevarlos al centro (p. 5).

De tal manera, por medio de este tipo de negación, Claudia López pone de manifiesto puntos de vista antagónicos, inicialmente 
visibiliza la posición de las otras voces convocadas en su discurso, las de Enrique Peñalosa y Lucia Bastidas; seguidamente, expresa de manera anticipada su oposición ante los mismos. Esta segunda movida, de acuerdo con Maingueneau (1984), corresponde a que el discurso está a menudo construido en respuesta anticipada a las objeciones más previsibles. La negación polémica también le permite a ella establecer un marco de referencia socio-político, para que el electorado conozca sus propuestas en materia de movilidad y las reconozca como sensatas. En la medida en que explicita que sus propuestas no están diseñadas de manera arbitraria y poco lógica, como Claudia López considera que sí están diseñadas las proposiciones de Enrique Peñalosa en materia de movilidad.

\subsubsection{La negación descriptiva}

Este tipo de negación le permite a Claudia López dar cuenta de información la cual puede ser verificable. Considérese los siguientes enunciados:

A. Claudia López: $[\ldots]$ ahora aclaro, que la ALO, que son terrenos públicos, no nos toca comprar un solo predio... (p. 5)

B. Claudia López: [...] vamos a hacer cuatro cuatro metrocables, esa es mi propuesta completa de movilidad, el metrocable de San Cristóbal, va a ser divino, ya tiene estudios y diseños, lo podemos hacer desde el 20 de julio, no solo hasta la Victoria como se propone hoy, sino yo quiero hacerle una estación más, la verdad no es una idea mía, es idea de la comunidad que vive allá, aquí María Jimena la gente no sabe en la localidad de San Cristóbal que hay una reserva muy bonita, la reserva del sur, como la van der Hammen del sur, que se llama el Parque Entre Nubes, si, si adicionamos una estación que no vaya solo hasta la victoria sino hasta Juan Rey, la gente va a poder ir en ese metrocable a conocer el bellísimo Parque Entre Nubes y va llevar turismo y empleo a esa localidad, entonces el metro cable de San Cristóbal... (p. 7). 
Esta clase de enunciados a través de los cuales se da cuenta de algo que puede ser verificable, le permiten a Claudia López dos propósitos: 1) Hacer que los ciudadanos bogotanos conozcan información que no es de amplio conocimiento público; 2) darle un matiz de objetividad a sus propuestas de movilidad para la Alcaldía de Bogotá, al utilizar este tipo de información verificable para construir su plan de gobierno en materia de transporte.

\subsection{Conclusiones}

Desde una mirada global, Claudia López usa la nominación y la negación como estrategias discursivas para legitimar sus propuestas de movilidad para la Alcaldía de Bogotá (2020 - 2023) y deslegitimar las propuestas de Enrique Peñalosa en materia de transporte.

En cuanto a la estrategia discursiva de la nominación, esta se usa para asignar los papeles a los actores sociales a los cuales Claudia López convoca en su discurso. Como se expresó en la discusión, estos actores sociales se enmarcan en uno de tres posibles papeles sociales: 1) el de victimario o ente responsable de ayudar a los demás; 2) el de víctima o aquella persona que debe ser ayudada y 3) el de posible facilitador o posible colaborador de las propuestas políticas de ella (los no victimarios y las no víctimas). Esta asignación de funciones se hace de manera estratégica y tiene alcances socio-políticos. Por una parte pretende crear distanciamiento con políticas las cuales buscan favorecer a los sectores adinerados de la sociedad de Bogotá y, también, pretende proyectar una postura objetiva de la candidata que se acerca a la imagen de un servidor del estado, sensible al bien público y que vela por los intereses de los menos favorecidos; por otra parte, aspira a crear adhesión de las comunidades de sectores populares; finalmente, pretende extender el mensaje de que el bien común prima sobre el bien individual. 
En cuanto a las voces convocadas en el discurso de Claudia López, se usa la estrategia discursiva de la negación para establecer su oposición a las políticas de movilidad de Enrique Peñalosa. La elección de los enunciadores negativos corresponde a una estrategia de ella para legitimar sus propuestas y deslegitimar las políticas de movilidad, no solo de Peñalosa sino también de cualquier posible candidato que se presente con propuestas similares a las del entonces alcalde de Bogotá. Al respecto, es relevante considerar las palabras de Maizels (2013), quien plantea que «cuando el sujeto niega y corrige queda identificado con el saber» (p. 971). Así, Claudia López logra, a través de la negación, construir una imagen de sí como una ciudadana, mujer y política sensata, quien evalúa el punto de vista del adversario y establece, a través de diversas razones, su distanciamiento o corte con los mismos; todo esto mientras ciertos puntos de vista escapan a la lógica de la necesidad de priorizar los recursos públicos, al servidor público como servisdor de los intereses de la mayoría y a la existencia de una demanda real justificada para dar solución a cierta problemáticas.

\subsection{Referencias}

Álvarez, A. y Chumaceiro, I. (2009). El discurso de investidura en la reelección de Uribe y de Chávez. Forma y Función, 22(2), 13-42. https://revistas.unal.edu.co/index.php/ formayfuncion/article/view/23758/24438.

Arrieta Arvilla, L. M. (2013). La construcción de los sujetos en el discurso del expresidente Uribe Vélez: un análisis desde las tonalidades valorativas y los actos de habla. Cuadernos de Lingüística Hispánica, (21), 103-116.

Bermúdez, N. (2014). Las emociones en el discurso político. «Pathograma» del kirchnerismo. Acta Poética, 35(1), 11-43. 
Caleri, S. (2005). Discurso político y liderazgo. El enunciador en el discurso de Elisa Carrió. La Trama de la Comunicación, 10, 1-14. https://rephip.unr.edu.ar/bitstream/handle/2133/441/ Silvina_Caleri\%20_A1a.pdf?sequence $=1$ \&isAllowed $=$ y.

Cárdenas Támara, F. (2013). (Des)orden y signos políticos dominantes del expresidente colombiano Álvaro Uribe Vélez. Estudios Políticos, (42), 85-111. http://www.scielo.org.co/pdf/ espo/n42/n42a05.pdf.

Delgado Marulanda, A. L. (2013). La polémica en el discurso del expresidente colombiano Álvaro Uribe Velez: los argumentos ad hominem y su función como configuradores del enemigo político, el «terrorismo». Cuadernos de Lingüística Hispánica, (22), 91-108. http://www.scielo.org.co/pdf/clin/n22/n22a07. pdf.

Ducrot, O. (1984). Le dire et le dit. Minuit.

(1987). Argumentation Et Topoï Argumentatifs. Actes de la 8èmerencontre des Professeurs de Français de L'enseignement Supèrieur, Helsinski, 27-57.

. (2001). Quelques raisons de distinguer «locuteurs» et «énonciateurs». Les polyphonistes scandinaves/De skandinaviske polyfonister, (3). M. Olsen, Roskilde trykkeri (pp. 19-41).

DuzÁn, M. J. (2019, 3 de abril). 03/04/19 Entrevista con Claudia López, precandidata a la Alcaldía de Bogotá por Alianza Verde-A [Video]. YouTube. https://youtu.be/bKROPdE0Itk. 
Fernández Sanmartín, A. (2009). La expresión de la modalidad epistémica en el español científico-médico y en el español conversacional. Análisis contrastivo. En P. Cantos Gómez y A. Sánchez Pérez (Eds.), Panorama de investigaciones basadas en corpus (pp. 576-595). Asociación Española de Lingüística del Corpus. https://www.um.es/lacell/aelinco/contenido/ index.html.

Fraschini, M. (2014). Los liderazgos presidenciales de Hugo Chávez y Álvaro Uribe. Dos caras de una misma forma de gobernar. Revista POSTData: Revista de Reflexión y Análisis Político, 19(2), 507-553. https://www.redalyc.org/ pdf/522/52233952008.pdf.

García León, J. E. y García León, D. L. (2014). Análisis crítico de las campañas publicitarias de Samuel Moreno y Enrique Peñalosa: hacia una aproximación de sus estrategias discursivas. Lingüística y Literatura, (65), 113-137. http:// www.scielo.org.co/pdf/linli/n65/n65a06.pdf.

García López, R. E. y Quintero Vélez, M. J. (2013). El Fenómeno sociodiscursivo de legitimación en el cubrimiento de las campañas de Carlos Gaviria y Álvaro Uribe durante las elecciones presidenciales del año 2006. Revista Folios, (38), 61-74. http://www.scielo.org.co/pdf/folios/n38/n38a05.pdf.

García, M. M. (2012). «Ma qué» y «otra que»: dos marcadores de descalificación del español rioplatense. Anuario de Lingüística Hispánica, 28, 57-75

Maingueneau, D. (1984). Genèses du discours. Mardaga.

Maizels, A. L. (2013). La negación en los discursos de campaña política de Cristina Fernández de Kirchner (2007). IV Congreso Internacional de Letras. http://eventosacademicos.filo.uba.ar/ index.php/CIL/IV-2010/paper/viewFile/2764/1182. 
Meneses, C., A.; Demanet, A.; Baeza, C. Y Castillo, J. (2012). El movimiento zapatista: impacto político de un discurso en construcción. Revista Enfoques: Ciencia Política y Administración Pública, 10(16), 151-174. http:// www.revistaenfoques.cl/index.php/revista-uno/article/ view/82/64.

Minervini, R. (2017). Análisis de un discurso político: la investidura de Lenín Moreno. Cultura Latinoamericana. Revista de Estudios Interculturales, 26(2), 54-73. DOI: 10.14718/CulturaLatinoam.2017.26.2.3.

Molina Montes, A. F. y Cortés Patiño, J. C. (s.f.). Estrategias discursivas en el discurso de la actual candidata a la Alcaldía de Bogotá: Claudia López. https://drive.google.com/file/ d/1twU_awqvrDCC9vdzrga2-RYKToWxXoTE/view.

Pardo Abril, N. G. (2013). Cómo hacer análisis crítico del discurso. Una perspectiva latinoamericana (2. ${ }^{\mathrm{a}}$ ed.). Universidad Nacional de Colombia. Instituto de Estudios en Comunicación y Cultura (IECO).

Puig, L. (2013). La polifonía en el discurso. Enunciación, 18(1), 127-143. https://doi.org/10.14483/22486798.5723.

Romero, J. E. (2001). El discurso político de Hugo Chávez (19961999). Espacio Abierto, 10(2). 229-245. https://www.redalyc. org/pdf/122/12210204.pdf.

Villarraga, L. (2012). Análisis del discurso de posesión de Juan Manuel Santos: la ideología de la Unidad Nacional. Forma y Función, 25(1), 35-51. https://revistas.unal.edu.co/index. php/formayfuncion/article/view/38502/40634. 



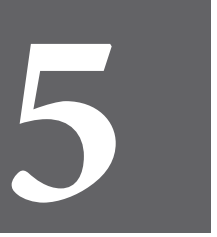

CAPÍTULO CINCO 



\title{
Lecciones semánticas: la resemantización y la metáfora
}

\author{
Claudia Liliana Agudelo Montoya ${ }^{1}$ \\ Gladys Yolanda Pasuy Guerrero ${ }^{2}$
}

\subsection{Introducción}

La resemantización es el mecanismo por el cual el sistema de una lengua multiplica su capacidad generativa al conferirle a un signo lingüístico ya establecido una nueva correlación entre su significante y su significado (polisemia); de tal manera que, dicho parentesco entra a operar como una nueva acepción del término, es decir, como un nuevo sentido. En este capítulo se revisarán los mecanismos generadores de sentido en el habla colombiana. Para lo cual, se tomará como objeto de estudio un conjunto de ciento ochenta verbos resemantizados del parlache. El parlache es una variedad del español hablado en Colombia el cual se abrió paso en los años 80, en las comunas de bajos recursos de la ciudad de

\footnotetext{
1 Profesora de la Universidad de Caldas. Ha dictado seminarios en la Maestría en Lingüística de la Universidad Tecnológica de Pereira. Correo electrónico: clamontoya2010@hotmail.com 2 Profesora de la Universidad de Caldas. Ha dictado seminarios y ha asesorado trabajos de grado en la Maestría en Lingüística de la Universidad Tecnológica de Pereira. Correo electrónico: vickypasuy@gmail.com
} 
Medellín, pero que, gracias a los medios masivos de comunicación, se ha extendido a estratos superiores y a muchas otras zonas del país como lo es Manizales. Dado que hunde sus raíces en grupos delincuenciales juveniles, las temáticas y referencias de los verbos del parlache tienen que ver con manifestaciones sociales y culturales tales como la vida, la muerte, la violencia, la droga, la religiosidad, la sexualidad y las relaciones interpersonales, entre otras.

La recolección de información se llevó a cabo a partir del Diccionario de Parlache de Castañeda y Henao (2006), y también se recurrió a la bibliografía documental especializada de los diferentes niveles del lenguaje. Ello con el fin de ofrecer una sustentación teórica del desplazamiento de los significados convencionales de los verbos hacia los nuevos sentidos.

Los mecanismos empleados para la ampliación del repertorio léxico han sido juiciosamente descubiertos y descritos por los investigadores Luz Stella Castañeda y José Ignacio Henao de la Universidad de Antioquia. Entre ellos se resaltan procesos lingüísticos como la utilización de metaplasmos de adición y supresión, el cambio de género gramatical, la inversión silábica, la fusión de significantes y significados de varias palabras, los préstamos, los calcos, las onomatopeyas, el uso de prefijos y duplicaciones, la semejanza fonética, entre otros fenómenos lingüísticos. Dentro de este extenso grupo, la investigación se detuvo en el mecanismo de la resemantización por ser el que mayor cuestión semántica convoca.

Finalmente, el ejercicio aquí presentado se ubica dentro del tipo de investigación documental y descriptiva, dado que utiliza fuentes bibliográficas propias de la teoría gramatical y de la filosofía del lenguaje. Esta detalla y ejemplifica las propiedades formales y funcionales que posee la lengua española como diasistema para introducir diversidad de sentidos en los usuarios, en los grupos sociales y en las zonas geográficas. 


\subsection{Presentación de las lecciones}

Posiblemente los tutores más importantes de la semiótica sean el lógico y matemático norteamericano Charles Sander Peirce y el crítico y filósofo inglés Ivor Armstrong Richards. Ambos se encargaron de instaurar, desde el siglo XIX, dos dimensiones del significado; una, la del valor referencial; y otra, la del valor de uso. Heredero de la naciente polémica entre la analítica y la pragmática, Charles Morris (1985) retoma los modelos tríadicos de dichos autores para conciliar una propuesta la cual pudiera contraponerse al modelo diádico del signo presentado por el lingüista Ginebrino Ferdinand de Saussure.

Así, a partir del reconocimiento del signo como un elemento que representa algo para alguien, Morris (1985) propone una nueva manera de concebir la naciente ciencia de la Semiótica como una correlación tripartita, en la cual el signo establece en primer lugar, una relación formal con otros signos en la estructura lógico-gramatical (Sintaxis); en segundo lugar, una relación con los objetos que representa (Semántica), ya sean estos de orden real y objetivo (designatum) o de mención idiomática (denotatum); y en tercer lugar, una relación con la conducta observable en el intérprete, la cual implica fenómenos de orden biológico, psicológico y sociológico (pragmática).

A partir de este marco conceptual se pretende argumentar que los estudios de los problemas semánticos se han desarrollado unas veces, orientados hacia el nivel sintáctico; y otras, hacia el nivel pragmático sin que ello sea obstáculo para superar el nivel de adecuación descriptivo del lenguaje. Las siguientes lecciones semánticas se vinculan con un fenómeno semántico en particular: la resemantización; entendida como la capacidad que adquiere un significante convencional de la lengua para asumir nuevas acepciones. Este proceso tan común, estudiado bajo el concepto de polisemia, se basa en la capacidad de movilidad del signo lingüístico (en este caso, de algunos verbos de la variedad de 
lengua colombiana denominada «parlache») para adaptarse a las variaciones y cambios que sus usuarios le atribuyan.

\subsubsection{Primera lección: la metáfora es un juego}

Desde la Filosofía Analítica se creyó que la metáfora era el principal factor causante de los problemas filosóficos. En la década de 1940, el filósofo austríaco Ludwig Wittgenstein (1988) redirecciona su pensamiento y plantea que el lenguaje metafórico, propio del uso ordinario de los idiomas naturales, no debe ser considerado como una amenaza al estudio del mundo considerado «real» sino, por el contrario, como el más genial productor de «mundos posibles» y de «juegos del lenguaje», establecidos por una determinada colectividad de usuarios integrantes de una misma «forma de vida».

En el caso de los verbos resemantizados del parlache, el usuario se encuentra con el hecho de poseer una disponibilidad léxica tan alta como la de utilizar verbos los cuales poseen varias acepciones aceptadas y registradas por la norma académica. Se advierten dos casos especiales: los verbos dar y tirar, los cuales poseen, cada uno, treinta y tres acepciones a las cuales se les suman, respectivamente, las de asesinar y consumir, aportadas por el Parlache.

\subsubsection{Segunda lección: las metáforas pueden ser verbales}

Desde la gramática tradicional, se vinculaba el fenómeno de la metáfora a la categoría gramatical de nombre o sustantivo. Christine Brooke-Rose (1958) plantea la posibilidad de proyectar el estudio de la metáfora, no solo del sustantivo a la gran mayoría de las partes de la oración, es decir, el verbo, el adjetivo, el adverbio, el pronombre y la preposición; sino, del nivel de la palabra al de frase. En consecuencia, los verbos, por tener carácter categoremático, también podrían sufrir desplazamientos 
metafóricos de órdenes similares a los del sustantivo; por ejemplo, los verbos resemantizados que aparecen identificados como tales en el Diccionario de Parlache (2006), suman ciento ochenta y seis tales como acostar, calentar, florear, insolarse, entre otros; los cuales actúan precisamente, como el corpus lingüístico de donde se deriva el presente análisis semántico extendido.

\subsubsection{Tercera lección: la metáfora cumple diversas funciones}

Para la teoría del conocimiento se requería dar respuesta a los problemas metodológicos y epistemológicos relacionados con la identificación y delimitación del significado literal y del metafórico. El filósofo azerbaiyano Max Black (1962), identificado con Wittgenstein, hace énfasis en que lo importante para la filosofía del lenguaje es el uso efectivo de las expresiones de la lengua ordinaria, la cual utiliza de manera sistemática el recurso de la metáfora para distintas funciones:

En primer lugar, para sustituir expresiones literales equivalentes a ella, por ejemplo, el verbo cocinar el cual se usa en un sentido nuevo para remediar algún vacío léxico o laguna del vocabulario como procesar cocaína. En segundo lugar, para comparar o asemejar dos conceptos, por ejemplo, el verbo resemantizado fumigar el cual se usa en un sentido transformado de su significado literal fumíguelo a mátelo/asesínelo; gracias a la analogía o similitud presentada entre ellos. Y, en tercer lugar, para integrar significados disímiles en una secuencia de asociaciones referida al criterio etimológico, a partir de la genealogía de las lenguas. Para este ejercicio con los verbos resemantizados del parlache, se toma como ejemplo el verbo enamorar el cual en parlache significa «rastrear». A continuación, se advierte que la apelación al étimo es válida, ya que se establece en una base de significación de la cual se deriva una metáfora escalonada o encadenada. Veamos: 
El vocablo amor, el cual es étimo de enamorar, heredado del latín, y proviene de la raíz indoeuropea amma (madre) y del sufijo de efecto o resultado - or; en español, se puede rastrear el significado de su derivado enamorar gracias a los paquetes de significación agregados por los morfemas circunfijos: por una parte, el prefijo griego y latino en- que en ambas lenguas significa «dentro/por dentro»; y por otra, la desinencia verbal -ar que es la terminación de infinitivo para el primer grupo verbal. Así, enamorar adquiere una definición conceptual como verbo transitivo la cual significa «excitar en uno el amor a otra persona».

En consecuencia, la polisemia del verbo enamorar se despliega en el parlache de una manera metafórica seriada, pues el sema principal que lo conforma, es decir, «sentir amor» se conserva en el verbo cortejar, el cual a su vez, se asocia con el verbo escoltar, este, a su vez, se asocia con el verbo acompañar; este último, relacionado con el verbo seguir; el cual, a su vez, se afilia con el verbo perseguir; y este, se asocia con el sentido último usado en el parlache, rastrear.

Del dinamismo de funciones del lenguaje metafórico se puede derivar la siguiente lección.

\subsubsection{Cuarta lección: la metáfora posee contenido cognitivo}

Para la retórica tradicional, la metáfora era solo un ornamento del lenguaje el cual carecía de contenido empírico. El mismo filósofo Max Black (1979) defiende el carácter cognitivo de la metáfora, apoyado en el hecho de que en ella se produce una tensión entre dos sistemas de tópicos o cosas que interactúan, con menor o mayor generalidad, para trasladar de manera analógica contenidos de un tópico marco a otro tópico foco; aunque ambos contenidos no sean supuestamente aplicables de manera inmediata y literal. Así, la comprensión dada en una determinada comunidad de usuarios de verbos resemantizados 
como avión-ar (comportarse como un avión), el cual en parlache significa «aventaj-ar»; o pirati-ar (comportarse como un pirata), el cual en parlache significa "cometer acciones delictivas contra la propiedad», se da gracias a la captación cognitiva de relaciones de implicación desde la cual puede derivar un nuevo sentido, por ejemplo, «comportarse como $»^{3}$.

\subsubsection{Quinta lección: la metáfora expresa el significado en sentido}

La lingüística descriptiva consideró el signo lingüístico como la relación diádica del significante y el concepto asociado los cuales guardan una relación inmutable a nivel sincrónico, pero mutable a nivel diacrónico. Los estudios literarios, en especial la revisión de los mecanismos poéticos permitió explorar los diferentes tipos de significado. Precisamente, uno de los primeros trabajos de Geofrey Leech (1969) distinguió siete tipos de significado los cuales reagrupó en tres grupos según se refirieran al valor conceptual, al asociativo o al temático.

En consecuencia, los verbos pueden expandir su valor desde un nivel básico literal (generalmente, conceptual o denotativo); pasar a otro estadio donde pueden soportar varios significados con la consecuente ambigüedad sintáctica, semántica y pragmática; y finalmente, lograr alcanzar un momento nuevo en el cual el sentido literal queda desplazado por el proceso metafórico. Por ejemplo, de los verbos resemantizados del parlache, el que adiciona el mayor número de nuevas acepciones es el verbo caer, el cual puede ser interpretado, dado el contexto, de seis maneras más, a saber: 1) «Arribar a un sitio en forma convenida o de improviso». 2) «Venir en conocimiento, llegar a comprender». 3) «Ser recluido en una prisión». 4) «Ser asesinado». 5) «Perderse un cargamento ilícito, por lo general a manos de la ley» y 6) «Desprestigiarse».

3 Para el caso de los verbos deadjetivales, se encuentra que también puede significar «comportarse/ actuar» como chicanear («comportarse como un chicano, un mejicano»), lo cual en parlache significa «presumir». 


\subsubsection{Sexta lección: el sentido creado por la metáfora no es indeterminado}

Max Black (1979) había defendido la autonomía e irreductibilidad del sentido metafórico, es decir, su capacidad para ser depositaria del conocimiento y para no referirse, necesariamente, a los hechos reales. Con una posición algo más moderada, Tzvetan Todorov (1971) plantó en los años 60, lo que llamó «intransitividad», para indicar la no-referencialidad de la palabra poética. Si bien dicho autor acepta que ella se agote en sí misma, también va a plantear el reconocimiento de que la evocación simbólica nunca podrá igualar la explicitación discursiva, pues dichas evocaciones pueden estar débil o fuertemente determinadas según la referencia hecha al saber compartido por los miembros de una sociedad. Estos grados de indeterminación se pueden notar en el verbo resemantizado; por ejemplo, "hacer un catorce», en el cual los términos relacionados están cargados de valoraciones subjetivas perdidas en la historia a tal punto que el usuario no es consciente del significado objetivo. Esta locuciónadquiere un significado de «hacer un favor»; expresión que prácticamente ningún usuario asocia a los catorce santos auxiliares los cuales se representan para los cristianos desde el siglo XIV, la ayuda, la bondad, la misericordia, entre otros (Banzhaf, 2006).

\subsubsection{Séptima lección: la metáfora se fija en una red de asociaciones}

Aceptado el hecho de que la metáfora está constituida por una distinción inestable entre lo literal y lo evocado-figurado, el semiólogo Jonathan Culler (1975) también propone, en los años 60, que la metáfora se alimenta de una red de asociaciones culturales y convencionales, inscritas en los miembros participantes de la comunicación. Dicha red de vinculaciones se puede notar en el siguiente ejemplo de los verbos resemantizados, es decir boletiar, el cual no ha sido aceptado y registrado en los diccionarios oficiales 
de la lengua española y es considerado una neología propia del parlache.

Hasta los años 80, dicho verbo significaba «avergonzar/ desprestigiar», pues era el efecto que tenía en el estudiante el tener que vender a toda costa las boletas emitidas en los establecimientos educativos públicos para rifar objetos de poca monta los cuales permitieran recolectar ganancias. Posteriormente, el verbo boletiar se resemantizó en «enviar boletas»; ello gracias a un fenómeno histórico concreto, a saber: la aparición de los grupos guerrilleros y criminales los cuales empezaron a anunciarles a sus víctimas, mediante notas escritas o boletas de papel, que eran objeto de una extorsión por determinada cuantía.

\subsubsection{Octava lección: la interpretación de la metáfora radica en descubrir la intención comunicativa del hablante}

$\mathrm{Al}$ enfrentar el lenguaje metafórico, el intérprete debe agotar dos instancias interpretativas - como mínimo-, para hallar el nuevo sentido. El filósofo Donald Davidson (1978) planteó que, para la interpretación de una metáfora, se requiere agotar inicialmente el significado literal; luego, preguntarse por los posibles significados o acepciones de las palabas del hablante para poder descifrar aquello que él desea dar a entender en esa determinada situación y contexto de uso. También aclaró que, en ese intento, el intérprete debe generar un proceso constante de «teorías de paso», es decir, de hipótesis de sentido las cuales se ajusten a la intención comunicativa pretendida por el emisor. Este proceso se puede advertir en la interpretación del verbo resemantizado del parlache brincar, cuando se escucha una expresión como Por ahí vi a Alex brincando", la cual inicialmente puede ser interpretada como «Vi a Alex haciendo deporte o jugando», pues el significado de base del verbo «brincar» resalta al sema de «dar brincos o saltos»; pero, a su vez, este mismo verbo comparte semas con en el verbo danzar, el cual tiene una acepción 
de «moverse de un lado para el otro con rapidez y agitación».

\subsubsection{Novena lección: la metáfora se fundamenta en modelos de conocimiento previos}

Se plantea la inquietud, entonces, sobre el proceso de constitución de la metáfora, si ella es constituida cada vez que es enunciada o si, por el contrario, las expresiones metafóricas instancian conceptos metafóricos preexistentes y disponibles en todo momento en la mente humana para producir y comprender el lenguaje figurativo. El filósofo Max Black (1979) retoma el asunto y plantea que la creatividad demostrada en la producción y la comprensión de las metáforas del lenguaje ordinario se fundamentan en la existencia de Modelos o mapas disponibles en el sistema conceptual humano, los cuales se activan de manera inconsciente al llevar a cabo procesos cognitivos en los cuales se deba seleccionar, destacar, suprimir o reorganizar los rasgos de un determinado "dominio o tópico» de la experiencia sobre otro. Tal es el caso del verbo resemantizado de florear a abalear, basado en la disposición de las piezas de la flor sobre el receptáculo que forma una especie de espiral sobre un mismo eje, tal y como queda la perforación dejada por una bala.

\subsubsection{Décima lección: las metáforas son producto de modelos culturales}

Dado que la vida cotidiana está alimentada por el pensamiento metafórico que nos permite estructurar y actualizar conceptos a partir de otros, George Lakoff (2004) plantea que este proceso depende de la experiencia directa que nuestro cuerpo haya tenido con el mundo. Las metáforas conformadas por el humano constituyen un sistema conceptual que delimitan la manera como percibimos y actuamos en el mundo. Así, esas metáforas conceptuales constituyen marcos de conocimiento, sujetos a verdades culturales relativas; en otras palabras, nuestra interpretación del lenguaje metafórico está delimitada por marcos 
culturales. De esta manera, se puede notar en el verbo vacunar, resemantizado del parlache y el cual, a pesar de conservar el núcleo léxico y el sema genérico de «respuesta de defensa», no se lo interpreta como «reaccionar ante microorganismos patógenos», sino como «reacción a la extorsión ejercida por los grupos criminales»; pues en el marco cultural colombiano, algunos grupos al margen de la ley piden dosis periódicas de dinero al ciudadano a cambio de no someterlo a mayores perjuicios patrimoniales, es decir, lo vacunan.

\subsection{Conclusiones}

El triángulo semiótico planteado por Charles Morris permite advertir que la mayoría de los fenómenos semánticos están asociados, ya sea al campo sintáctico o al campo pragmático. Desde este último campo, en la relación del signo y los usuarios, se entiende cómo el lenguaje despliega toda su creatividad en el uso hecho por los hablantes. Los signos se crean y recrean para ser fieles a las situaciones, a los contextos y a las necesidades de sus usuarios. Uno de los procesos de significación más relevantes es la resemantización entendida como «el proceso mediante el cual se asigna un nuevo valor de significado a una palabra preexistente» (RACU, s. f., párr. 1). En ese orden de ideas, el papel protagónico lo tiene la metáfora, pues el lenguaje figurado permite ignorar, remediar o superar muchos de los problemas relacionados con el signo, el significado y el contexto.

La metáfora es eminentemente interactiva y pragmática ya que permite la realización de dos o más actividades mentales simultáneas entre conceptos en una evocación múltiple en la cual genera parte del contenido del enunciado, al cual modifica y lo convierte en hecho de enunciación; es decir, deja de transmitir información referencial para producir acciones hacia la ejecución de tal proceso cuenta con la memoria colectiva de los usuarios, quienes se encargan de convertir el significado directo en sentido indirecto. 
La metáfora se construye en una red de asociaciones, las cuales le brindan estructura y la sistematizan. Tales vinculaciones se basan en modelos conceptuales relativos al lenguaje, al pensamiento y a las experiencias culturales de los hablantes. De este modo, se entiende al parlache como una variedad de uso del habla colombiana surgida en un contexto sociocultural muy particular en el cual la metáfora refleja la experiencia vivida en el mundo de la violencia y el narcotráfico.

El estudio cognitivo de la metáfora debe continuar explorando la naturaleza de las operaciones mentales relacionadas con la creatividad del lenguaje. La metáfora presente en los verbos resemantizados puede funcionar como pretexto para investigaciones sobre la noción de construcción gramatical, de parámetros cognitivos semánticos y de inferencias pragmáticas, derivadas de los diferentes contextos de situación. Así queda abierto el camino para seguir explorando este campo.

\subsection{Referencias}

Banzhaf, H. (2006). La simbología y significado de los números. Edaf.

Black, M. (1962). Metaphor. In M. Black, Models and Metaphors. (pp 25-47) Cornell University Press.

(1979). More on Metaphor. In A. OrTony, Metaphor and Thought (p.p 19-41). Cambridge University Press.

Brooke-Rose, C. (1958). Grammar of Metaphor. Secker and Wargbug

Castañeda, L. y Henao, J. I.. (2006). Diccionario de parlache. La Carreta Editores. 
Culler, J. (1975). Structuralist Poetics. Routledge.

Davidson, D. (1978). What Metaphors Mean. In S. Sacks, On Metaphor. (p.p 31-47). University of Chicago Press.

Lakoff y Johnson, (2004). Metáforas de la vida Cotidiana.). Cátedra

Leech, G. (1969). A Linguistic Guide to English Poetry. Longman.

Morris, C. (1985) Fundamentos de la teoría de los signos. Ediciones Paidós Ibérica, S.A.

Todorov, T. (1971). The Poetics of Prose. Cornell University Press.

Real Academia de Ciencias del Uruguay [RACU]. (s. f.). Procesos de Resemantización. [entrada en blog]. Wordpress. com. https://realacademiadecienciasdeluruguay. wordpress.com/epistemia/depto-de-lexolinguistica/ neosemantica/resemantizacion/\#: : text $=\mathrm{La} \% 20$ rese mantizaci $\%$ C $3 \%$ B 3 n $\% 20$ es $\% 20$ e $1 \% 20$ proceso, Lex o mancia $\% 20$ o\% 201 a $\% 20$ Espeleolog\%C3\%ADa\%20Ling\%C3\%BC\%C3\%ADstica.

Wittgenstein, L. (1988). Investigaciones Filosóficas. Crítica. 



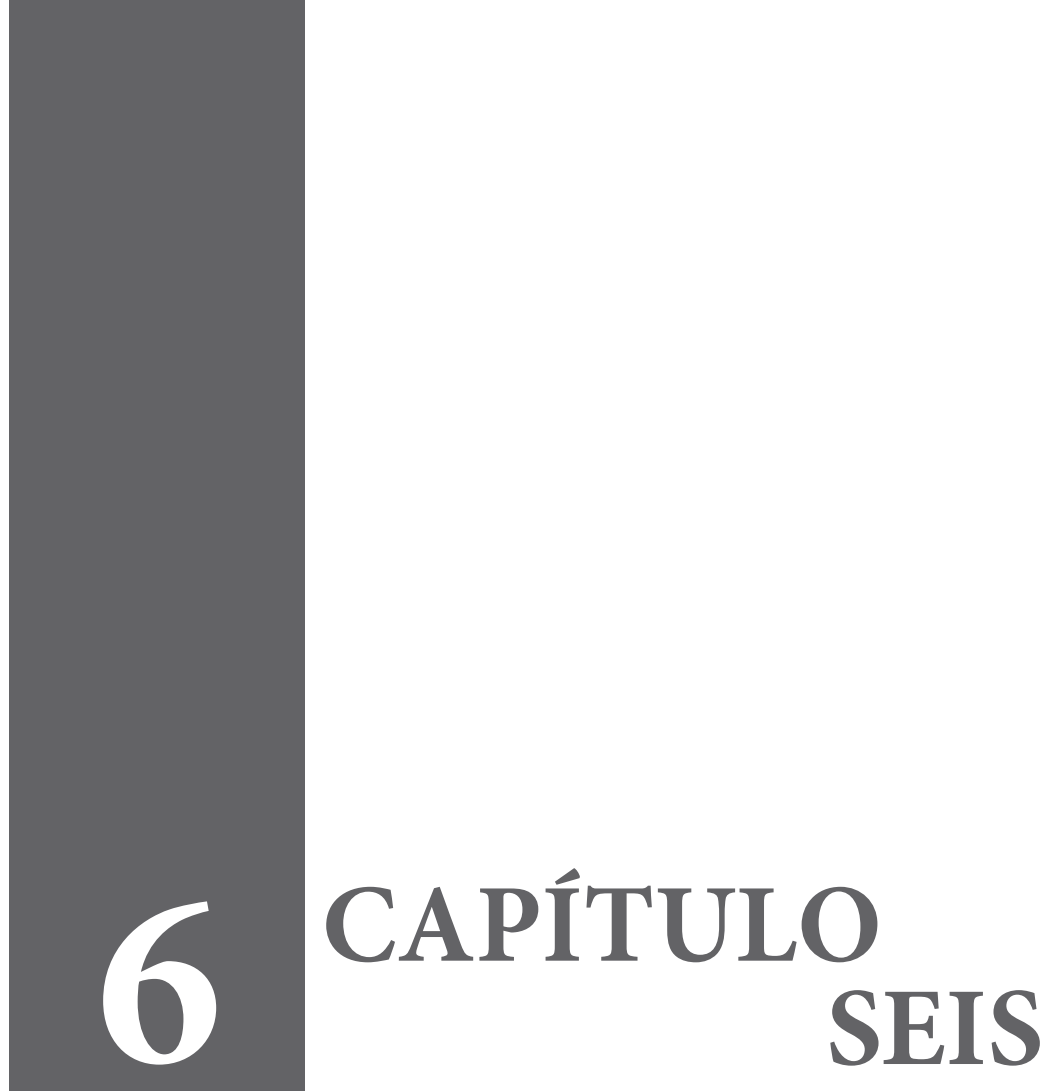





\title{
Ir a + infinitivo: una mirada desde la prensa escrita colombiana ${ }^{1}$
}

\author{
Santiago Cifuentes Osorio ${ }^{2}$ \\ Paula Andrea Hoyos Giraldo ${ }^{3}$
}

\subsection{Introducción}

Las perífrasis verbales se han estudiado desde las gramáticas tradicionales hasta la actualidad. Existe una amplia bibliografía la cual estudia estas en elel español desde los niveles morfológico, sintáctico y semántico; sin embargo, no hay muchos trabajos

1 Artículo derivado del trabajo de grado presentado en la Maestría en Lingüística de la UTP titulado Análisis de la perífrasis verbal ir a + infinitivo en la prensa escrita colombiana.

2 Licenciado en Lenguas Modernas de la Universidad de Caldas y Magíster en Lingüística de la Universidad Tecnológica de Pereira. Actualmente se desempeña como docente del Departamento de Lingüística y Literatura de la Universidad de Caldas, donde ha dictado cursos de Introducción a la Literatura, Literatura Occidental I, Habilidades Comunicativas en Lengua Española, Textos y Discursos, Español para Extranjeros, Fonética y Fonología, Morfosintaxis y Psicolingüística. Correo: santiago.cifuentes@ucaldas.edu.co.

3 Licenciada en Lenguas Modernas de la Universidad de Caldas, Magíster en Lingüística de la Universidad Tecnológica de Pereira. Actualmente docente del Departamento de Lingüística y Literatura de la Universidad de Caldas, donde ha dictado cursos de Español para Extranjeros, Fonética y Fonología, Morfosintaxis, Semántica, Sociolingüística, Semiótica y Semiología, Habilidades Comunicativas en Lengua Española y Textos y Discursos. Correo: paula.hoyos@ ucaldas.edu.co. 
monográficos generales y son pocos los cuales analizan las construcciones perifrásticas en la prensa escrita. Debido a los pocos estudios que se han realizado en torno a la aparición de las perífrasis en ese contexto se hace necesario incurrir en este campo que se ha mostrado exclusivo y poco accesible.

La utilidad de la propuesta radica en revelar las funciones de las perífrasis verbales de ir a + infinitivo en el periódico colombiano de circulación nacional El Tiempo. Los propósitos específicos de la investigación consisten en clasificar, analizar y contrastar el modo como se presentan las dichas perífrasis en la prensa colombiana al comparar dos secciones del periódico (cultural y editorial) y su frecuencia de aparición. Esto con el fin de realizar un análisis cuantitativo que permita establecer cuáles son las construcciones perifrásticas prevalecientes en ese contexto y posteriormente analizar cualitativamente los datos obtenidos, de tal modo que se pueda aportar a los estudios de gramaticalización del verbo ir como auxiliar de la perífrasis estudiada.

Además de los sustentos teóricos que soportan el análisis de la perífrasis verbal ir a infinitivo, esta investigación ha tomado como base un corpus en el cual se evidencia la producción perifrástica en la prensa escrita colombiana.

Se utiliza una metodología mixta a partir de los métodos analítico y comparativo, con componentes paradigmáticos, tanto cuantitativos como cualitativos. De igual manera, se vale de datos estadísticos para explicar el comportamiento de la perífrasis en el corpus y posteriormente interpretar y comprender dichos datos.

Los resultados se analizan a partir del contraste de la teoría con los datos del corpus, para así develar las funciones de dicha perífrasis, presentes en la prensa colombiana en un período sincrónico de su historia (enero de 2017). 


\subsection{Caracterización del corpus}

El corpus utilizado como punto de partida para el análisis de la perífrasis verbal ir a + infinitivo en la prensa escrita colombiana, proviene de dos secciones del periódico de circulación nacional El Tiempo. Las secciones analizadas fueron la «Editorial» y la «Cultural», con el fin de clasificar dichas perífrasis en relación con la variedad de uso «el registro» y la «frecuencia de uso».

La recopilación del corpus se realiza durante un mes (del 2 de enero al 1 de febrero de 2017). Esto con el propósito de obtener un número significativo de ediciones analizables. Se analizan ochenta y nuve textos con una producción total de treinta casos. La compilación de los datos se hace inicialmente de manera manual y posteriormente con la ayuda del procesador de textos Tropes.

\subsection{Marco teórico}

Llamadas conjugaciones perifrásticas (Gili y Gaya, 1961), corresponden a aquellas en las cuales aparece un verbo conjugado (auxiliar), seguido de un verbo en infinitivo (auxiliado), gerundio o participio. Cabe destacar que, entre estas formaciones puede haber un nexo el cual puede ser la conjunción «que» o una preposición.

Para comprobar si un verbo es un auxiliar, habrá que fijarse si este ha perdido su significado parcial o completamente, pues de conservarlo no es posible hablar de auxiliar y, por ende, no constituirá una construcción perifrástica (Gili y Gaya, 1961). Basta con mirar el siguiente ejemplo: voy a escribir un correo, donde el verbo ir no conserva su significado entendido como desplazamiento de un lugar a otro, sino más bien, se hace referencia a una representación metafórica a través de la cual se aporta la construcción de un sentido de inmediatez.

A su vez, Gómez-Torrego (1988) define las perífrasis verbales 
como construcciones que tienen dos o más verbos, los cuales constituyen un solo núcleo de predicado, y en donde el verbo principal o auxiliado debe ser una forma no personal (infinitivo, gerundio, participio); mientras que el verbo auxiliar será el responsable de manifestar los accidentes verbales.

Al decir que ambos verbos constituyen un solo núcleo de predicado, se afirma categóricamente que hacen parte indisoluble de una edificación en la cual sus partes no funcionan como elementos complementarios o subsidiarios (Gómez-Torrego, 1999); razón por la cual no podría distinguirse más allá de la forma simplificada de auxiliar y auxiliado, ya que estos constituyen un predicado que conforma una oración simple.

En este sentido, Alarcos (1999) advierte que los elementos de la perífrasis verbal adquieren funciones que se complementan, pues el auxiliar modifica o precisa el sentido del auxiliado, mientras este último determina sintácticamente al verbo, razón por la cual esta estructura es estable de cara a la construcción de una forma en la cual prevalecen rasgos morfológicos, sintácticos y semánticos, considerados estables.

\subsubsection{La perífrasis ir a + infinitivo}

Ir a + infinitivo es una perífrasis verbal la cual se caracteriza por la presencia del verbo ir como auxiliar y por una forma no personal en infinitivo. Tradicionalmente se ha relacionado esta perífrasis con el futuro, por las características figurativas que se expresan en el plano de lo temporal (valor tempoaspectual). Sin embargo, también se le relaciona con aspectos los cuales distinguen la actitud del hablante de cara a los acontecimientos que este enuncia (valor modal).

De esta forma, se establece que el uso de la perífrasis ir $a+$ infinitivo es variado, ya que aporta diferentes rasgos. Entre ellos se tienen aquellos que expresan posteridad, rasgo que suele asociarse 
con la característica de la inminencia. De igual forma, esta perífrasis se utiliza para referirse a un momento anterior como, por ejemplo, «Parecía que iba entrar en la ciudad de un momento a otro» (RAE, 2010, p. 541). También aparece en construcciones introducidas por la conjunción «si», por ejemplo, en si te vas a ir, vete (en donde funciona como condicional). Del mismo modo, se emplea en oraciones subordinadas temporales cuando estas están introducidas por «cuando»; por ejemplo, cuando nos vayamos a quedar. Cabe agregar que también aparece en oraciones relativas referidas al tiempo, como en el momento en que vayamos a comer.

\subsubsection{El valor temporal}

La perífrasis ir a infinitivo tiene entre sus valores el rasgo de temporalidad futura, no obstante, al considerarse un futuro inmediato, en algunos casos, no cabe la posibilidad para el futuro simple, como en "¿Qué hora es? Van a ser las tres. Falta muy poco para ser las tres» (Gómez-Torrego, 1999, p. 66). Así, la posibilidad de poder sustituir la perífrasis anterior por el futuro está sujeta a un nexo referencial de tiempo inmediato, por lo que no es posible sustituir la construcción por serán las tres. En su lugar debe relacionarse con un contexto inmediato por medio de algún vínculo, dentro de poco, ya casi... serán las tres. Así mismo, tampoco resulta posible la sustitución de la perífrasis verbal por el futuro simple en casos como «vámonos, que va a llover. Vámonos que lloverá» (p. 66), pues el significado es distinto.

De este modo, una de las características más sobresaliente de esta construcción está dada por su carácter de inmediatez, pues ella puede referirse a la realidad física temporal o puede hacer mención a una «realidad psicológica deseada, temida o vista como más segura» (Gómez-Torrego, 1999, p. 67).

No obstante, se puede advertir que en los casos en donde la perífrasis es equivalente al futuro simple, esta puede asociarse a unos más coloquiales y afectivos. Así mismo, en las perífrasis 
que denotan obligatoriedad y vienen precedidas por el verbo ir como auxiliar, se puede expresar el futuro como un deber o una necesidad, por ejemplo «Va a haber que expulsarlo del colegio (habrá que expulsarlo)»(Gómez-Torrego, 1999, p. 67).

De esta manera, esta construcción también puede aportar rasgos fuera de los temporales. Así, cuando el auxiliar aparece en pretérito perfecto simple o en elaboraciones compuestas, se refiere a la realización inesperada o fortuita de un evento, tal como «Y me fui a caer, así como si nada; o, me he ido a caer, así como si nada». Basta destacar que, estos valores solo son posibles con verbos que expresan procesos delimitados, conocidos como verbos télicos (RAE, 2009).

En relación con lo anterior, se agrega el valor aspectual de incoativo (estar a punto de), el cual se da conjuntamente con el valor de temporalidad. De este modo, la equivalencia con el futuro simple no es posible, pues no posee el valor aspectual de «estar a punto de» como en la construcción «Va a salir el sol (no es lo mismo que saldrá el sol)»(Gómez-Torrego, 1999, p. 68).

\subsubsection{Valor modal}

Además del valor anterior, Gómez-Torrego (1999) comenta que, por una parte, está el valor modal intencional, el cual se relaciona con la disposición del sujeto para llevar a cabo una acción; y por otra, la existencia del valor modal de inoportunidad, cuando el auxiliar está conjugado en pretérito perfecto (simple o compuesto), el cual muestra una actitud de molestia o desagrado por parte del hablante. Relacionado con los valores anteriores, y vinculado con la función conativa, están los valores de advertencia, amenaza, reproche, complacencia, entre otros (me las vas a pagar), donde el hablante busca influir en el comportamiento del interlocutor. Este tipo de construcciones suelen ser de carácter coloquial, y se asocian con los valores de futuridad y de intencionalidad. 
En contrapartida a los rasgos de temporalidad ya establecidos, esta perífrasis pierde su sentido prospectivo en algunas retóricas exclamativas e interrogativas de intención de refutar: «¿De dónde voy a haber sacado yo la llave del departamento de los señores Feliu?»(RAE, 2009, p. 542). Asimismo, esta perífrasis establece una correlación directa entre el futuro de conjetura y el presente de incertidumbre pues se utiliza comúnmente en la lengua oral con estos valores, por ejemplo «Eso va a ser ['seguramente es'] que [...] le ha dicho algo sobre la sardana» (RAE, 2009, p. 542).

En consecuencia, se observa que ir a + infinitivo puede ser una construcción polivalente en relación con su contexto de enunciación - motivo el cual merece una especial atención-, sobre todo cuando se trata de distinguir las diferencias entre la lengua escrita y la oral. No se puede resaltar menos que sus significados están directamente relacionados con su contexto y su cotexto, de modo que, casos de ambigüedad pueden ser escasos siempre que se posea la información necesaria para precisar la intención del hablante o los propósitos del predicado.

En adición a los valores mencionados, se establecen otros valores con relación a ir a +infinitivo, estos son: el valor expresivo, el cual en contextos exclamativos, en los que se utiliza la perífrasis, se apela a la función expresiva en la cual el hablante pretende reforzar lo que ha dicho (una negación, una duda o una afirmación.), como por ejemplo tienes que hablar mañana - iy qué les voy a decir!. Asimismo, esta construcción es utilizada cuando se quiere destacar la certeza de las cosas, el desprecio hacia el oyente o el significado de logro o de conquista, como se da en «si te fueses a curar, iría de rodillas hacia la iglesia (= si lograras curarte...)» (Gómez-Torrego, 1988, p. 71).

Algunos gramáticos como Gómez-Torrego (1999) y la RAE (2009;2010) concuerdan en que la perífrasis, además de expresar futuridad, puede simultáneamente adquirir una variedad considerable de valores discursivos los cuales discurren 
desde la posibilidad de denotar una amenaza, una advertencia, una petición; hasta la expresión de una intención, de una probabilidad o una posibilidad. Cabe resaltar que estos valores los confiere la situación comunicativa en la cual el hablante, a través de la perífrasis, imprime al acto de habla con mayor firmeza, determinación o intensidad (RAE, 2009). Así se advierte en los siguientes ejemplos: se van a acordar de mí (advertencia), te va a salir caro el paseo (advertencia), ¿me vas a contar de una $v e z$ ? (petición con cierto grado de firmeza), entre otros; los cuales, aunados a variaciones entonativas, realzan el valor discursivo.

\subsection{Resultados y discusión}

Al recolectar treinta y un ejemplares de El Tiempo, se analizaron ochenta y nueve textos provenientes de las secciones «Cultural» y «Editorial» entre el 2 de enero y el 1 de febrero de 2017. Los temas trabajados en dichas secciones fueron variados, en la editorial predominaron temas de interés general y de actualidad; por otra parte, los temas más abordados en la sección cultural fueron: música, libros, arte, cine, teatro y televisión.

En el corpus se evidenció una producción considerable de construcciones perifrásticas con diferentes verbos auxiliares y auxiliados. Se encontró que el $64 \%$ de las perífrasis verbales corresponden a aquellas con auxiliar más infinitivo en donde ocasionalmente aparecían los nexos que y a (ver Figura NRO. 1); lo cual implica una mayor productividad de las perífrasis de infinitivo y a su vez ratifica el dinamismo de la misma, presentado por Gómez-Torrego (1999), puesto que puede seleccionar los complementos y sujetos de la construcción. 


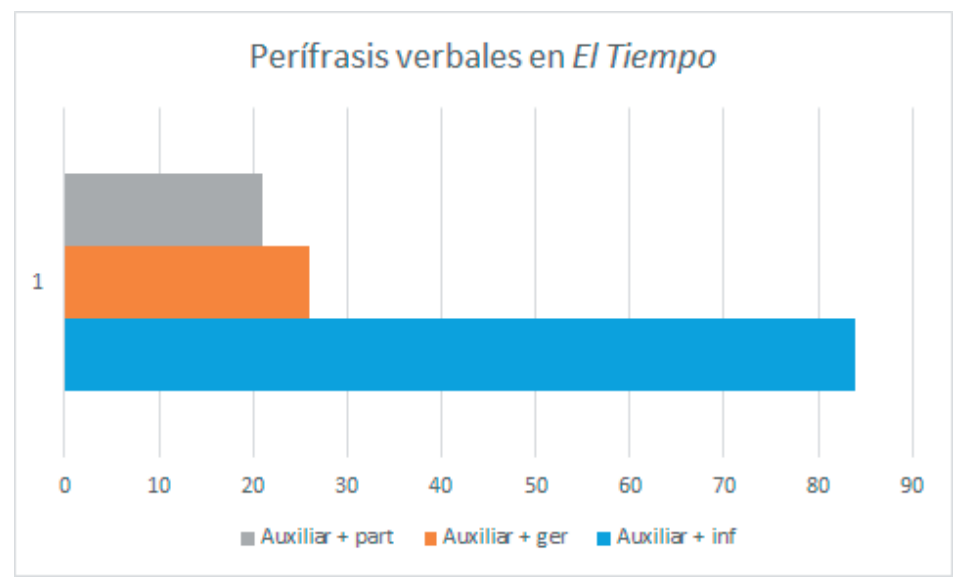

Figura Nro. 1. Distribución de las perífrasis verbales en El Tiempo. Elaboración propia.

En lo que respecta a las perífrasis verbales ir a +infinitivo, en la Figura NRO. 2 se evidencia que hay vitalidad en sus usos en contextos y registros variados, puesto que, en las secciones trabajadas del periódico El Tiempo muestran una producción estable del verbo ir en perífrasis verbales, en comparación con la aparición de otros verbos auxiliares como poder y deber.

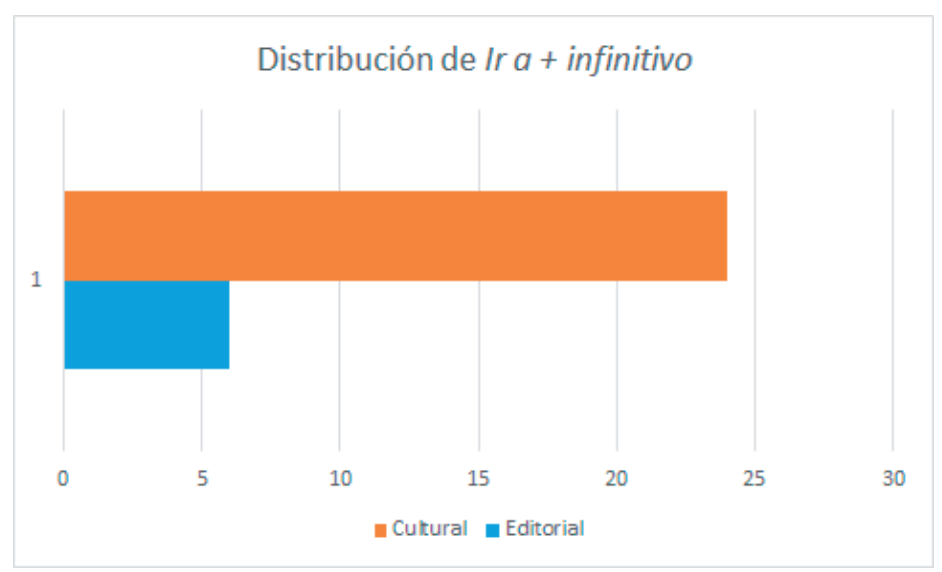

Figura Nro. 2. Distribución de ir a + infinitivo en El Tiempo. Elaboración propia. 
Se puede observar que la distribución de la sección cultural aporta de manera significativa al corpus, dado que el $80 \%$ de los datos corresponden a ella, y la «Editorial» al, $20 \%$.

\section{Funciones de las perífrasis ir a + infinitivo en El Tiempo}

Las funciones de las perífrasis de ir a + infinitivo se presentan en relación con el verbo principal, es decir, con el verbo auxiliado. Estas se definen a partir de los valores presentados por la perífrasis. A continuación, se relacionan dichas funciones y valores de las perífrasis de futuro encontradas en el corpus analizado (ver TABLA NRO. 11).

\begin{tabular}{lll}
\hline Ir + a + infinitivo & Función & Valor \\
\hline 1. Van a ayudar & Temporalidad futura & Tempoaspectual \\
2. Va a ocurrir & Temporalidad futura & Tempoaspectual \\
3. *Iban a trabajar & Desplazamiento & \\
4. Han ido a parar & No temporalidad & Tempoaspectual \\
5. Va a ser & Temporalidad futura & Tempoaspectual \\
6. Iba a beneficiar & Temporalidad futura & Tempoaspectual \\
\hline$*$ construcción no perifrástica & & \\
\hline
\end{tabular}

TABLA NRO. 11. Funciones $y$ valores de ir a + infinitivo: editorial. Elaboración propia.

Se observa que la construcción se da en presente y pretérito del indicativo, lo cual denota una futuridad. En el caso del pretérito, dicha temporalidad futura establece una correspondencia con el condicional simple del modo indicativo (Gómez-Torrego, 1988), lo cual representa un cambio a nivel morfosintáctico mas no discursivo.

Igualmente, Gómez-Torrego (1988) afirma que de dicho valor de temporalidad se desprende el valor de incoatividad y, como se observa en los ejemplos, existe una equivalencia semántica entre ir a + infinitivo y comenzar $a+$ infinitivo.

Se advierte que la construcción «iban a trabajar» se puede tomar como una construcción perifrástica o como la aparición plena del verbo ir: 
a) Iban a trabajar: se desplazaban de un lugar hacia su trabajo.

b) Iban a trabajar: se disponían a trabajar, comienzo de la acción trabajar.

Es evidente que, desde el nivel sintáctico la construcción es ambigua; pero en el corpus se confirma que el significado del verbo ir se conserva, lo cual comprueba que el enfoque discursivo y sociolingüístico se deben tener en cuenta para que el análisis pueda ser más profundo.

Por otro lado, la aparición de la perífrasis «han ido a parar» llama la atención en el sentido en que no se le puede atribuir una función de futuridad, posibilidad, incoatividad o expresividad. El ejemplo representa el fin de una acción y se produce por la aparición del verbo auxiliado «parar». En ese caso, su equivalencia semántica sería «están», lo cual evidentemente expresa un valor en el presente. La perífrasis trabajada puede aportar sentidos no temporales, ya que en este caso expresa un valor discursivo el cual refleja el carácter intempestivo y fortuito de la acción (ver TABLA NRO. 12).

\begin{tabular}{|c|c|c|}
\hline Ir a + infinitivo & Función & Valor \\
\hline 1. Iba a tener & Temporalidad futura & Tempoaspectual \\
\hline 2. Iba a publicar & Temporalidad futura & Tempoaspectual \\
\hline 3. Van a quedar & Temporalidad futura & Temporal \\
\hline 4. Se va a hacer & Temporalidad futura & Tempoaspectual \\
\hline 5. Vamos a poner & Temporalidad futura & Temporal discursivo \\
\hline 6. Vamos a hacer & Intencionalidad & Modal \\
\hline 7. Va a encontrar & Temporalidad futura & Tempoaspectual \\
\hline 8. Va a girar & Temporalidad futura & Tempoaspectual \\
\hline 9. Voy yo a cantar & Intencionalidad & Modal \\
\hline 10. Van a dar & Temporalidad futura & Tempoaspectual \\
\hline 11. Iba a dar & Temporalidad futura & Tempoaspectual \\
\hline 12. Iba a decir & Intencionalidad & Modal expresivo \\
\hline 13. *Iba a trabajar & Temporalidad futura & Tempoaspectual \\
\hline 14. Vamos a probar & Incoativa & Tempoaspectual \\
\hline 15. Voy a interpretar & Temporalidad futura & Tempoaspectual \\
\hline 16. *Vayan a ver & Desplazamiento & Desplazamiento \\
\hline 17. $*$ Se fue a vivir & Desplazamiento & TA/discursivo \\
\hline $\begin{array}{l}\text { 18. Vamos a dejarnos } \\
\text { llevar }\end{array}$ & Temporalidad futura & Tempoaspectual \\
\hline 19. Iba a resultar & Temporalidad futura & Tempoaspectual \\
\hline 20. Iba a contarle & Temporalidad futura & Temporal discursivo \\
\hline 21. Van a pasar cosas & Inmediatez & Tempoaspectual \\
\hline 22. Vas a conocer & $\begin{array}{l}\text { Temporalidad futura }+ \text { intencionalidad de } \\
\text { advertencia }\end{array}$ & Modal/Tempoaspectual \\
\hline 23. Iba a ser & Temporalidad futura & Tempoaspectual \\
\hline 24. Iba a cantar & Temporalidad futura & Tempoaspectual \\
\hline
\end{tabular}

TABLA NRO. 12. Funciones $y$ valores de ir a + infinitivo: cultural. Elaboración propia. 
La mayoría de las construcciones perifrásticas del corpus aparecen en presente y en pretérito imperfecto del indicativo; en consecuencia, admiten todo tipo de predicados y el sujeto gramatical puede variar, lo cual implica la desemantización del verbo y posterior gramaticalización.

Las perífrasis cinco, ¿qué vamos a poner para el programa...?, y seis, ¿...esto que vamos a hacer?, hacen parte de enunciados interrogativos los cuales tienen valor discursivo orientado a la exhortación introspectiva, en donde el hablante cuestiona la falta de ideas, a la vez que puede interpretarse el plural como una advertencia con la que intenta persuadir a su equipo de actuar con prontitud ante un suceso próximo. Se advierte en estos casos un rasgo de incertidumbre que se relaciona con el valor de inmediatez de la perífrasis verbal.

En la perífrasis nueve, ¿con qué corazón voy yo a cantar en Venezuela? Se aprecia que el valor de intencionalidad es contrariado por el enunciado interrogativo del cual hace parte. Se repara en esta construcción un valor discursivo de inoportunidad, en el cual se expresa la inconveniencia de llevar a cabo ese evento bajo las circunstancias actuales. En todo caso, podría señalarse que el valor se da por el efecto que la interrogación y el complemento (con qué corazón), tienen sobre la prospección del verbo.

Así mismo, en la construcción perifrástica doce, ¿quién nos iba a decir algo? Se observa una función expresiva con valor discursivo la cual refuerza la certeza de un suceso venidero en lo que sería una variación de lo que Gómez-Torrego (1999) denomina valor exclamativo-expresivo el cual tiene por finalidad reforzar una afirmación o negación. Se comprueba que esta perífrasis se considera como el refuerzo de la afirmación anterior por la acción del pronombre interrogativo y de los signos de pregunta.

Se nota la construcción vamos a probar, es decir, la catorce, con valor exhortativo, pues se interpreta como una invitación a los 
demás para continuar con algo, y en adición, el valor el cual denota es de inminencia en relación con las expectativas establecidas por el cotexto con la proximidad de los acontecimientos; obsérvese a yo dije 'bueno, vamos a probar pa' y ve', y finalmente salió una combinación de cumbia tradicional... Se manifiesta una conexión de causa y efecto entre los acontecimientos la cual demuestra la inmediatez del proceso; de allí que la acción interna de la perífrasis se percibe como delimitada por la consecución de los hechos.

Dada la posibilidad de ilación encontrada en las perífrasis verbales de infinitivo, se puede advertir que, vamos a dejarnos llevar (dieciocho). Se construye en primer lugar, por la perífrasis vamos a dejar $y$, en segundo lugar, por la locución verbal dejarse llevar; de modo que, el valor semántico aportado por esta última se relaciona con un valor volitivo, en el cual se manifiesta el deseo de no hacer algo sino de sentirlo, lo cual indica la inmediatez del suceso, además de cierto valor imperativo.

En lo concerniente a la construcción y menos, que Rhodes iba a contarle todos los detalles al mundo (veinte), se presenta un valor de sorpresa el cual se interpreta como algo inesperado, esta interpretación como consecuencia de algo previo que el hablante no había concebido dentro de sus expectativas.

La perífrasis veintiuno en contexto, cuando nos dicen que, si hablamos de eso, nos van a pasar cosas malas, cuenta con valor discursivo de advertencia o amenaza, conexión la cual se determina por la relación establecida por la perífrasis con el cotexto, pues obedece al discurso referido. Esta perífrasis si bien se percibe como una realidad psicológica temida por el hablante, se establece por el contexto en el cual el enunciado emana una amenaza la cual perfila esta significación. Se repara en que el discurso referido trae al enunciado a un interlocutor que quiere actuar sobre la voluntad del hablante al mostrar el posible resultado de sus acciones como parte de un infortunio; además, presenta un valor modal donde el hablante busca influir en el comportamiento del interlocutor, 
y el contexto suele ser generalmente de carácter coloquial, lo cual se comprueba con el registro informal en donde se inscribe la muestra.

El corpus muestra en su mayoría valores tempoaspectuales dada la naturaleza de la perífrasis, ya que los casos trabajados presentan desemantización e inmediatez, es decir que, el verbo auxiliar ir pierde su rasgo de significación principal, puesto que no implica desplazamiento físico y aporta al verbo auxiliado el traslado en el tiempo, la futuridad; sin embargo, dicha futuridad no se presenta como un prospecto sino como una acción que continúa de inmediato en la línea del tiempo.

En la perífrasis iba a ser (veintitrés) se reafirma una futuridad de conjetura la cual equivale a cierto grado de incertidumbre, en la medida en que se admite la equivalencia seguramente sería. También cabe mencionar que, desde el aspecto lexical, la mayoría de los verbos auxiliados son verbos de acción y la perífrasis adquiere un significado intencional de futuridad.

En muchas de las construcciones perifrásticas prevalece un valor discursivo relacionado con el valor modal de intencionalidad, ya que permite a los hablantes acentuar alguno de los rasgos pragmáticos de los enunciados, lo anterior como rasgo característico de la oralidad. Habría de tenerse en cuenta que las muestras relacionadas con la sección de cultura se relacionan con el género periodístico de la entrevista; también habría de mencionarse que, de los valores tempoaspectuales de las perífrasis en estas situaciones, el hablante enfatiza el valor modal lo cual implica una atenuación del temporal sin que esto conlleve a una pérdida de este valor.

También, cabe destacar que tanto en la editorial como en la sección de cultura - en algunos casos-, cuando se utiliza el pretérito imperfecto en las perífrasis, este se refiere a situaciones infortunadas, fallidas o sorpresivas, en las cuales se matiza la 
temporalidad para darle mayor relevancia a lo inesperado; obsérvese en: supuestamente iba a beneficiar, y en, y menos, que Rhodes iba a contarle. Aunque este valor es introducido por elementos en posiciones preverbales, establecen un tópico.

Es indiscutible que en la mayoría de las apariciones de la perífrasis trabajada, se presenta un valor de temporalidad futura caracterizada por la inmediatez, ya sea física o psicológica puesto que el hablante ve los hechos más próximos con la construcción perifrástica, que con la construcción simple (Gómez, 1988). Esto se evidencia también en los datos correspondientes a la sección Editorial presentados anteriormente, dado que, el carácter periodístico debe usar construcciones más generales y alejadas del sujeto con el fin de mostrar la objetividad que lo caracteriza.

\subsection{Conclusiones}

En la presente investigación se analizaron las perífrasis verbales de infinitivo ir a + infinitivo presentes en el periódico $E l$ Tiempo entre el 2 de enero y el 1 de febrero de 2017, esto desde el nivel morfosintáctico y sociolingüístico. Se establecieron las funciones y valores de dichas construcciones perifrásticas y su análisis permitió comprobar un alto uso del valor de temporalidad futura, lo cual reafirma la vitalidad de la perífrasis en un registro formal en el ámbito periodístico.

Adicionalmente, se comprobó con el análisis del corpus que la perífrasis ir a + infinitivo presenta más valores que el futuro simple, pues aparte del valor de futuridad, se comprobaron virtudes como la intencionalidad, la incoatividad, la inmediatez, la incertidumbre, la voluntad, la obligación, la exhortación, la sorpresa y los valores discursivos. Estos resultados ratifican que el hablante cuenta con más posibilidades discursivas al hacer uso de la construcción perifrástica, opciones que tiempos gramaticalizados como el futuro simple no le facilitan. 
De igual manera, los valores encontrados en el corpus evidencian el grado de desemantización del verbo $i r$, el cual a su vez reafirma la relación inminente como futuro próximo en la medida en que la mayoría de las construcciones no adquieren el mismo sentido en futuro simple, esto porque la inmediatez de la acción, la actitud del hablante y su cercanía con la acción no permitiría utilizar la construcción simple, además de los valores adicionales expresados por esta perífrasis.

La perífrasis verbal está determinada en la mayoría de los casos por los tiempos gramaticales referidos al presente y pretérito imperfecto del modo indicativo en donde su valor es tempoaspectual, a través de la correspondencia con el futuro y el condicional simple, lo cual reafirma su funcionalidad y determina su variación e influencia en el cambio; puesto que el condicionamiento semántico y pragmático representa diferencias entre las variantes, es decir, el contexto influyó de manera significativa en el análisis del corpus porque establecía el significado discursivo. Es importante destacar que, para realizar el análisis de las perífrasis fue necesario analizarlas en relación con los adyacentes, ya que podían incidir sobre la acción denotada por el verbo y, en términos discursivos, sobre el propósito el cual enmarca la acción, es decir, estas no se tomaron como unidades aisladas. De esta manera el corpus evidenció la relevancia de los componentes semántico y pragmático dentro de la investigación.

Un aporte importante dentro de la investigación se presentó desde el nivel pragmático, pues inicialmente no se había tomado como criterio de análisis, pero en el momento de estudiar el corpus se evidenció su influencia en la discusión. Por un lado, el valor discursivo el cual se presentó en el corpus y, por otro, se comprobó que dicho valor no dependía de la variedad de uso, fuera esta formal o informal; de ahí que, en cualquier construcción producida por el hablante, sea cual sea la situación comunicativa, debe estar implícito el acto ilocutivo. Adicionalmente, algunos de los casos, además de esa intención, muestran que el que habla 
desea causar una reacción en el interlocutor, por ejemplo, cuando ese valor discursivo representa una advertencia o amenaza.

Se comprobó que, un factor influyente en la aparición de la perífrasis fue el registro del habla, ya que la mayoría de los datos analizables provinieron de la sección «Cultural» con un registro informal, es decir, veinticuatro perífrasis fueron aportadas al corpus por esta sección. Se puede concluir que la perífrasis es vital y de alta productividad en la lengua hablada; puesto que, si bien se encontró en la prensa, la mayoría de los artículos publicados en esta sección eran transcripciones de entrevistas realizadas a los artistas o invitados. Por añadidura se observa que, en las muestras de habla provenientes de la lengua oral es donde la perífrasis es más versátil y prolífica, dado que, los valores tempoaspectuales son constantemente reforzados por el valor modal de intencionalidad en construcciones las cuales cuentan con amplios matices que van desde el refuerzo positivo hasta el negativo.

El verbo ir también se presenta como verbo auxiliado a través de la combinación ir a + infinitivo de ir, como en "voy a ir», lo cual permite constatar la eventual gramaticalización del verbo y el propósito que esta construcción enmarca por parte del hablante al expresar una intención vinculada con un futuro próximo.

Así, se pudo comprobar que la perífrasis, en correspondencia con sus valores, aludía a propósitos, finalidades exhortativas y acontecimientos inesperados o inoportunos por parte de los hablantes como se evidenció en los resultados y la discusión.

Finalmente, los resultados demuestran que hay más valores asociados a la perífrasis ir a + infinitivo que los vinculados al futuro simple. Además, se observa que existe una necesidad en los hablantes de mostrar otras funciones las cuales no están asociadas a las formas gramaticalizadas, porque en la bibliografía revisada no se asocia al futuro simple con la inmediatez, lo cual implica que, dadas las características del uso, en algún momento este exigirá la inclusión de la perífrasis ir a + infinitivo dentro de los tiempos gramaticalizados. 


\subsection{Referencias}

Alarcos Llorach, E. (1999). Gramática de la lengua española. Espasa Calpe.

Gili Gaya, S. (1961). Curso superior de sintaxis española (8. ${ }^{a}$ ed.). Publicaciones y Ediciones SPES, S.A.

Gómez-Torrego, L. (1988). Perifrasis verbales. Sintaxis, semántica $y$ estilística. Arco libros.

. (1999). Gramática descriptiva de la lengua española. Espasa Calpe.

Real Academia Española. (2009). Nueva gramática de la lengua española: Sintaxis II. Espasa Libros.

. (2010). Nueva gramática de la lengua española. Manual. Espasa. 
Por cuarta vez, la Maestría en Lingüística pone en consideración de la comunidad académica, interesada en los estudios del lenguaje, una obra construida con los aportes de profesores estudiantes, conferencistas y egresados de este programa de postgrado. Así, las sucesivas publicaciones en las que, mediante convocatoria pública, hay participación de los distintos estamentos, los cuales conforman dicha maestría, se convierten en un espacio académico en donde se comparten, fortifican y adquieren conocimientos teóricos y prácticos, así como metodologías, para la investigación linguíística en diferentes entornos socioculturales. Esto, a través del estudio de la lengua, tanto en su fase de sistema formal como en su uso contextual.

Los capítulos de esta obra, como en las anteriores, ofrecen elementos de discusión, los cuales se espera que sirvan de motivación para investigar el lenguaje desde disciplinas y teorías que abordan el sistema formal de la lengua y las interdisciplinariedades que explican su uso.

\section{Facultad de Ciencias de la Educación} Colección Ensayos 